\title{
Interaction between Titles II and III of the Clean Air Act as Amended, 1990
}

Decision and Information Sciences Division

Argonne National Laboratory

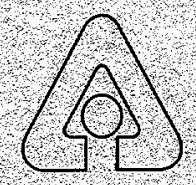

\section{MASTER}




\section{Argonne National Laboraten}

Argonne National Laboratory with facilities in the states of lilinois and Idaho, is owned by the United States Govemment, and operaled by the University of Chicago under the provisions of a contract with the Department of Eaergy.

This technical memo is a product of Argonne's Decision and Information Sciences (DIS) Bivision. For information on the division's scientific and engineering activities, contact:

Director, Decision and Infomation Sciences Division Argonne National Laboratory Argonne, ilinois 60439-4815 Telepthone (708) 2525464

Presented in this technical memo are prelininary results of ongoing work or work that is more limited in scopo and dep th than that described in formal reports issued by the bis Division

Publishing support senvices were provided by Argonne's Information and Publishing Division (for more information, see IPDs home page: lttp:(wwwipdanlgov)

\section{Disclaimer}

This report was prepared as an account of woik sponsored by an agency of the United States Government. Neither the United States Government nor any agency thereof nor any of the ir employeos, makes any warranty, express or implied or assumes any legal liability or responsibility for the accuracy completeness, of usefulhess of any information, ap paratus, product, or process disclosed, or represents that its use would not infinge privately owned tights. Reference herein to any specific commercial product process, or senice by trade name, trademark, manufacturer, or otherwise, does not hecessarly constitute or imply Its endorsement; recommendation or favoring by the United States Govemment or any agency thereof. The views and opiniens of authors expressed herein do not necessarily state or leflect those of the United States Govemment or any agency theroot

Reproduced directly from the best available copy

Available to DOE and DOE contractors from the Office of Scientific and Tochnical Intormation, P.O. Bo 62 Oak Ridge. TN 37831; prices avallable from (615) 5768401

Available to the public from the National Technical Information Service, U.S. Depaitment of Commerce 5285 Port Royal Road, Springfield, VA 22161. 


\section{Interaction between Titles II and III of the Clean Air Act as Amended, 1990}

by C.B. Szpunar

Policy and Economic Analysis Group,

Decision and Information Sciences Division,

Argonne National Laboratory, 9700 South Cass Avenue, Argonne, Illinois 60439

September 1993 (Printed February 1996)

Work sponsored by United States Department of Energy, Office of Environmental Analysis and Sustainable Development 
This report is printed on recycled paper. 


\section{CONTENTS}

NOTATION

ABSTRACT

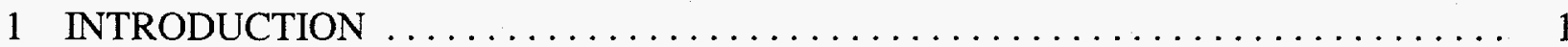

1.1 Study Rationale $\ldots \ldots \ldots \ldots \ldots \ldots \ldots \ldots \ldots \ldots \ldots \ldots \ldots \ldots, 2$

1.1.1 Title II — Reformulated Gasoline $\ldots \ldots \ldots \ldots \ldots \ldots \ldots \ldots \ldots \ldots . \ldots 2$

1.1.2 Title III - Hazardous Air Pollutants $\ldots \ldots \ldots \ldots \ldots \ldots \ldots \ldots \ldots \ldots$

1.1.3 Conflict between Title II and Title III . . . . . . . . . . . . . . . . . . 3

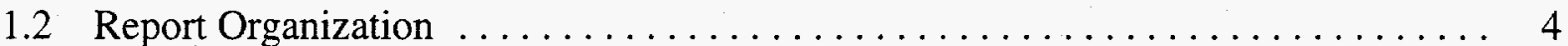

2 REFORMULATED GASOLINE MANDATE $\ldots \ldots \ldots \ldots \ldots \ldots \ldots \ldots \ldots$

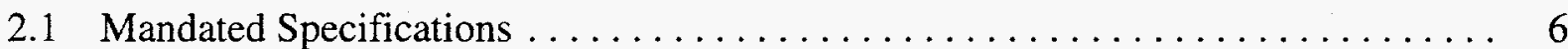

2.1.1 The Programs ..................................... 6

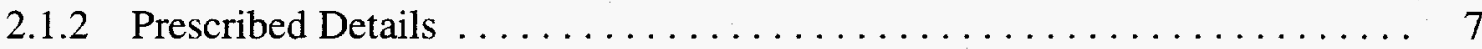

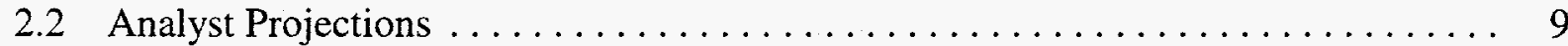

2.2.1 Meeting the Reformulated Gasoline Challenge .............. 10

2.2.2 Shifting Components for Reformulated Gasoline .............. 11

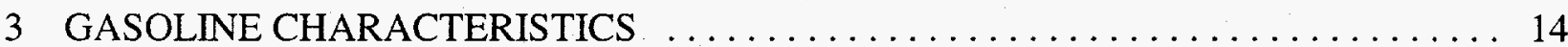

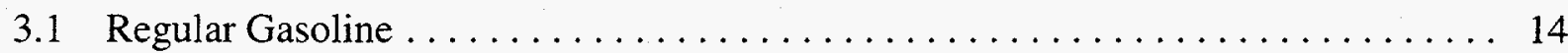

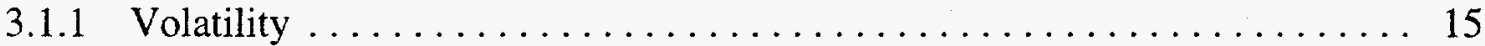

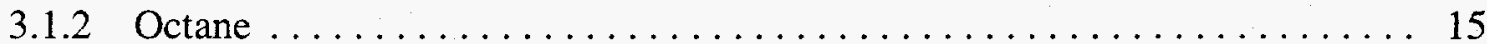

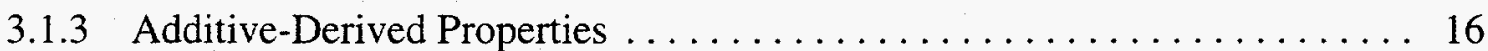

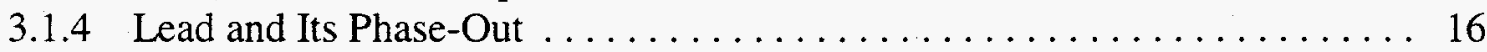

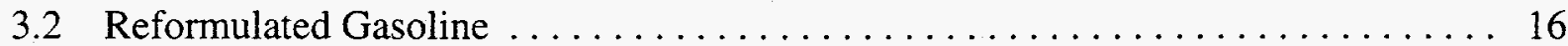

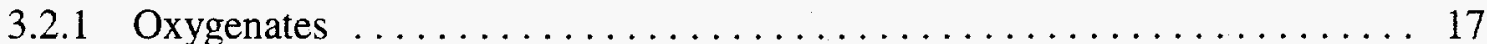

3.2.2 Catalyst Technology and Additives $\ldots \ldots \ldots \ldots \ldots \ldots \ldots \ldots \ldots$

4 PROJECTED IMPACT OF REFORMULATED GASOLINE MANDATE ON REFINING CAPACITY $\ldots \ldots \ldots \ldots \ldots \ldots \ldots \ldots \ldots \ldots \ldots . \ldots \ldots$

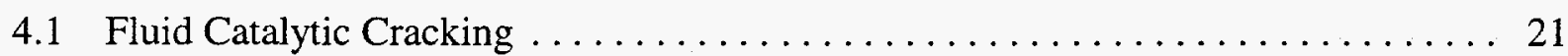

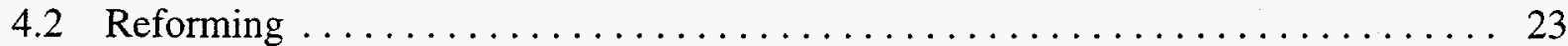

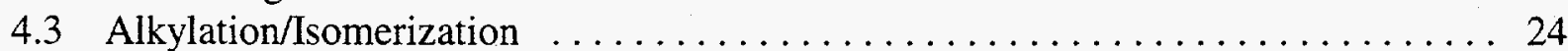

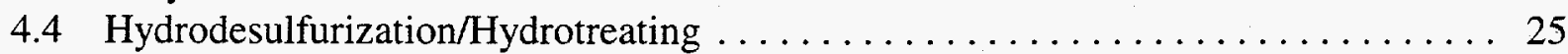

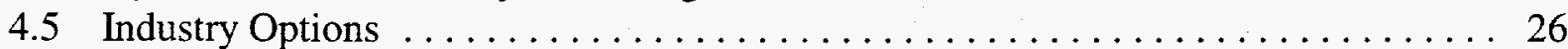

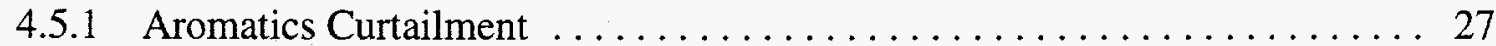

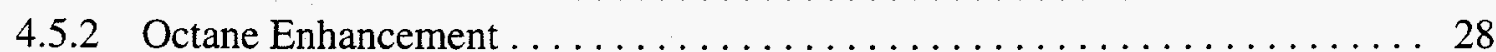




\section{CONTENTS (Cont.)}

5 FEEDSTOCK/BLENDSTOCK DEMAND AND SUPPLY . . . . . . . . . . . . 29

5.1 Refinery Products Affected by Reformulated Gasoline $\ldots \ldots \ldots \ldots \ldots \ldots \ldots 29$

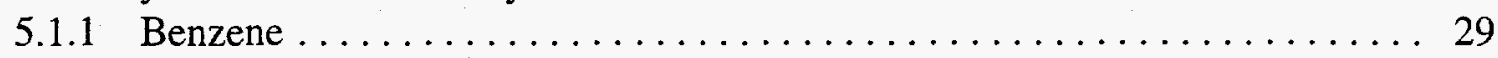

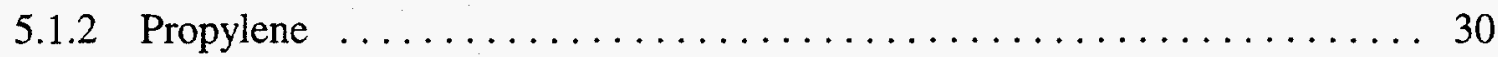

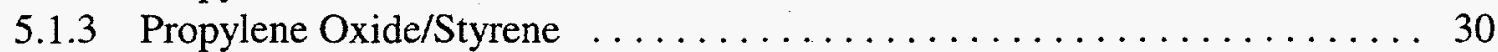

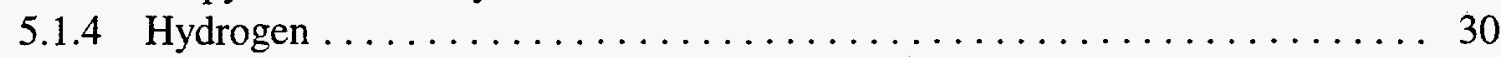

5.2 Oxygenates and Other Feedstocks for Ether Blendstocks $\ldots \ldots \ldots \ldots \ldots \ldots \ldots 33$

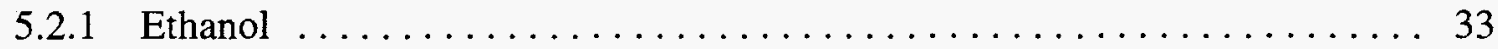

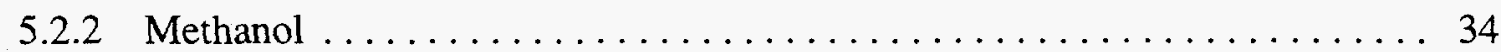

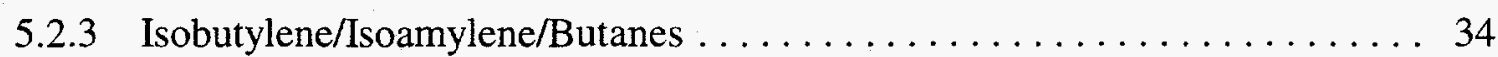

5.3 Oxygenate Blendstock for Reformulated Gasoline $\ldots \ldots \ldots \ldots \ldots \ldots \ldots \ldots$

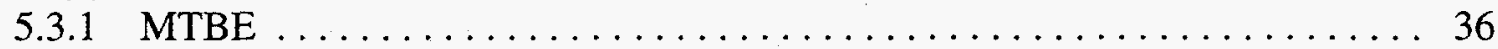

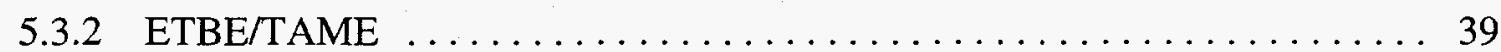

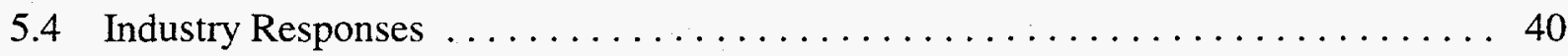

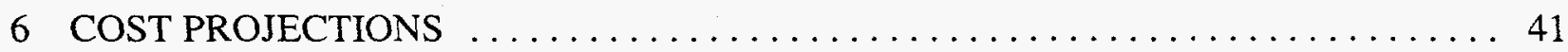

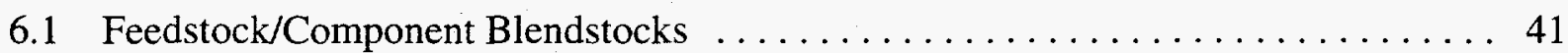

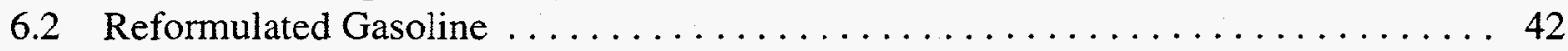

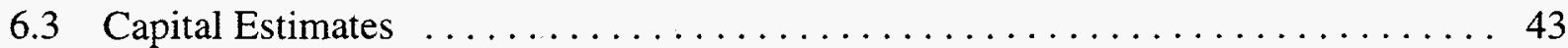

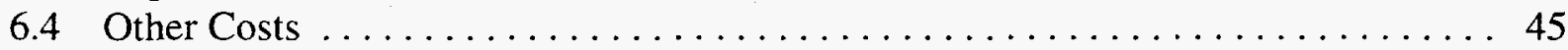

7 EMISSIONS AND ATMOSPHERIC IMPACT $\ldots \ldots \ldots \ldots \ldots \ldots \ldots \ldots \ldots \ldots$

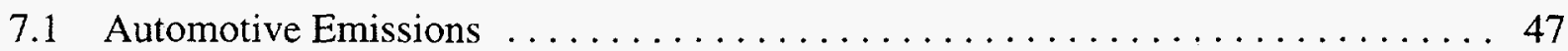

7.2 Atmospheric Impact of Reformulated Gasoline .................. 48

7.3 MTBE Stationary Source Emissions and Assessment $\ldots \ldots \ldots \ldots \ldots \ldots \ldots . \ldots 1$

7.3.1 Determining the Level of HAP Emissions Expected ............ 51

7.3.2 Assessing Regulatory Treatment for Non-MTBE Oxygenates .......... 52

7.3.3 Skewing the Oxygenate Market Because of MACT Applicability ....... 53

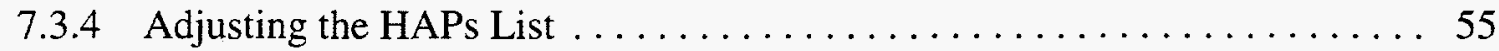

8 CHALLENGES AND FUTURE DIRECTIONS $\ldots \ldots \ldots \ldots \ldots \ldots \ldots \ldots \ldots \ldots$

8.1 Automotive Emissions from Title II Reformulated Gasoline . . . . . . . . . . . 59

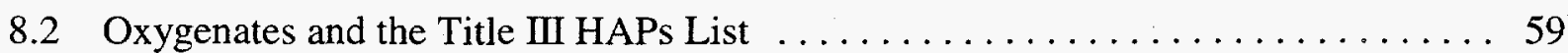

8.3 State Implementation Plans . . . . . . . . . . . . . . . . . . . . . . 59

8.4 EPA Mobile Source Air Toxics Study $\ldots \ldots \ldots \ldots \ldots \ldots \ldots \ldots \ldots \ldots \ldots \ldots \ldots \ldots \ldots \ldots$

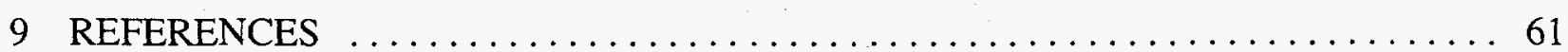




\section{CONTENTS (Cont.)}

APPENDIX A: Refinery Processes and Terms $\ldots \ldots \ldots \ldots \ldots \ldots \ldots \ldots \ldots \ldots \ldots \ldots \ldots$

APPENDIX B: Case Study That Illustrates Refiners' Choices $\ldots \ldots \ldots \ldots \ldots \ldots \ldots \ldots 77$

APPENDIX C: Industry Responses to Reformulated Gasoline $\ldots \ldots \ldots \ldots \ldots \ldots$

\section{TABLES}

$1 \quad 1989$ U.S. Motor Gasoline Formulation $\ldots \ldots \ldots \ldots \ldots \ldots \ldots \ldots \ldots \ldots \ldots \ldots$

21991 Hydrogen Balance in U.S. Refineries $\ldots \ldots \ldots \ldots \ldots \ldots \ldots \ldots \ldots \ldots \ldots \ldots \ldots$

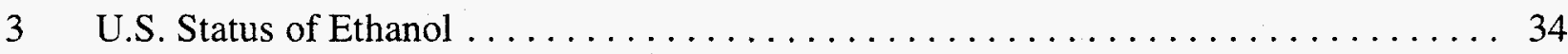

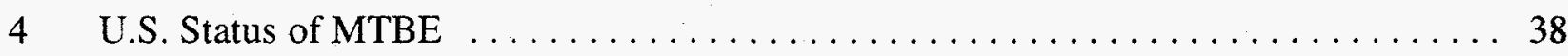

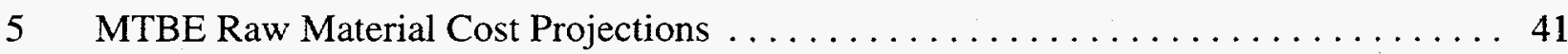

6 Results of Research Studies on the Incremental Cost of Using

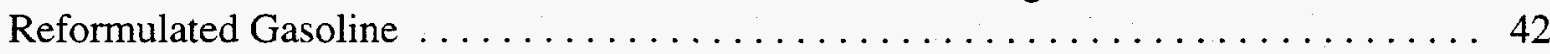

7 Results of Research Studies on the Capital Cost of Using

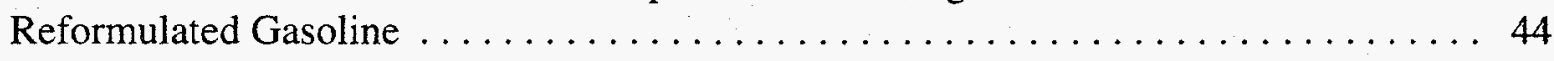

8 Regional Differences in Incremental Capital Investments for Gasoline . . . . . . . . . . . . . . . . . . . . . . . . . . . . . 46

9 North American MTBE Projected Expansions and New Plants ............. 53

A.1 Representative Product Yields from Catalytic Cracking as Demanded

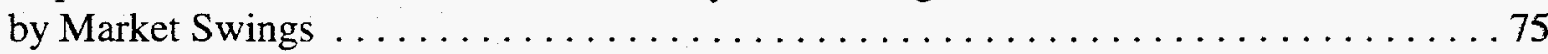

B.1 Reformulated Gasoline Pool Projected from a Typical 100,000-bbl/d Refinery . . . . . 80

C.1 Worldwide Projected Expansions of and New MTBE Plants $\ldots \ldots \ldots \ldots \ldots . \ldots 8$ 


\section{FIGURES}

1 Adjustments to Refinery Streams Required to Produce Oxygenates $\ldots \ldots \ldots \ldots 22$

2 Reactions to Produce Oxygenates for Reformulated Gasoline . . . . . . . . . . . 54

A.1 Refining Crude Oil: Fundamental Pathways to Fuel Products $\ldots \ldots \ldots \ldots \ldots$

A.2 Processing Conventional Gasoline Components from Refinery Streams . . . . . . 73 


\section{NOTATION}

ACS

API

AQIRP

ASTM

bbl

CAAAs

CARB

CDC

$\mathrm{CO}$

$\mathrm{CO}_{2}$

d

DOE

EIA

ETBE

EPA

FCC

gal

HAP

lb

LPG

MACT

MMT

MON

mpg

MTBE

NAAQS

NFA

$\mathrm{NO}_{\mathrm{x}}$

PADD

PAN

ppb
American Chemical Society

American Petroleum Institute

Air Quality Improvement Research Program

American Society for Testing Materials

barrel(s)

Clean Air Act Amendments

California Air Resources Board

Centers for Disease Control

carbon monoxide

carbon dioxide

day(s)

U.S. Department of Energy

Energy Information Administration

ethyl tert-butyl ether

U.S. Environmental Protection Agency

fluid catalytic cracking

gallon(s)

hazardous air pollutant

pound(s)

liquefied petroleum gas

maximum achievable control technology

methylcyclopentadienyl manganese tricarbonyl

motor octane number

mile(s) per gallon

methyl tert-butyl ether

National Ambient Air Quality Standard

nonframework alumina

nitrogen oxides

Petroleum Administration for Defense District

peroxyacetyl nitrate

part(s) per billion 


\begin{tabular}{|c|c|}
\hline $\begin{array}{l}\text { ppm } \\
\text { psig }\end{array}$ & $\begin{array}{l}\text { part(s) per million } \\
\text { pound(s) per square inch gauge }\end{array}$ \\
\hline RON & research octane number \\
\hline RVP & Reid vapor pressure \\
\hline $\begin{array}{l}\text { SAR } \\
\text { Scf } \\
\text { SIP } \\
\text { SR }\end{array}$ & $\begin{array}{l}\text { silica-to-alumina ratio } \\
\text { standard cubic feet } \\
\text { state implementation plan } \\
\text { straight run }\end{array}$ \\
\hline $\begin{array}{l}\text { TAEE } \\
\text { TAME } \\
\text { TBA }\end{array}$ & $\begin{array}{l}\text { tert-amyl ethyl ether } \\
\text { tert-amyl methyl ether } \\
\text { tert-butyl alcohol }\end{array}$ \\
\hline $\begin{array}{l}\text { VOC } \\
\text { vol\% }\end{array}$ & $\begin{array}{l}\text { volatile organic compound } \\
\text { volume percent }\end{array}$ \\
\hline $\mathrm{wt} \%$ & weight percent \\
\hline $\mathrm{yr}_{1}$ & year \\
\hline
\end{tabular}




\title{
INTERACTION BETWEEN TITLES II AND III OF THE CLEAN AIR ACT AS AMENDED, 1990
}

\author{
by
}

\section{C.B. Szpunar}

\begin{abstract}
This report examines some issues that would affect the refining industry if the requirements for hazardous air pollutants set out in Title III of the Clean Air Act Amendments were to impede the market entrance of oxygenated fuels, as required by Title II. It describes the mandate for reformulated gasoline; considers gasoline characteristics in light of component shifts in refining; examines the supply of, demand for, and cost of various feedstocks and blendstocks; and identifies the emissions and atmospheric impacts that might result from the production and use of reformulated gasoline. Attention is focused on methanol and MTBE, two potential blendstocks that are also hazardous air pollutants, and on maximum achievable control technology standards, which might be applied to the stationary sources that produce them.
\end{abstract}

\section{INTRODUCTION}

Although air quality in the United States has improved over the past decade because of the emission controls imposed on both industrial and mobile sources of air pollution, many cities continue to exceed national ambient air quality standards (NAAQSs). In an announcement on August 16, 1990, the U.S. Environmental Protection Agency (EPA) cited 96 metropolitan areas, led by Los Angeles, for still failing to comply with ozone standards. According to the EPA, despite improvements in some areas, 133 million people live in areas that exceed ozone standards, and almost 78 million live in areas that exceed carbon monoxide (CO) limits (Smylie et al. 1991). Many urban areas are subject to severe photochemical air pollution, mainly as a result of emissions from mobile sources. In nine major U.S. cities, ${ }^{1}$ mobile sources emit $17-34 \%$ of total hydrocarbons, $32-82 \%$ of total $\mathrm{CO}$, and $14-49 \%$ of total nitrogen oxides $\left(\mathrm{NO}_{\mathrm{x}}\right)$ (Smylie et al. 1991).

1 Los Angeles, New York, Hartford, Chicago, Philadelphia, Baltimore, Milwaukee, Houston, and San Diego. 
Using oxygenated fuels in the winter and using reformulated gasoline year round in lightduty automobiles and trucks are widely viewed as important steps toward improving air quality in those cities. So pervasive is this view that in 1990, significant legislative and regulatory activities were initiated at federal, state, and local levels to incorporate reformulated and oxygenated fuel programs into ozone and CO control strategies (Smylie et al. 1991).

Specifically, both the EPA and the U.S. Congress want to change the composition of gasoline so it (1) is less volatile, (2) has a lower aromatic content, and (3) contains a significant level of chemically bound oxygen (e.g., from ethers or alcohols). Because highly volatile olefins can react with alcohols to make ethers, thereby reducing the amount of olefins available for aromatics production, the oil refining industry has embraced the production and blending of ethers as the solution to improving air quality and increasing chemically bound oxygen for improved combustion (Diebold et al. 1992).

\subsection{STUDY RATIONALE}

\subsubsection{Title II — Reformulated Gasoline}

Title II of the Clean Air Act Amendments (CAAAs) is concerned with reducing pollutant emissions from mobile sources, especially autos; it mandates the introduction of reformulated gasoline blends (and other alternative fuels) in the most serious ozone nonattainment areas. Federally regulated reformulated gasolines are required no later than January 1, 1995, in the nine areas cited as having "extreme" ozone pollution problems (about $25 \%$ of the nation's gasoline market). In addition, another 100 cities with marginal, moderate, or "severe" ozone problems may opt to participate in the reformulated gasoline program to help reduce pollution. State implementation plans (SIPs) that address this goal are required by November 1993 (Hadder 1992).

The CAAAs and the regulations emanating from the legislation will require the use of reformulated gasoline with a minimal concentration of oxygen-containing additives, fewer aromatics, a strict maximum on benzene content, lower Reid vapor pressure (RVP), fewer photoreactive components such as olefins, and no lead (Johnson and Peterson 1991). The challenge to the refining industry is to comply with these regulations without increasing the retail price of gasoline too much (Gilman 1990). To reduce the financial impact of impending gasoline (and diesel) regulations, refineries will need to reevaluate their unit operations and assess innovative catalyst and process technologies.

Oxygenated fuels had already been required for the winter of 1992/1993 (Parkinson 1992). The CAAAs require areas that do not meet federal $\mathrm{CO}$ standards to use oxygenated fuels during the winter months, when $\mathrm{CO}$ levels are highest. Thus, 41 metropolitan areas were mandated to use 
winter gasoline supplies containing $2.7 \%$ oxygen by weight $(2.7 \mathrm{wt} \%$ oxygen) beginning in November 1992 for at least four months (through February) (Oil and Gas Journal [O\&GJ] 1992a). Adding oxygenates such as methyl tert-butyl ether (MTBE), other ethers, ethanol, or other alcohols to gasoline provides the required oxygen.

\subsubsection{Title III - Hazardous Air Pollutants}

Title III of the 1990 CAAAs sets out the federal regulatory requirements for hazardous air pollutants (HAPs) (also known as air toxics). It lists 189 chemical species, including organic compounds, inorganic compounds and elements, and chemical classes or categories, as being HAPs.

Under the CAAAs, industrial sources deemed "major sources" - those that emit 10 tons per year or more of any one of the 189 listed species or 25 tons per year of a combination of substances - may be required to apply the maximum achievable control technology (MACT). Additional controls could be required if the EPA finds that an unacceptable level of risk to public health remains even after MACT is applied (U.S. Congress 1990, Section 112(f)). Refineries are considered major sources.

\subsubsection{Conflict between Title II and Title III}

The Title III HAPs list includes methanol and MTBE, two blendstocks that can be used to satisfy the Title II requirements for the oxygen content of oxygenated fuels and reformulated gasolines. Other blendstocks, however, such as ethanol, ethyl tert-butyl ether (ETBE), tert-amyl methyl ether (TAME), and tert-amyl ethyl ether (TAEE), do not appear on the HAPs list.

Fuel distribution could be seriously affected if Title III HAP constraints interfere with meeting Title $I I$ gasoline reformulation requirements. Outcomes that may affect the consumer include these:

- Additional constraints on components of reformulated gasoline;

- Increased process energy requirements during refining and blending;

- Increased cost of blendstock/feedstock inputs, resulting in an overall increase in the cost of delivered fuel;

- Reduced heat content of reformulated gasoline; and

- Adverse health effects. 
Specifically, certain questions arise:

- Will Title III (which regulates HAPs from stationary sources) impede the commercial implementation of Title II (which mandates the use of reformulated gasoline and oxygenated fuels by mobile sources)? In other words, will Title III impede the marketing and distribution of reformulated gasoline and oxygenated fuels?

- Will Title III dictate that MACT be applied to stationary sources, such as the units that produce methanol and MTBE, if such units are found to emit 10 tons per year individually or 25 tons per year in combination with other HAPs, but that MACT not be applied to ethanol, ETBE, TAME, and TAEE units?

- If the MACT standards developed for refineries and fuel blenders are too severe to allow production of methanol and MTBE, will the market for oxygenated fuels and reformulated gasoline be skewed toward ethanol, ETBE, TAME, and/or TAEE blendstocks?

- What MACT standard for methanol and/or MTBE would skew the market for oxygenate blendstock (if it is possible to determine)?

- Are ethanol, ETBE, TAME, and TAEE likely to be added to the HAPs list, or are these oxygenates - one alcohol and two paraffinic organic ethers - relatively risk-free in terms of public health?

\subsection{REPORT ORGANIZATION}

This report begins to examine some of the issues that would affect the refining industry if Title III requirements for HAPs were to impede the market entrance of oxygenated fuels, as required by Title II. Section 2 outlines the mandate for reformulated gasoline. Section 3 highlights the characteristics of gasoline that are of importance when components and component shifts in refining are being considered. Section 4 considers the impact on refiners and specific refinery processes from producing reformulated gasoline.

Refineries and blenders are executing plans to install new capacity and to modify and expand existing capacity to supply oxygenate blendstocks. Currently, much MTBE is captive blendstock and could be generated if existing refinery processes were modified. Section 5 discusses the demand for and supply of the various feedstocks and blendstocks that could accommodate a shift 
to reformulated gasoline. Costs of oxygenate blendstocks that have been projected by refiners and blenders, although sketchy, are reported on in Section 6.

One objective of this study is to identify the sources and magnitudes, if possible, of emissions and the atmospheric impact resulting from the production and use of reformulated gasoline (Section 7). Section 8 presents challenges and research directions for the future.

Appendix A provides statistics for a typical refinery to help assess its flexibility in allowing its processes to be modified to produce reformulated gasoline. This examination will allow an assessment of whether MTBE is economical and appropriate compared with other available blendstocks not subject to MACT standards. Appendix B highlights refiners' options, and Appendix $\mathrm{C}$ is an outlook on the refining industry. Specifically, analyst projections, estimated costs, and industry responses to date are considered. 


\section{REFORMULATED GASOLINE MANDATE}

Ozone and other pollutants form in the atmosphere as a result of the sunlight-driven photochemical reaction of volatile organic compounds and $\mathrm{NO}_{\mathrm{x}}$. Such precursor hydrocarbons and $\mathrm{NO}_{\mathrm{x}}$ are emitted directly into the atmosphere by motor vehicles, other mobile sources, and stationary sources (industrial/commercial facilities) (Smylie et al. 1991). Reformulated, oxygenated, and alternative fuels can be designed and employed to lessen the tonnage and reactivity of mobile source emissions that contribute to the photochemical process.

Air quality benefits from the use of reformulated, oxygenated, and alternative fuels may be achieved in several ways (Smylie et al. 1991). These fuels will:

- By less photochemically reactive and thus reduce the subsequent formation of ozone and other pollutants (e.g., through lowered aromatics content with concurrent use of oxygenates such as MTBE to maintain octane rating) by adjustment of their chemical composition;

- Be less volatile (and thus emit a smaller amount of evaporative hydrocarbons);

- Reduce exhaust emissions of hydrocarbons, $\mathrm{CO}$, and possibly $\mathrm{NO}_{\mathrm{x}}$; and

- Reduce emissions of additional substances of regulatory interest that are commonly found in gasoline (e.g., benzene and other HAPs).

\subsection{MANDATED SPECIFICATIONS}

\subsubsection{The Programs}

The EPA has determined that aliphatic (paraffinic) alcohols and ethers, in specific volumes and combinations, are "substantially similar" to components of conventional gasoline and are therefore able to provide the oxygen that gasoline will be needed under the 1990 CAAAs. It is in this context that compounds such as MTBE are considered oxygenates, ${ }^{2}$ even though they may have other properties and uses (Anderson 1993).

2 Oxygenates are liquid organic compounds that can be blended into gasoline to increase its oxygen content. During combustion, the additional oxygen in the gasoline converts $\mathrm{CO}$ to carbon dioxide and may reduce emissions of ozoneforming compounds (e.g., by converting volatile organic compound emissions to carbon dioxide and water). 
Oxygenated gasolines are required by the 1990 CAAAs for the (1) oxygenated fuels program and (2) reformulated gasoline program. The oxygenated fuels program began on November 1, 1992. It requires that the gasoline sold in 39 metropolitan areas that did not meet federal air quality standards for $\mathrm{CO}$ must contain a minimum of $2.7 \mathrm{wt} \%$ oxygen. The program runs for at least four winter months, although areas may choose to extend it. The reformulated gasoline program is scheduled to begin on January 1, 1995. After that date, all gasoline sold year-round in the nine large metropolitan areas with the most serious ozone problems must contain a minimum of $2.0 \mathrm{wt} \%$ oxygen. Other areas with ozone problems may choose to use the reformulation program (Anderson 1993).

\subsubsection{Prescribed Details}

The intent of the CAAAs is to reduce auto emissions. To do so, refiners must reformulate their gasolines by blending components produced by new or upgraded refinery processes and units (Yepsen and Witoshkin 1991). Some characteristics were mandated to be achieved by the winter of 1992/1993. However, federal regulations for reformulated gasoline to reduce emissions of ozone precursors will not go into full effect until January 1, 1995, in the nine areas with extreme or severe ozone pollution problems (estimated at about $22-33 \%$ of the nations's gasoline market) (Simonsen et al. 1993; Hadder 1992; Unzelman 1991). In addition, approximately 100 other cities with marginal, moderate, or serious ozone problems may opt to participate in the reformulated gasoline program. Moreover, spillover effects resulting from the way gasoline is distributed may introduce reformulated gasoline and oxygenated fuels into areas adjacent to areas under mandates (Hadder 1992).

Federal regulations emanating from the 1990 CAAAs ultimately prescribe a formula for reformulating gasoline (Diebold et al. 1992; Parkinson 1992; O\&GJ 1992a; Yepsen and Witoshkin 1991) that includes the following elements:

- Decrease butane (from 3\% to $0 \%$ ) and light straight-run (SR) compounds (from $4 \%$ to $0 \%$ );

- Decrease fluid catalytic cracking (FCC) naphtha (from $38 \%$ to a maximum of $34 \%)$;

- Decrease benzene (from $2 \%$ to a maximum of $1 \%$, although the average is on the order of $1.53 \%$, and some blended gasolines contain up to $5 \%$ ) (Hadder 1992; Gilman 1990); 
- Decrease aromatics (from $32 \%$ to a maximum of $25 \%$ by decreasing the $\mathrm{T}_{90}$; some gasolines average $29 \%$ aromatics by volume [ $29 \mathrm{vol} \%]) ;^{3}$

- Decrease the RVP (from 9.6 to a maximum of 9.0 in the North and 7.8 in the South effective summer 1992 [Parkinson 1992] and a maximum of 8.1 in the North and 7.2 in the South effective 1995 [Levine 1992]);

- Decrease sulfur;

- Eliminate additives containing heavy metals (Hadder 1992), particularly lead additives, by January 1996 (Parkinson 1992);

- Increase the oxygen content to a minimum of $2.7 \mathrm{wt} \%$ in CO nonattainment areas (equivalent to about $15 \% \mathrm{MTBE}$ ), or to a minimum of $2.0 \mathrm{wt} \%$ in ozone nonattainment areas (about 11\% MTBE California), in winter gasoline supplies for affected metropolitan areas effective November 1992 and in all year-round reformulated gasoline supplies subsequently;

- Ensure that all gasolines contain detergents by January 1995; and

- Require that $\mathrm{NO}_{\mathrm{x}}$ emissions be no greater than those from present gasolines.

The short list below summarizes the objectives of using reformulated gasoline described above:

- Decrease SR paraffins, FCC naphtha, aromatics, RVP, $\mathrm{T}_{90}$, and sulfur;

- Eliminate heavy metals (lead); and

- Increase oxygenates (ethers).

The refiner is required to adopt the more stringent of two options: the above formula or the following standard of a 15\% reduction from 1990 levels in ozone-forming VOCs and toxics to be achieved by 1995 and a 25\% reduction to be achieved by 2000 (Hadder 1992; Levine 1992). The EPA has provided a two-year grace period (until 1997) for the industry to meet the full requirements of reformulation. By that time, a refiner's reformulated gasoline specifications must satisfy the

$3 \mathrm{~T}_{90}$ is the temperature at which only $10 \%$ of the original feed material is left as residual (higher-boiling hydrocarbons) upon distillation. $T_{90}$ is lowered by physically separating, or undercutting, the initial crude oil feed. 
complex refining model ${ }^{4}$ being developed by the EPA's Emission Control Technology Division in Ann Arbor, Michigan (Parkinson 1992).

During the grace period, a simple model for reformulated gasoline applies. The EPA will consider refiners to be in compliance if they use a maximum benzene content of $1.0 \%$ and cut toxic pollutants by $15 \%$. They will not have to comply with the rules for a maximum $25 \%$ aromatics content and a cut in VOCs to 15\% below 1990 levels. Instead, they may use the most expedient means to reduce the summer RVP to 7.2 in the South or 8.1 in the North rather than the stipulated 7.8 pounds per square inch (psi) in the South and 9.0 psi in the North (Parkinson 1992).

The CAAAs have also limited highway diesel fuel to a maximum sulfur content of $0.05 \mathrm{wt} \%$ and a minimum cetane ${ }^{5}$ index of 40 , which will be effective on October 1, 1993 (Hadder 1992). In addition to meeting the federal requirements, California's diesel regulations have called for a maximum aromatics content of $10 \mathrm{vol} \%$ (decreased from a prior average of $30 \mathrm{vol} \%$ ), a measure designed to reduce particulate emissions (Parkinson 1992).

According to a source at Akzo Chemicals, Inc., in Houston (Gilman 1990), to reduce the financial impact of these gasoline and diesel regulations, refinery unit operations as well as innovative catalysts and process technologies will need to be reevaluated and redefined. The challenge to refineries appears to be to comply with these regulations without causing excessive increases in retail gasoline prices. The profitability of refineries must be maintained if they are to remain competitive.

\subsection{ANALYST PROJECTIONS}

Basically, the question boils down to what changes in overall refinery operations will be necessary to enable U.S. refiners to produce the prescribed reformulated gasoline. Meeting the challenge requires shifts in the refinery scheme. Some projections follow.

4 Care must be taken in applying refinery models because they have a tendency to overoptimize refinery operations. Disaggregation of refinery complexity levels reveals important differences in product producibility and process requirements that go undetected at the aggregate level. More important, a major difficulty with disaggregation is the limited availability of data on raw material inputs and product outputs for different levels of refinery complexity (Hadder 1992).

$5 \quad$ Diesel's cetane number is a quality that parallels gasoline's octane number. See footnote 6. 


\subsubsection{Meeting the Reformulated Gasoline Challenge}

The program that requires year-round sales of reformulated gasoline by 1995 to satisfy CAAA mandates is not expected to pose significant technical problems for refiners. However, nearly all U.S. refiners will probably need to make added investments (O\&GJ 1992a).

The nine metropolitan areas with extreme or severe ozone pollution problems - about 22-33\% of the nations's gasoline market - will have to use reformulated gasoline (Hadder 1992; Unzelman 1991; Simonsen et al. 1993). In addition, approximately 100 other cities with marginal, moderate, or serious ozone problems may opt to participate in the reformulated gasoline program. Other areas may be forced to participate to some extent because they are adjacent to reformulated gasoline areas and may experience spillover due to marketing distribution effects. Hadder (1992) expects the minimum market for reformulated gasoline in 1995 to be on the order of $30 \%$. If other areas opt in to request clean gasolines, they could account for an additional $20-35 \%$ of current gasoline demand, and the total market for clean gasolines could exceed 50\% by 1996-1997.

On the other hand, Simonsen et al. (1993) suggests that some (unspecified) groups may be blindly advocating nationwide reformulation of gasoline without evaluating the various alternatives on a cost/benefit basis. If severe reformulation were implemented nationwide, the entire gasoline pool of 7.3 million barrels per day (bbl/d) might be affected. Severe reformulation could require total aromatics content to be decreased from $32 \%$ to $25 \%$ nationwide, along with a possible reduction in heavy ends $\left(\mathrm{T}_{90}\right)$. Large increases in the use of oxygenates could add 11-15 vol\% more to the gasoline pool, requiring almost 1 million $\mathrm{bbl} / \mathrm{d}$ of oxygenates. This change effectively replaces a large portion of octane-boosting components such as aromatics and heavy ends, which are produced primarily by FCC and catalytic reforming units.

Industry projections (Rhoades 1992) forecast that oxygenates from a number of sources will probably be sufficient to meet demand for reformulated gasoline and oxygenated fuels. A report from Chemical Market Associates, Inc., estimates captive supply and demand of butylenes and oxygenates. A report from Pace Consultants, Inc., predicts demand for gasoline and oxygenates and examines the role ethanol may play in changing those values. MTBE is considered the most important oxygenate, although ethanol, ETBE, and TAME are gaining market strength. (Ethanol's strength is derived from the previous Administration's ruling, which grants a waiver to reformulated gasoline containing ethanol. This waiver allows ethanol blends to have an RVP that is 1 psi higher than that of other types of gasoline.)

Winter (1992/1993) fuel demand for gasoline-blending oxygenates such as MTBE or ethanol was predicted to exceed U.S. oxygenate production by 140,000 to $220,000 \mathrm{bbl} / \mathrm{d}$, with the shortfall expected to be made up from inventory or imports (O\&GJ 1992d). One point estimate of $192,000 \mathrm{bbl} / \mathrm{d}$ in MTBE shortfall was based on an estimated North American capacity of $168,000 \mathrm{bbl} / \mathrm{d}$ (Shearman 1991). 
Refineries in California, which has the nation's worst air quality, face the greatest challenge. The California Air Resources Board (CARB) in Sacramento has prescribed Phase 2 specifications for reformulated gasoline that set strict limits on RVP and sulfur, aromatic, oxygen, and olefin content, and even on the distillation temperatures at which $50 \%$ and $90 \%$ of the gasoline boils $\left(\mathrm{T}_{50}\right.$ and $\mathrm{T}_{90}$ ). Its Phase 1 specifications went into effect in January 1992, resulting in the phase-out of unleaded gasoline, a summertime RVP of 7.8 psi (April 1992), and reductions in aromatics and olefins (Parkinson 1992).

According to Clossey at ARCO Chemical Co. (Parkinson 1992), California's Phase 2 specification of $7 \mathrm{psi}$ is designed to reduce the RVP. This specification requires not only that less butane be blended in but also that pentanes be removed, with the result that no refiner is able to use butane. The most difficult and costly challenge of the California regulations concerns the reduction of $\mathrm{T}_{90}$ from $330^{\circ} \mathrm{F}$ to an average of $290^{\circ} \mathrm{F}$ to remove heavier gasoline components. (Limiting $\mathrm{T}_{90}$ results in substantial reductions in exhaust emissions of volatile organic compounds.) The problem is what to do with this high-boiling fraction. Refiners must ship it overseas (an option that is not likely to be available in years to come) or hydrocrack it to lighter gasoline (a very costly proposition). In addition, California refiners cannot yet meet the emissions goal for diesel that involves reducing aromatics from 30 to $10 \mathrm{vol} \%$. Aromatics reduction requires severe and costly hydrotreating, and there may not be enough time to build hydrotreaters (Parkinson 1992).

\subsubsection{Shifting Components for Reformulated Gasoline}

According to Gilman (1990), Congress's target can be interpreted to be a $50 \%$ reduction in ozone-forming and $\mathrm{CO}$ emissions from cars and light-duty trucks by the year 2000 . However, this target coincides with a projected increase in gasoline volume of $0.7 \%$ annually and a projected increase in the road octane number demanded by the consumer - $(\mathrm{RON}+\mathrm{MON}) / 2^{6}-$ from 89.3 to 89.8. Nevertheless, these demands will have to be met without the conventional octane and volume boosters: butanes and tetraethyl lead. Phase 2 precludes the traditional approach of adding butanes and tetraethyl lead available in the early 1980s because it prescribes summer RVP limits of 8 psi and a 95\% phase-out of tetraethyl lead in North America by 1992.

Hence, mandated reformulated gasoline specifications reduce the aromatic and light olefin content, resulting in a decrease in octane number that must be compensated for in another way. A 1989 National Petroleum Refiners Association gasoline survey indicated that the U.S. gasoline pool contains, on average, $32 \%$ aromatics and $13 \%$ olefins (Gilman 1990).

$6(\mathrm{RON}+\mathrm{MON}) / 2$ is the average octane number. RON (research octane number) is a measure of low-speed performance at full throttle, and MON (motor octane number) is a measure of cruising and moderate acceleration at part throttle. 
Refinery light olefins must be upgraded (alkylated) to be used in reformulated gasoline. And although pentenes in and of themselves are a major ozone precursor, they can be upgraded (alkylated) to meet specifications for reducing VOC emissions (O\&GJ 1992b).

Ozone nonattainment areas will require that $22 \%$ of U.S. gasoline be reformulated with a maximum of $25 \mathrm{vol} \%$ aromatics in 1995. This shift will result in a drop in aromatics in average summer gasoline of about $2 \mathrm{vol} \%$ from a 1989 baseline, and the downward trend will probably continue throughout the decade. Also, the concentration of light olefins will fall off slightly, as more of these light compounds are converted and upgraded to branched-chain paraffins and ethers to minimize evaporative emissions (Unzelman 1991).

The most significant change in reformulated gasoline composition is expected to be an oxygenate-hydrocarbon shift, in which aromatics will be replaced with ethers - primarily with MTBE during the 1990s. The trend will be toward an average fuel that combusts more completely and tends to be more stable with respect to evaporative emissions. Octane and RVP control can be provided by replacing $n$-butane and light hydrocarbons with ethers (Unzelman 1991).

A source at HyOx, Inc., in California (Unzelman 1991) forecasts that U.S. gasoline demand will reach 7.6 million bbl/d in 1995. Projections indicate that ethers will make up about $3.5 \mathrm{vol} \%$ of U.S. gasoline, or about $260,000 \mathrm{bbl} / \mathrm{d}$; and that more than $200,000 \mathrm{bbl} / \mathrm{d}$ of those ethers will be MTBE generated at U.S. refineries, so the balance will need to come from imports, with some possible contribution from alternative ethers such as TAME and ETBE.

Gasoline demand could reach 8 million $\mathrm{bbl} / \mathrm{d}$ by the year 2000 . At that time, projections indicate that ethers will make up $7 \mathrm{vol} \%$ of the gasoline blended at U.S. refineries. Combined ethers from refinery operations, the majority of them being MTBE, could total 485,000 bbl/d. The balance to meet the $7 \mathrm{vol} \%$ pool requirement, about $75,000 \mathrm{bbl} / \mathrm{d}$, would need to come from MTBE imports (Unzelman 1991).

It is estimated that year-round reformulated gasoline and special winter blends designed to meet standards for ozone and $\mathrm{CO}$ nonattainment areas will represent $65 \%$ of U.S. gasoline in the year 2000. If these calculations assume that MTBE will represent the combined ethers, the 7 vol\% could come close to meeting annual oxygen requirements for ozone nonattainment areas, if distribution is ideal. Supplementary oxygen will be needed from downstream alcohol blending to cover the logistics of geographical distribution and CO nonattainment during winter months (Unzelman 1991).

Producers of MTBE may not be able to find enough butane feedstock to meet demand without disrupting petrochemical markets and perhaps even running out of butanes. Will there be a butane shortfall? There may be, since there is only a limited supply of butane. Hence, companies that have not counted up the available butanes as feedstock could overbuild MTBE capacity (O\&GJ 1992c). 
Until 1995, small U.S. MTBE plants are expected to absorb much of the remaining isobutylene feed from FCC units. The additional feed could come from isomerizing unwanted $n$-butane, rejected in its paraffinic form in order to control RVP. The oil industry will probably construct ether plants and use imports rather than alcohols to fulfill oxygen requirements. By 1995 , the $3.5 \mathrm{vol} \%$ of ethers could supply about $90 \%$ of the oxygen requirements for ozone and $\mathrm{CO}$ nonattainment areas, if distribution is perfect. The balance could be supplied by downstream blending of alcohols, primarily ethanol, as gasohol (e.g., 10\% ethanol equivalent to $3.7 \mathrm{wt} \%$ oxygen). To meet demand, the current ethanol blending rate of 50,000 to $60,000 \mathrm{bbl} / \mathrm{d}$ would need to be expanded considerably (Unzelman 1991).

How might international supply issues affect the production of domestic oxygenated fuels and reformulated gasoline? First, to ensure there are enough butanes to meet oxygenate demand, governments could order reductions in gasoline volatility. That order would drive butanes from gasoline into MTBE production. Under this scenario, however, MTBE production would probably still not be enough to meet oxygenate demand. That situation would, in turn, force refiners to turn to ethanol and other oxygenates, which would then compete on the basis of oxygen content. Ethanol prices could rise to a level of profitability, and MTBE prices might then fall. One certainty is that if MTBE plants are overbuilt and if butane supplies limit MTBE production, methanol prices will collapse (O\&GJ 1992c).

If other industrialized countries suggest or recommend that MTBE be used as an oxygenate or in some other quality additive capacity, this situation will surely deplete the international availability. For example, since November 1991, the Japanese Agency of Natural Resources and Energy has ruled that up to $7 \mathrm{vol} \%$ of MTBE may be allowed in gasoline as an octane enhancer (Shearman 1991).

Internationally, the amount of methanol that can be sold as a feedstock for MTBE production is estimated to be limited to 20.4 million metric tons per year, an amount that is only about double the current world capacity and far less than has been estimated to be required for new plants expected to be built (O\&GJ 1992c).

Moreover, oxygenated fuels and reformulated gasoline could have significantly disruptive effects on the supply of and demand for hydrocarbons used by the gasoline and chemical industries. Butylenes and other $\mathrm{C}_{4} \mathrm{~s}$ could become scarce, while the prices of propylene, benzene, and aromatics could fall (Johnson and Perterson 1991). Areas of particular concern for a potential producer of MTBE or ETBE include how to find a source of feedstocks, plan for adequate storage, understand the technology involved and its related cost, choose the best location and determine the best market opportunities, make environmental evaluation/contingency plans, and predict future markets (Williams 1991). 


\section{GASOLINE CHARACTERISTICS}

\subsection{REGULAR GASOLINE}

Motor gasoline (commonly referred to as gasoline, petrol, or gas) is a complex mixture of hydrocarbons that boils below $355^{\circ} \mathrm{F}\left(180^{\circ} \mathrm{C}\right)$ or, at most, below $390^{\circ} \mathrm{F}\left(200^{\circ} \mathrm{C}\right)$. Typically, these hydrocarbons have 4 to 12 carbon atoms per molecule in their structure and are derived from the various classes of organic compounds empirically named paraffins (alkanes), olefins (alkenes), and aromatics (i.e., benzene and compounds that resemble benzene in their chemical behavior) (Morrison and Boyd 1966; Speight 1992c).

Thus, gasoline is a nonhomogeneous mixture of hydrocarbons used to fuel the spark-ignited internal combustion engine. It consists of more than 100 different hydrocarbons - the lightest or lowest-boiling compound being isobutane, the heaviest being a variety of substituted naphthalenes. All the hydrocarbons in gasoline are the products of a limited number of refining processes (see Section 4) designed to increase the yield or quality of gasoline components (naphthas) (Shannon 1992).

In practice, no two quantities of gasoline are identical; in fact, refiners purposefully create different gasolines to address summer and winter conditions and respond to the crude stock and refinery equipment that are available. And recently, refiners and regulators have been exploring opportunities to reformulate gasoline to reduce its emissions of hydrocarbons, toxics, and other pollutants (Sperling 1990). Refiners adjust the conditions of, and thereby the volumes from, various refinery processes (see Appendix A) to formulate a finished product that, upon appropriate blending, will meet the quality requirements of the particular market being supplied and the American Society for Testing Materials (ASTM) specifications for motor gasoline, especially with respect to its volatility, octane rating, additive-derived properties, and lead content.

Some essential operating characteristics of finished gasoline are listed below and described in more detail in the following subsections:

- Volatility is controlled by using:

- Low-boiling vapor for spark-ignited start,

- Middle-boiling hydrocarbons to power and propel the vehicle, and

- Few heavy aromatics so chamber deposits are not formed.

- Octane is set to prevent spark knock by controlling:

- RON (measure of low-speed performance at full throttle) and

- MON (measure of cruising and moderate acceleration at part throttle). 
- Additives are applied to:

- Reduce oxidation,

- Prevent corrosion from moisture, and

- Loosen harmful carburetor deposits.

\subsubsection{Volatility}

The volatility of gasoline is controlled to strike a balance between insufficient vaporization and excessive vaporization. For spark-ignited internal combustion engines to function, there must be a gaseous mixture of fuel vapor and air that sustains combustion when ignited by the spark discharge. Thus, low-boiling hydrocarbons are required in a cold cylinder and middle-boiling hydrocarbons are expected to produce power and propel the vehicle, but too much vapor cannot be allowed to cause problems during sustained operation (Shannon 1992).

Traditionally, aromatics have improved a fuel's total energy content and thus its economy because they are denser and possess higher heat contents than the total fuel. However, the heavier aromatics contribute a disproportionately large share to the buildup of combustion chamber deposits - a major pollution source (Shannon 1992).

As lead was phased out, volatile butane was added to gasoline for its blending octane properties. Isomerization of straight-chain pentanes and hexanes to branched-chain hydrocarbons with higher octane has also served to increase the octane, but it increased the volatility of gasoline as well (Diebold et al. 1992).

\subsubsection{Octane}

A gasoline's octane number is an indication of the fuel's ability to prevent the occurrence of spark knock in an engine. Spark knock is an audible sound resulting from the explosion of a portion of the air-fuel charge before to the arrival of the flame front; i.e., the timed spark ignites a flame that propagates smoothly through the charge, except when spark knock occurs (Shannon 1992).

The numerical octane scale is based on blends of $n$-heptane (assigned a value of 0 ) and isooctane (or 2,2,4-trimethylpentane) (assigned a value of 100). Octane blending is nonlinear by nature. For commercial gasolines, RON (a measure of low-speed performance at full throttle) is higher than MON (a measure of cruising and moderate acceleration at part throttle). Both are required to adequately define the antiknock quality during operation (Shannon 1992). 


\subsubsection{Additive-Derived Properties}

Most of the desirable features of gasolines require the deliberate application of additives during and after refining. Both technical capability and economic considerations play a part in determining which properties will be imparted and emphasized (Shannon 1992). Additives are used in motor gasolines to prevent a number of problems that could occur during distribution and combustion:

1. Gasolines must be made less susceptible to oxidation, so they can be stored for many weeks without forming the excessive "gum" caused by free-radicalcatalyzed reactions; this gum can cause operating problems.

2. Gasolines must be kept free of moisture to prevent corrosion.

3. Gasolines require detergents to loosen and solubilize harmful carburetor deposits (Shannon 1992).

\subsubsection{Lead and Its Phase-Out}

The original purpose of putting lead in gasoline was to increase the octane number; a secondary purpose was to protect exhaust valves (Diebold et al. 1992). Tetraethyl lead was used because it is effective antiknock agent, trapping unwanted hydroperoxide radicals (HOO-) formed ahead of the advancing flame front in an internal combustion engine. Since 1975, methylcyclopentadienyl manganese tricarbonyl (MMT) has been used as an antiknock agent to produce lead-free gasoline (Shannon 1992).

As lead was phased out, gasoline refiners substituted progressively more aromatics with higher blending octane values (e.g., benzene, toluene, xylene, and higher-boiling aromatic compounds). However, such higher-boiling aromatics resist combustion and contribute significantly to the amount of unburned hydrocarbons in the exhaust, including toxic benzene (Wise 1992; Diebold et al. 1992).

\subsection{REFORMULATED GASOLINE}

The first reformulated gasoline, which was supplied by ARCO in southern California, was blended with MTBE, cost 2 cents per gallon more than conventional gasoline, and achieved modest emission impacts. It reduced hydrocarbon emissions from the tailpipe by $4 \%$, evaporative emissions by about $21 \%, \mathrm{CO}$ emissions by $9 \%$, and $\mathrm{NO}_{\mathrm{x}}$ emissions by $5 \%$ (Sperling 1990). 


\subsubsection{Oxygenates}

The contributions of oxygenates to reformulated gasoline are summarized in the list below and discussed in this section.

- Oxygenates lower the photochemical reactivity of gasoline and thereby reduce its contribution to ozone formation.

- Oxygenates give gasoline a higher octane value.

- MTBE is relatively inexpensive.

- MTBE and, even more so, ETBE lower the volatility characteristics of gasoline.

- Adding oxygenates to gasoline can maintain the liquid fuel industry as environmental regulations change.

Adding oxygenates to gasoline can significantly reduce exhaust emissions of hydrocarbons and $\mathrm{CO}$, especially in older cars. Almost all $\mathrm{CO}$ emissions during summer come from mobile sources. Mobile sources often emit 10 times more $\mathrm{CO}$ than hydrocarbons. However, $\mathrm{CO}$ contributes less to ozone formation than do hydrocarbons (EPA 1988; Smylie et al. 1991). Furthermore, oxygenates may actually increase emissions of $\mathrm{NO}_{\mathrm{x}}$, another precursor to ozone formation. However, EPA data suggest that at some point, the increase in $\mathrm{NO}_{\mathrm{x}}$ emissions diminishes as higher levels of oxygenates are added (Smylie et al. 1991). For example, gasoline with 15\% MTBE (2.7 wt\% oxygen) may not significantly increase $\mathrm{NO}_{\mathrm{x}}$ emissions, even though lower percentages of MTBE appear to increase them.

The major contribution of oxygenates toward ozone abatement may eventually result from their combination of high octane value and net low reactivity toward photochemical ozone formation (i.e., lower photochemical reactivity). Oxygenates could be used to replace compounds such as the multialkyl aromatics (e.g., xylenes), which combine high octane value with very high photochemical reactivity (Smylie et al. 1991).

Faced with a surplus of butanes at the refinery, refiners found that butane could be converted commercially to the very reactive isobutene and then reacted with methanol to produce MTBE. MTBE contributes a very high octane and moderate volatility to gasoline and is completely miscible with it. In addition, the presence of oxygen in the fuel (in any of numerous forms) has been shown to promote complete combustion and reduce tailpipe emissions (Diebold et al. 1992). 
Thus, ethers like MTBE may be expected to play a prominent role as components of U.S. gasoline in the 1990s. Their blending characteristics are a "good fit" with the probable requirements for reformulated gasoline (Hollrah and Burns 1991). The most significant oxygenatehydrocarbon shift will be to replace aromatics with ethers, primarily MTBE. This exchange will reduce the carbon-to-hydrogen ratio, and the net effect will be lighter average gasoline and higher API (American Petroleum Institute) gravity. The trend will hold regardless of which oxygenates are involved, because all the prospective candidates have higher API gravities than do aromatics (Unzelman 1991). However, the resulting reformulated gasoline will have a lower Btu content because of the added oxygenate (Parkinson 1992).

As the API gravity of average summer gasoline increases, the Btu content will drop, tending to reduce the fuel economy or miles per gallon (mpg) achieved by using future gasoline. However, a lighter gasoline should combust more completely, thereby counteracting some of the effect of lower Btu content (Unzelman 1991).

It is expected that by 1995, the majority of gasolines requiring oxygen will be blended with ethers. If ethers are in short supply, the industry may have to rely more heavily on alcohols to meet oxygen requirements in $\mathrm{CO}$ nonattainment areas during the cold season. Later in the decade, however, ethers are expected to assume the major role in the oxygenate-hydrocarbon shifts (Unzelman 1991).

So far, MTBE, a reaction product of methanol and isobutylene, is relatively inexpensive to produce and competitively priced with other octane blending agents currently available (Hollrah and Burns 1991).

ETBE, a reaction product of ethanol and isobutylene, has blending attributes similar to those of MTBE. And its volatility characteristics are even lower than those of MTBE. The average RVP blending value for selected sample gasolines decreased from 4 psi (5\% ETBE) to 2 psi (15\% ETBE) and from $12 \mathrm{psi}$ (5\% MTBE) to 7 psi (15\% MTBE). This drop is significant; an RVP blending value difference of 5 psi could change the RVP of the finished blend by 0.75 psi at a concentration of $15 \%$ ether (Hollrah and Burns 1991). Ethanol blending is expected to have only a minor impact on the characteristics of average summer gasoline. It could have a greater impact on the volatility of average winter gasoline (Unzelman 1991).

In these same selected sample gasolines, the average gains in octane number for $5 \% \mathrm{MTBE}$ or 5\% ETBE were 1.4 for regular unleaded gasoline and 1.0 for premium unleaded gasoline; for $15 \%$ MTBE blends, they were 3.1 for regular and 2.2 for premium; for $15 \%$ ETBE blends, they were 3.7 for regular and 2.2 for premium; and for $10 \%$ ethanol blends they were 2.4 for regular and 1.8 for premium. Acceptable octane numbers $[(\mathrm{RON}+\mathrm{MON}) / 2]$ of $108-115$ were achieved with $5-15 \%$ MTBE, ETBE, or ethanol in regular unleaded gasoline (Hollrah and Burns 1991). Another contribution to the gasoline pool's MON may be alkylate, because the pool's MON is increased 
when $\mathrm{C}_{5}$ alkylate rather than $\mathrm{C}_{5}$ olefins is blended into gasoline. Thus, high-RVP $\mathrm{C}_{5}$ olefins can be replaced by low-RVP $\mathrm{C}_{5}$ alkylate. Alkylation will provide octane and reduce RVP, particularly desirable goals for reformulated gasoline (Gonzalez 1992).

CARB's Phase 2 specifications will make alkylate the only component that can be increased without causing any detriment to other blending specifications. These specifications call for reductions in sulfur, benzene, and other components beyond federal reformulated gasoline limits. Alkylate provides gasoline RON and MON without olefins and aromatics. Studies show that California's reformulated gasoline may eventually contain as much as $36 \%$ alkylate (Gonzalez 1992).

\subsubsection{Catalyst Technology and Additives}

Catalyst technology and operational changes will be needed to minimize the amount of capital required for gasoline reformulation. The following processes and catalysts can minimize capital expenditures for producing reformulated gasoline (Gilman 1990).

- In the 1980 s, catalyst manufacturers provided octane-boosting catalysts to fill the octane void resulting from the lead phase-out.

- Technology evolved into using low nonframework alumina (NFA) zeolite catalysts possessing high silica-to-alumina ratios (SARs).

- Low NFA zeolites and crystalline matrices favor production of $\mathrm{C}_{4} \mathrm{~s}$ and heavier hydrocarbons. Both produce highly olefinic $\mathrm{C}_{4} \mathrm{~s}$ that are attractive feeds for alkylation and MTBE units.

- The catalyst architecture best-suited for reformulated gasoline will contain a high SAR, to be exchanged with a rare earth element (promoting hydrogen transfer to convert olefins generated by primary cracking to paraffins) and accompanied by a very selective matrix.

- Octane catalysts that exhibit low hydrogen transfer rates permit olefins from primary carbenium ions to rearrange and promote isomerization, improving middle-boiling hydrocarbon octane performance (Gilman 1990).

MMT is an additive (catalyst) that has been recognized for its octane-improving capability for more than 20 years. It has been used in almost all unleaded gasoline since 1978 . However, the 
EPA is concerned about its environmental impact and has raised questions about the health, environmental, and performance characteristics of the agent (Hollrah and Burns 1991). ${ }^{7}$

Special catalyst technology exists to convert unreactive 3-methyl-1-butene to the reactive form, 2-methyl-2-butene. In the presence of hydrogen, the trifunctional Etherol catalyst isomerizes the normally unreactive 3-methyl-1-butene into the reactive 2-methyl-2-butene by a double-bond shift reaction (Unzelman 1991).

A number of novel FCC catalysts are being designed specifically to maximize product value for refiners desiring to use maximum branched light olefins rather than MTBE, TAME, and alkylate feedstock. A combination of surface-enhanced zeolites and selective matrix materials has been used to modify the catalyst architecture so it provides better access to active sites yet minimizes the residence time of primary products. This modification allows refiners to optimize the yield of desirable products without increasing the low-profitability side components, thereby helping them to meet the challenges associated with producing environmentally acceptable gasolines (Harris et al. 1992).

MTBE can be formed by the acid-catalyzed addition of methanol to isobutylene by using a commercially available sulfonated styrene-divinyl benzene resin catalyst. The related acidcatalyzed dehydration of tert-butyl alcohol to synthesize isobutylene and water is currently being studied (Gron et al. 1992).

7 In preparing this report for publication in 1995, the following new information became available: In April 1995, the EPA finally issued the emissions waiver that Ethel Corp. had sought for 17 years for its MMT octane-enhancing fuel additive. The U.S. Court of Appeals ordered the EPA to do so because it found that MMT does not cause a significant increase in emissions. Nevertheless, the EPA is still concerned about health effects, although Ethel Corp. has argued that MMT poses no human health threat ( $C \& E$ News 1995). 


\section{PROJECTED IMPACT OF REFORMULATED GASOLINE MANDATE ON REFINING CAPACITY}

To reduce emissions from the gasoline engine, the aromatics content and RVP of the motor gasoline pool must be reduced and a minimum amount of oxygen must be added to it. This reformulation will limit the contribution of high-octane components like benzene, toluene, and butanes and will require the increasing use of oxygenates. To compensate for the loss in octane, the use of alkylate and, of course, oxygenates will grow. The FCC unit - as a producer of olefinic propanes, butanes, and pentanes - will then become an important feedstock producer for the alkylate- and oxygenate-producing processes. Moreover, it will become the focal point of most important refinery modifications. Hence, process adjustments and FCC catalyst formations that increase the yield of the above desirable light products will become of prime importance (Yung et al. 1992).

In blending reformulated gasoline, the reduction of butane to obtain lower RVP and the reduction of reformate to obtain lower aromatics content may be generally compensated for by increasing the percentages the of alkylate and/or SR naphthas (Hadder 1992). Current technology allows for an increase in light olefins at the front end of the gasoline stream (e.g., isoamylenes), which will provide some of the feeds needed to produce oxygenates (Yepsen and Witoshkin 1991).

Nevertheless, refiners will have to add new refinery plant capacity and make major changes in refinery design to produce the needed components for mandated reformulated gasoline (Yepsen and Witoshkin 1991; Sperling 1990). Relatively larger refinery process capacity additions will be required, specifically for butane isomerization, alkylation, aromatics recovery, and distillate hydrotreating (Hadder 1992). (See Figure 1.) And since refineries are not expected to be able to handle both the three current gasoline grades and the three new reformulated grades, most production will likely be reformulated gasoline (Yepsen and Witoshkin 1991).

\subsection{FLUID CATALYTIC CRACKING}

Naphtha generated by the FCC unit is currently the largest single gasoline component. The unit contributes approximately $50 \%$ to gasoline pools, $38 \%$ directly and $12 \%$ indirectly from alkylation (Yepsen and Witoshkin 1991). The FCC unit, along with the reformer, also contributes a large amount of aromatics; reformate contains up to $70 \%$ aromatics, compared with $20-27 \%$ from the FCC unit. The FCC unit and its propylene conversion units are primary sources of olefins (Simonsen et al. 1993; Gilman 1990).

The nationwide reformulation of gasoline would also lead to the reduction of gasoline RVP from about 9.6 to less than $8.5 \mathrm{psi}$ - even lower in the summer months. The result may be a large 


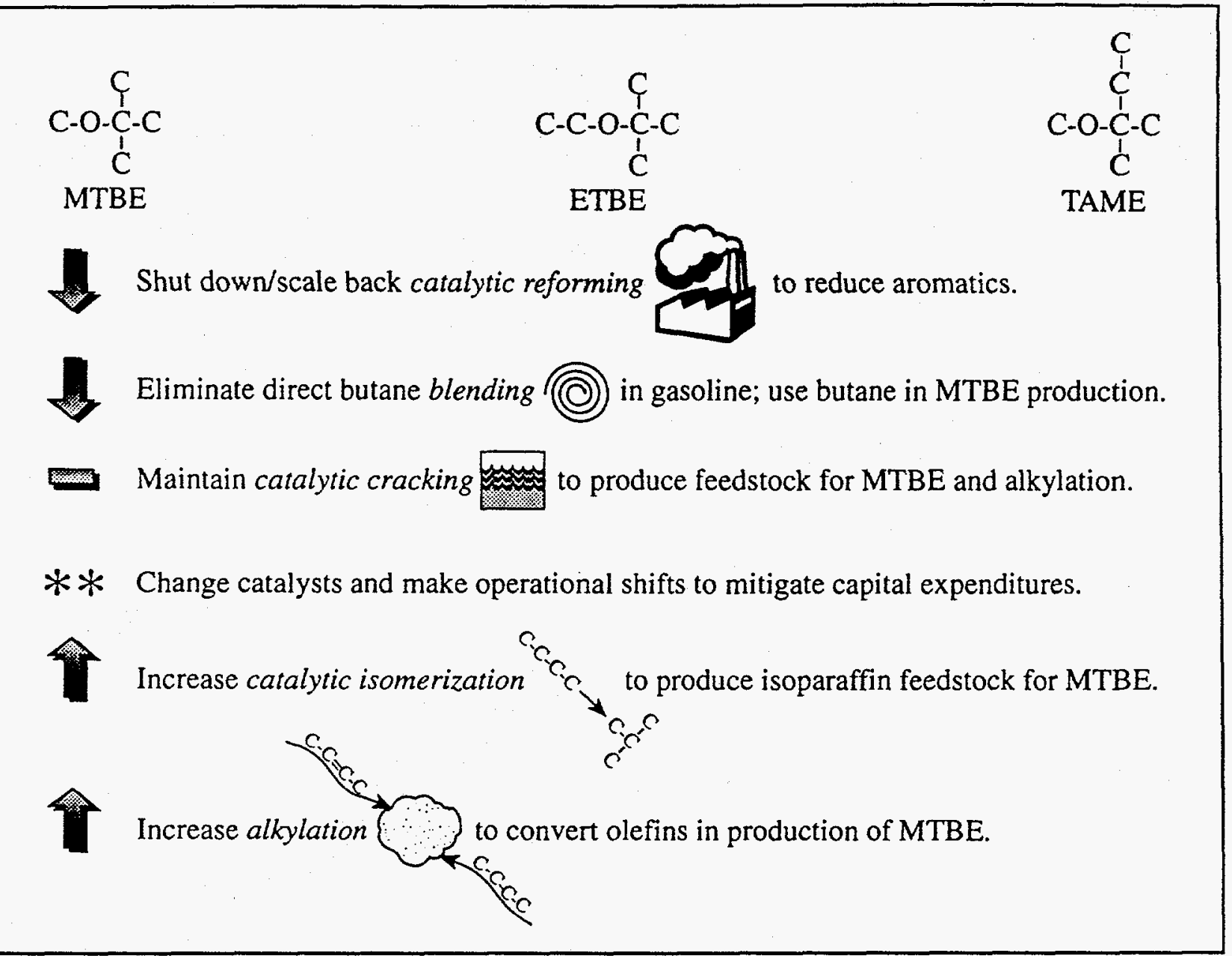

FIGURE 1 Adjustments to Refinery Streams Required to Produce Oxygenates

surplus of heavy ends from the FCC unit. Potential reductions in $\mathrm{T}_{90}$ after 1995 could dramatically reduce the quantity of FCC unit naphtha available for the gasoline pool. However, reducing $\mathrm{T}_{90}$ would be very expensive and would not help improve air emissions much (Simonsen et al. 1993).

A larger refiner with downstream, especially in-plant, petrochemical facilities should have the flexibility to further process refined products. Small refiners will probably choose to sell their gasoline to blending companies. A mid-sized refiner without chemical facilities may have to spend substantial capital unless it decides to integrate with another nearby refiner or petrochemical plant (Gilman 1990).

The most rapid growth is expected to be in butane dehydrogenation (olefin production) and FCC butylenes processes. Virtually any U.S. refinery that has an FCC unit that can accept at least $30,000 \mathrm{bbl} / \mathrm{d}$ feed is a likely site for a MTBE unit (Shearman 1991). 
The FCC unit is expected to continue in its prominent role as the centerpiece of refinery operation and the major contributor (at greater than 50\%) to the gasoline pool. However, its contribution is expected to change as it supplies more feedstock to units such as those used for MTBE and alkylation, to produce gasoline with a lower RVP and virtually no aromatics and olefins. The refiner has the most freedom to change the catalyst of all the FCC unit operating variables. Most refiners will probably choose to operate the FCC unit in the overcrack mode (i.e., to crack as many aromatics as possible) to try to assure attractive octanes (Gilman 1990).

Pretreatment of feed to the FCC unit will allow for additional overcracking and provide the unit with the flexibility to handle poorer-quality feeds, which result from the reduction in available hydrogen because of reduced reformer operations that yield less hydrogen. Overcracking will be used to transalkylate (convert) benzene to xylenes, a more acceptable component of gasoline. The FCC unit should operate in the overcrack mode because downstream units, such as the MTBE, alkylation, and isomerization units, will contribute more to the reformulated gasoline pool (Gilman 1990).

The refining industry plans to have the FCC unit generate light olefins, a feature that will make alkylation more important. $\mathrm{C}_{4}$ and $\mathrm{C}_{5}$ olefin cuts from a upgraded $\mathrm{FCC}$ unit can provide extra feedstocks to the alkylation unit. To maximize reformulated gasoline production, $\mathrm{C}_{4}$ and $\mathrm{C}_{5}$ olefins could be converted to ethers and alkylate (Gonzalez 1992).

MTBE and TAME units will have added value because their raffinate ${ }^{8}$ can be processed by means of alkylation (Gonzalez 1992). MTBE demand is estimated to require $800,000 \mathrm{bbl} / \mathrm{d}$ of isobutylene feedstock in addition to the $100,000 \mathrm{bbl} / \mathrm{d}$ now produced in refinery FCC units (Yepsen and Witoshkin 1991).

\subsection{REFORMING}

Production of aromatics, including benzene, can be cut by reducing the severity of the reformers. However, to meet the benzene requirement, cyclohexane (benzene's precursor alkane) will also have to be fractionated (removed) from the reformer feed with the lighter fractions, then blended back into the gasoline. Benzene must also be removed from the reformate (Parkinson 1992).

Light reformate is high in benzene content, $4.01 \mathrm{vol} \%$. Mid-cut reformate contains most of the toluene, ethylbenzene, and xylenes, plus some $\mathrm{C}_{9}$ aromatics from naphtha reforming. Heavy reformate is primarily $\mathrm{C}_{9}$ and $\mathrm{C}_{10}$ aromatics, plus $\mathrm{C}_{10+}$ aromatics higher than $\mathrm{T}_{90}$. Both the mid-cut and heavy reformates contain more than $90 \mathrm{vol} \%$ total aromatics (Unzelman 1991).

8 Raffinate is that portion of the crude that remains undissolved and is not removed by the selective solvent (Considine 1989). 
Currently, most of the aromatics in U.S. gasoline result from the combination of two refinery streams - reformed naphtha and FCC gasoline - which represent approximately 70 vol\% of the U.S. gasoline pool (Unzelman 1991). To meet reformulated gasoline mandates, reformers will have to contribute less to the reformulated gasoline pool, a conclusion that is based on the fact that reformers generate up to 70 vol\% aromatics, of which 5 vol\% is benzene. Aromatics reduction can be accomplished by reducing the reformer throughput and severity or by extractive distillation, the latter of which would increase capital expenditures and utility costs (Gilman 1990). Reformer severity could be reduced if a gasoline with a high enough octane could be assured when benzenes and other aromatics in gasoline are replaced with alkylate and ethers (MTBE/TAME) (Gonzalez 1992).

Steam methane reforming of hydrocarbons is used widely in refineries to generate hydrogen. The reaction is favored by high temperatures and low pressures (less than 300 pounds per square inch gauge or psig). Reforming technology is limited in practice to natural gas or light naphtha feedstocks, since the presence of catalyst poisons and heavier olefins causes problems (Simonsen et al. 1993).

\subsection{ALKYLATION/ISOMERIZATION}

The combined reductions of aromatics, benzene, and olefins under California's regulations will probably remove more octane than can be replaced by the oxygenate allowed in the gasoline specifications. CARB has proposed a 1.8-2.2\% oxygen content, below the federal minimum of $2.7 \%$ in $\mathrm{CO}$ nonattainment areas, to mitigate $\mathrm{NO}_{\mathrm{x}}$ formation (Parkinson 1992).

Two logical sources for the additional octane are alkylation and isomerization. Alkylation is practical because it takes unwanted olefins as feed and converts them to a high-octane component. According to Robert Cunningham, "Alkylation is going to increase by $70 \%$ in California" (Parkinson 1992). In 1989, the total volume of all alkylate in the U.S. gasoline pool amounted to approximately 11 vol\% (Unzelman 1991).

Some saturated olefins (i.e., pentanes) will also have to be removed by distillation to meet the 7.0-psi RVP specification (Cunningham, UOP). UOP offers a process that alkylates $\mathrm{C}_{5}$ olefins that have not already been alkylated by a liquid-extraction process to remove sulfur and then uses selective hydrogenation to remove trace diolefins (Parkinson 1992).

$\mathrm{C}_{5}$ olefins can be removed from the front end of cracked gasoline and alkylated, although operating coșts are high because of excessive acid consumption. However, the highly reactive $\mathrm{C}_{5}$ olefins can be converted to TAME. Special catalyst technology exists to convert unreactive 3-methyl-1-butene to the reactive form, 2-methyl-2-butene. In the presence of hydrogen, a trifunctional catalyst isomerizes the normally unreactive 3-methyl-1-butene into the reactive 
2-methyl-2-butene by a double-bond shift reaction. Thus, it may become economical for refiners to convert these compounds to ether because of the need to meet oxygen requirements (Unzelman 1991).

Alkylation will become more important in gasoline reformulation because alkylate possesses a low RVP (4 psi) and virtually no olefins and aromatics. Also, the alkylation unit can convert photochemically reactive $\mathrm{C}_{5}$ olefins to an attractive gasoline-blending component. The placement of an MTBE and/or TAME unit - removing isobutylenes and/or isoamylenes and processing additional propylene and butylene - upstream of the alkylation unit will reduce the amount of feed going to the alkylation unit by $10 \%$ (Gilman 1990).

Isomerization units will have to be built to increase the octane of the light SR fraction; they convert $n$-paraffins to isoparaffins. And the heavy SR fraction will also need to be isomerized, rather than reformed, to reduce benzene production. An isomerization reactor is similar to a reformer in that it uses a platinum-based catalyst and operates at low pressure. Thus, a refinery can readily retrofit a cyclic reformer to become an isomerization reactor (Gilman 1990). And more $n$-butane will probably need to be isomerized and dehydrogenated by using catalysts and hydrogen (Yepsen and Witoshkin 1991).

\subsection{HYDRODESULFURIZATION/HYDROTREATING}

Many California refineries use hydrodesulfurization units to pretreat the feed for their FCC units. (Hydrodesulfurization units in large refineries treat other streams as well.) Although refiners are expected to increase the operating severity of these units to remove more sulfur, additional hydrotreating capacity will be needed to cut sulfur to 40 parts per million (ppm) by weight (Parkinson 1992).

Hydrotreating the feed to the FCC unit improves the gasoline yield, according to Clossey of ARCO. On the other hand, hydrotreating the product not only removes sulfur but also saturates the olefins (alkylation), converting them to paraffins (alkanes) and reducing the octane value. A hydrotreating catalyst that removes the sulfur downstream of an FCC unit without saturating the olefins was reported to be near commercialization by Houston-based Criterion Catalysts Co. (Parkinson 1992).

Hydrogen processing (hydroprocessing) is critical to improve the quality of the product fuels and satisfy feed pretreatment requirements for certain catalytic units. The crude quality determines how the hydrogen balance in a refinery will be handled (i.e., whether the reformer will be able to operate at reduced rates or hydrogen will need to be imported). In any event, use of hydrogen will need to be conserved and improved (Gilman 1990). 


\subsection{INDUSTRY OPTIONS}

The impact of oxygenates in motor gasoline and the effect of aromatics and end-point reduction will dramatically change gasoline composition and processing technology. SR and heavy naphtha streams from $\mathrm{FCC}$ units in the range of $350-450^{\circ} \mathrm{F}$ are particularly difficult to refine if the end-points of $90 \%$ gasoline specifications are reduced. One solution may be the UOP technology under development, which incorporates an active, solid, acid catalyst operating at mild conditions to achieve selective cracking of heavy naphtha and kerosene-range materials. High yields of isobutane and isopentane are obtained with virtually no production of light ends (Schmidt et al. 1992).

The range of actions that the industry could take in response to the new gasoline regulations include these:

- Manufacturing or importing sufficient MTBE or TAME to meet the oxygen specification. Ethanol and methanol could be used, but in the near-term, there is not likely to be enough ethanol available, and direct methanol blending causes engine damage and problems with water in the gasoline distribution system.

- Reducing reformer operations. Since MTBE and TAME in the gasoline pool will significantly increase its octane rating, it will be necessary to reduce octane production by shutting down or scaling back reformer units (since the octane level sets the reformer activity). This action will serve to reduce the amount of benzene and aromatics.

- Eliminating entirely the direct blending of butane. This action will be needed to reduce RVP and make available the butane needed to manufacture MTBE.

- Reducing alkylation levels for direct gasoline blending. The octane glut created by adding oxygenates to the gasoline pool, combined with the scarcity and increasing price of isobutane and isobutylene, will greatly reduce the attractiveness of alkylate production in direct gasoline blending. However, reformulated gasoline may require increased alkylation for oxygenate production.

- Maintaining FCC unit volumes. Imported gasoline may be replaced by imported additives such as MTBE (Johnson and Peterson 1991). The FFC unit is the major contributor to the gasoline pool but may also supply feedstock to the MTBE and alkylation units. 
Moreover, catalyst technology and operational changes will be needed to mitigate the required capital for gasoline reformulation. Various processes and catalysts can be used to reduce capital expenditures for producing reformulated gasoline (Gilman 1990). In addition, specific items related to aromatics curtailment and octane enhancement are offered for consideration below.

A case study by Akzo in Houston illustrates specific refiners' choices regarding feed, product distribution and quality, and capital expenditures to meet reformulated gasoline specifications (Gilman 1990). Appendix B lists pertinent facts, factors, and data for a fictional but typical $100,000-b b l / d$ refinery with no downstream petrochemical facility.

\subsubsection{Aromatics Curtailment}

Aromatics typically make up $29 \mathrm{vol} \%$ of gasoline from FCC units, a level that exceeds the $25 \mathrm{vol} \%$ target. Therefore, refiners could:

- Process more naphthenic or paraffinic gas oils. This procedure would be very difficult to implement because crude sources are limited; it is not a viable option.

- Alter operating conditions to lower unit conversion. This negative option would reduce overall conversion (producing about 4.5 vol\% less gasoline) and reduce the octane number by $0.5 \mathrm{RON}$.

- Undercut the full distillation range of gasoline. Distilling out the heaviest $10 \%$ (the fraction containing $80-100 \%$ of the aromatics) would reduce gasoline volume by $4 \%$ and pose a new problem for the rejected heavy aromatics being generated $(300,000 \mathrm{bbl} / \mathrm{d})$. Hydrocracking, new hydrocracking capacity, and additional hydrogen sources would be required (Yepsen and Witoshkin 1991).

Regarding the limitation of aromatics, the alternatives are (1) fractionation, followed by hydrogenation and saturation back to cyclohexane, or (2) solvent extraction for sale as a petrochemical. An FCC catalyst that reduces production of aromatics is being developed by W.R. Grace \& Co.'s Davison Chemical Division in Baltimore; it is in the precommercialization phase (Parkinson 1992). 


\subsubsection{Octane Enhancement}

Naphtha, reformates, and alkylates from FFC units were dominant (exceeding $75 \%$ ) in the 1989 U.S. motor gasoline formulation (Table 1). Reformate levels have increased in recent years so that octane levels could be maintained while lead antiknock compounds were being phased out. Some of these gasoline components, however, could become obsolete, along with the equipment that produces them (Johnson and Peterson 1991).

Reportedly, MMT (previously described in Section 3.2.2) raises the octane quality of gasoline and allows refiners to operate reformers at less severe conditions. This lower severity reduces fuel gas requirements and, as a result, may lower U.S. refinery emissions by an estimated 7,500 tons per year. The lower reformer severity also produces a gasoline with a $1.0-1.5 \%$ lower aromatic content. For [RON+MON]/2, an octane improvement of 0.9 for regular and 0.5-0.6 for premium is claimed. MMT octane improvement costs were estimated at one-third of the cost for processing oxygenates (\$15-20/bbl crude) (Hollrah and Burns 1991).

TABLE 11989 U.S. Motor Gasoline (MOGAS) Formulation

\begin{tabular}{lrrlrrr}
\hline \multicolumn{1}{c}{ Blendstock } & $\begin{array}{c}\text { Percent } \\
(\%)\end{array}$ & $\begin{array}{r}\text { Volume } \\
(\mathrm{bbl/d})\end{array}$ & \multicolumn{1}{c}{ Blendstock } & $\begin{array}{r}\text { Percent } \\
(\%)\end{array}$ & $\begin{array}{r}\text { Volume } \\
(\mathrm{bbl} / \mathrm{d})\end{array}$ \\
\hline FCC naphtha & 37.64 & $2,582,710$ & Light coker naphtha & 0.67 & 45,905 \\
Reformate & 26.92 & $1,847,302$ & Natural gasoline & 0.52 & 35,547 \\
Alkylate & 12.12 & 831,347 & Aromatics & 0.44 & 30,423 \\
SR naphtha & 3.65 & 250,175 & Pyrolysis gasoline & 0.29 & 20,012 \\
C $_{5+}$ isomerate & 3.64 & 249,622 & Poly gasoline & 0.28 & 18,876 \\
Normal butane & 3.08 & 210,976 & Dimate & 0.14 & 9,705 \\
Hydrocrackate & 2.41 & 165,179 & TAME & 0.00 & 0.00 \\
Light paraffins & 2.18 & 149,857 & Lead & 0.00 & 0.00 \\
Raffinates & 1.13 & 77,240 & Other & 2.16 & 146,537 \\
Ethanol & 1.02 & 70,000 & Subtotal & 100.00 & $6,860,678$ \\
Toluene/xylene & 0.91 & 62,215 & Imports & & 431,311 \\
MTBE & 0.80 & 55,061 & Total & & $7,291,989$ \\
\hline
\end{tabular}

Source: Johnson and Peterson (1991). 


\section{FEEDSTOCK/BLENDSTOCK DEMAND AND SUPPLY}

Gasoline demand is forecasted to reach 7.6 million bbl/d in 1995 in the United States. Ethers are projected to make up about $3.5 \mathrm{vol} \%$ of U.S. gasoline, or about $260,000 \mathrm{bbl} / \mathrm{d}$. More than $200,000 \mathrm{bbl} / \mathrm{d}$ of these ethers are projected to be MTBE generated at U.S. refineries. The balance is projected to come from imports, with some potential contribution from alternative ethers such as TAME and ETBE (Unzelman 1991).

In most proposed new gasoline formulations, the addition of oxygenates, such as MTBE, ETBE, or TAME, is being considered to maintain an acceptable octane. However, the production of MTBE and ETBE will ultimately be limited by the availability of isobutylene. And traditional commercial routes for producing isobutylene will probably be unable to meet the large growth in demand anticipated for fuel ethers (Gajda 1991).

The U.S. fuel alcohol and ether industry grew from its infancy in 1979 to approximately 3.0 billion gal of production capacity in 1992. By 1995, $4.1 \mathrm{billion}$ gal/yr are expected to be required (Haigwood 1991).

To some extent, reformulated gasoline will use a different set of hydrocarbon raw materials than does present gasoline, thereby disrupting supply-demand balances (Johnson and Peterson 1991). This section examines (1) existing refinery products that will be affected by the onslaught of reformulated gasoline, (2) oxygenates and other compounds that may serve as ether blendstock, and (3) oxygenates that may serve directly as blendstock for reformulated gasoline.

\subsection{REFINERY PRODUCTS AFFECTED BY REFORMULATED GASOLINE}

\subsubsection{Benzene}

Benzene's removal from gasoline is expected to create an annual excess or glut of 8 billion $\mathrm{lb}$ on chemical markets over the current balanced market of 13 billion lb/yr (Yepsen and Witoshkin 1991). Thus, benzene will probably not be made, because reforming units will have to be cut back to eliminate octane. Its price will probably decrease. Benzene is currently produced as a by-product of ethylene manufacture, in catalytic reforming units, and by hydrodealkylation of toluene. The last process has set the price to date. The pricing relationships between benzene and toluene will certainly be disrupted (Johnson and Peterson 1991). Moreover, a collapse in prices for benzene and all aromatics is predicted (O\&GJ 1992c). 


\subsubsection{Propylene}

There will be a glut of propylene when the reformulated gasoline program is implemented. Currently, catalytic cracking is a major source of by-product propylene. But the reduction in alkylation activity could reverse this trend and reduce the price of propylene. Propylene is an important ethylene by-product, as are butadiene and benzene, whose prices may also become depressed by gasoline reformulation. These declining coproduct values, coupled with higher feedstock costs because of the higher prices of liquefied petroleum gases (LPGs), will result in higher ethylene prices as gasoline is reformulated (Johnson and Peterson 1991).

\subsubsection{Propylene Oxide/Styrene}

Industry technology coproduces styrene with propylene oxide or MTBE with propylene oxide. In early 1993, all three products were oversupplied in North American markets and were balanced to soft worldwide. With the wave of new capacity, the three products are likely to become increasingly unstable, as strong demand in one serves to produce much unwanted coproduct. The weakest demand is probably for styrene, with poor prospects until the end of the decade. Although MTBE capacity additions may be in a lull, they are expected to pick up again as the next CAAAs gasoline reformulation deadline nears in 1995. Demand for propylene oxide is still growing enough worldwide that several companies are considering new plants (Morris 1993).

ARCO is the world's largest propylene oxide and MTBE producer. ARCO has $60 \%$ of the propylene oxide capacity in North America ( 2.3 billion $\mathrm{lb} / \mathrm{yr}$ ) and $40 \%$ worldwide ( 3.8 billion $\mathrm{lb} / \mathrm{yr}$ ). Dow Chemical has $35 \%$ globally because of its chlorhydrin technology. Texaco is expected to bring on line 400 million lb/yr. In styrene production, ARCO is third, behind Dow and Royal Dutch/Shell (Morris 1993; Hunter 1993).

\subsubsection{Hydrogen}

Refinery demand in the United States for hydrogen is expected to continue to increase by $5-10 \% / y r$, depending on the extent of implementation of the 1990 CAAAs and other proposed environmental legislation. Refiners will probably see a large upswing in hydrogen demand, yet existing hydrogen production may decline. Two commercially viable processes capable of meeting this demand are steam methane reforming, a mature process, and partial oxidation. While both technologies provide high-purity hydrogen, partial oxidation can do so at reduced capital cost, with feedstock flexibility, and without the emissions problems (e.g., formation of $\mathrm{NO}_{\mathrm{x}}$ ) normally associated with steam methane reforming (Simonsen et al. 1993). 
Five states make up two-thirds of the U.S. crude oil refining capacity, and they have the largest hydrogen production design capacity: California, Texas, Louisiana, Illinois, and Pennsylvania. Currently, more than 10 of the 184 active U.S. refineries do not have enough hydrogen (less than 15 million standard cubic feet or scf per day), and fewer than 30 have a significant excess hydrogen supply (greater than 15 million scf/d) (Simonsen et al. 1993).

Current estimates put the U.S. hydrogen market at approximately 3,670 billion scf/yr. The refining industry is the largest end user, consuming about $60 \%$ of this supply (Table 2). Of refinery demand, $60 \%$ is recovered in the refinery from catalytic reforming; the remaining $40 \%$ is recovered from hydrogen production design facilities. This split is expected to be reversed in the next 5-10 years (Simonsen et al. 1993).

To reduce benzene and aromatics in the reformate, the refiner must prefractionate the reformer feed to minimize benzene precursors $\left(\mathrm{C}_{5} \mathrm{~s}\right.$ and $\left.\mathrm{C}_{6} \mathrm{~s}\right)$. This action requires additional hydrogen plants (Yepsen and Witoshkin 1991).

The reduction of aromatics, accomplished by a decrease in reformer severity, could result in a $20-30 \%$ drop in by-product hydrogen production. This drop is equivalent to $0.85-1.25$ billion scf/d of hydrogen that would have to be replaced by design production. Consequently, the increase in heavy ends from the reformer might have to be hydrotreated, which would require additional hydrogen. Thus, the 1990 CAAAs could lead to some additional hydrotreating of catalytic naphtha and a scale-back on reformer severity on a regional basis (Simonsen et al. 1993).

If the refinery undercuts the full distillation range of gasoline - distilling out the heaviest $10 \%$ (the fraction containing $80-100 \%$ of the aromatics) - the rejected heavy aromatics generated $(300,000 \mathrm{bbl} / \mathrm{d})$ will require hydrocracking. Hence, new hydrocracking capacity and additional hydrogen sources will be required (Yepsen and Witoshkin 1991).

If the $90 \%$ point for gasoline is reduced from about $350^{\circ} \mathrm{F}$ to $300^{\circ} \mathrm{F}$, the 10 vol\% heavycut catalytic naphtha will have to be hydrotreated or hydrocracked, producing diesel or possibly the higher-value-added jet fuel. This activity will require at least $1,500 \mathrm{scf}$ of hydrogen per barrel of feed. A reduction in naphtha of 10 vol\% would produce about $550,000 \mathrm{bbl} / \mathrm{d}$ of heavy
TABLE 21991 Hydrogen Balance in U.S. Refineries

$\begin{array}{lr}\text { Supply }\left(10^{9} \mathrm{scf} / \mathrm{d}\right) & \\ \text { Catalytic reforming } & 4.1 \\ \text { Design hydrogen } & 2.5 \\ \text { Catalytic reforming losses } & -0.6 \\ \text { Total } & 6.0\end{array}$

\begin{tabular}{ll} 
Demand $\left(10^{9} \mathrm{scf} / \mathrm{d}\right)$ & \\
Catalytic hydrocracking & 2.6 \\
Catalytic hydrorefining & 1.2 \\
Catalytic hydrotreating & 2.2 \\
Total & 6.0 \\
\hline
\end{tabular}

Source: Texaco (Simonsen et al. 1993). 
catalytic naphtha. To saturate this aromatic feed, approximately 0.80 billion scf/d of additional hydrogen would be required. Another option is to send the aromatics stream to a partial oxidation hydrogen generation unit (Simonsen et al. 1993).

To better understand the potential impact that various reformulation scenarios may have on the refining industry and, specifically, on the demand for hydrogen, Texaco analyzed the hydrogen supply/demand scenario in two reformulation cases - mild (based on current CAAAs legislation along with minor modifications to automobile hardware) and severe (based on a nationwide implementation of Phase 2 of the CAAAs and California's proposed reformulated fuels) (Simonsen et al. 1993).

Demand for "on-purpose" hydrogen has increased 3.5\%/yr over the past 10 years and is projected to grow from 2.5 billion $\mathrm{scf} / \mathrm{d}$ in 1991 to $3.7-6.2$ billion $\mathrm{scf} / \mathrm{d}^{9}$ over the next $5-10$ years, depending on federal and regional regulations. This amount is equivalent to an increase of 5-10\% per year. Total hydrogen production capacity is projected to grow from 6.0 billion scf/d in 1991 to 6.9-8.4 billion scf/d over the next 5-10 years. Depending on the strategy chosen, 40-120 new hydrogen facilities (average size, 30 million scf/d) could be needed within this decade (Simonsen et al. 1993).

Regarding diesel, the 1990 CAAAs require that sulfur levels in diesel fuel be reduced nationwide from about 0.35 to $0.05 \mathrm{wt} \%$ by October 1993 . This reduction will require less than 0.15 billion scf/d of hydrogen. The CAAAs also require a minimum cetane index of 40 , corresponding to a cetane number of about 45 . The need for lighter products and a higher cetane number will increase hydrogen demand. The additional hydrogen needed for diesel reformulation would be in excess of 0.6 billion scf/d. Reducing aromatics to $10 \mathrm{vol} \%$ would require approximately $1,000 \mathrm{scf}$ of additional hydrogen per barrel of diesel. Thus, if the total diesel market is assumed to be about $1.5 \mathrm{million} \mathrm{bbl} / \mathrm{d}, 1.5 \mathrm{billion} \mathrm{scf} / \mathrm{d}$ of additional hydrogen would be needed. If the aromatics content were reduced to only $20 \mathrm{vol} \%$, then about 0.9 billion scf/d of hydrogen would be needed (Simonsen et al. 1993).

Even more hydrogen may be required to:

- Saturate the heavy end of the barrel in conventional refining, because the U.S. crude slate is expected to get heavier and higher in sulfur as the demand for lighter products is increasing.

- Replace many existing design hydrogen facilities - mainly steam methane reformers - that are becoming outmoded.

9 The lower estimate represents the mild reformulation case; the higher estimate the severe case. 
- Improve the quality of the gasoline and diesel fuel that foreign-export-oriented offshore refineries sell to the U.S. market (Simonsen et al. 1993).

\subsection{OXYGENATES AND OTHER FEEDSTOCKS FOR ETHER BLENDSTOCKS}

\subsubsection{Ethanol}

As the need for additional oxygenates increases and the availability of $\mathrm{C}_{4} \mathrm{~s}$ to make MTBE decreases, the search for oxygen-containing materials will intensify. Because ethanol can oxygenate twice as much gasoline as can an equal volume of MTBE, some refiners believe the addition of ethanol is a preferred way to meet the specifications. If refiners were willing to pay twice as much for ethanol as for MTBE, ethanol from agricultural biomass would become economical without any government subsidies. Even synthetic ethanol made from ethylene could become viable (Johnson and Peterson 1991). However, at present, ethanol production is not considered economical without government subsidies. (An extension of the federal excise tax exemption for ethanol did not improve the supply [Shearman 1991].)

Ethanol's current strength is derived from a waiver allowing ethanol blends to have an RVP that is 1 psi higher than that of other types of gasoline. (The 1 psi is the RVP increase corresponding to a $10 \%$ ethanol blend.) The waiver applies only to reformulated gasoline and is limited to $30 \%$ of the total reformulated gasoline market in northern U.S. cities. However, refiners in nonattainment cities may still need to offset RVP, since the API and several environmental groups oppose this waiver. Since ethanol is far more expensive to produce than MTBE to date, its use can become economical only after special subsidies and tax credits are taken into account. In addition, ethanol has high water solubility, which prevents ethanol blends from being shipped in common carrier pipelines. Furthermore, the API claims that ethanol causes more smog than gasoline-based fuels. Hence, the market standing of ethanol remains very much in doubt (Rhoades 1992).

Recent statistics on ethanol production, stockpiling, and MOGAS blending are given in Table 3. The Energy Information Administration (EIA) in the U.S. Department of Energy (DOE) anticipated that the projected ethanol capacity of about $94,000 \mathrm{bbl} / \mathrm{d}$ would increase slightly to $96,000 \mathrm{bbl} / \mathrm{d}$ by early 1993 . In terms of oxygen content, $1 \mathrm{bbl}$ of ethanol equals $2.04 \mathrm{bbl}$ of MTBE (O\&GJ 1992d). Current annual ethanol nameplate capacity is about 1.3 billion gal, produced at a rate of approximately 75,000 bbl/d. Archer Daniels Midland, the nation's largest producer, accounts for nearly $75 \%$ of the nation's production. With favorable incentives, capacity could increase by 1 billion gal by the year 2000 (Haigwood 1991). 
TABLE 3 U.S. Status of Ethanol

\begin{tabular}{lccc}
\hline \multicolumn{1}{c}{ Source } & $\begin{array}{c}\text { Dec. } \\
1992\end{array}$ & $\begin{array}{c}\text { Calendar Year } \\
1992\end{array}$ & $\begin{array}{c}\text { Jan.-June } \\
1993\end{array}$ \\
\hline Production $\left(10^{3} \mathrm{bbl} / \mathrm{d}\right)$ & 75 & 70 & 75 \\
Stocks $\left(10^{6} \mathrm{bbl} / \mathrm{d}\right)$ & 1.79 & Not applicable & 2.50 \\
MOGAS blendstock $\left(10^{3} \mathrm{bbl} / \mathrm{d}\right)$ & 100 & 69 & Not available \\
\hline
\end{tabular}

Sources: DOE (1993a,b).

In addition, the use of ethanol to produce ethers similar to MTBE (e.g., ETBE) is being contemplated. The advantage of using ethanol over methanol to make ethers is that higher-boiling ethers lower the volatility of the blended gasoline. An additional advantage is that ethanol lets refiners switch between using methanol and ethanol to produce ethers, giving them the flexibility to address prevailing market conditions (Diebold et al. 1992).

\subsubsection{Methanol}

According to the International Trade Commission, the United States produced 1.2 billion gal of methanol in 1990. Significant growth in methanol supplies is expected worldwide (Wilund 1993). However, the petrochemical industry predicts that as more MTBE production facilities are brought into production, temporary shortages of methanol will occur. Because refiners can switch between using methanol and ethanol to produce ethers fairly easily, they should be able to take advantage of local market conditions (Brockwell et al. 1991; Diebold et al. 1992).

\subsubsection{Isobutylene/Isoamylene/Butanes}

Currently, isobutylene (isobutene) is in plentiful supply because of Canadian and Saudi Arabian production. However, demand will be high in 1993 and later as worldwide alkylation and etherification capacity increase (Gilman 1990). Overall isobutylene demand is expected to increase at an average rate of $8.7 \% / y r$ from 1991 through 1996; demand for isobutylene for the manufacture of $\mathrm{MTBE}$ is forecast to grow at $21 \% / \mathrm{yr}$, reaching 12 million metric tons in 1996 . However, availability of isobutylene for alkylation is expected to decline by $6.0 \% / \mathrm{yr}$ from 1991 to 1996 , falling from 5.8 to 4.2 million metric tons/yr (Rhoades 1992).

Production of isobutylene by isobutane dehydrogenation is projected to increase at a rate of $42 \% / y r$ from 1991 to 1996 . Moreover, new additions to capacity for the selective hydrogenation 
of butadiene are expected to result in a growth rate of $80 \% / y$ for refinery/chemical stream isobutylene (Rhoades 1992).

According to Yepsen and Witoshkin (1991), demand for MTBE will require $800,000 \mathrm{bbl} / \mathrm{d}$ of isobutylene feedstock in addition to the $100,000 \mathrm{bbl} / \mathrm{d}$ produced in refinery FCC units. Current production capacity of MTBE in North America is approximately 126,500 bbl/d. In November 1991, it was reported that another $76,000 \mathrm{bbl} / \mathrm{d}$ was scheduled to be on stream by January 1992 , and construction plans accounted for an additional 96,000 bbl/d (Hollrah and Burns 1991).

To reduce ozone, the RVP must be lowered, primarily by removing butane. The excess butane likely to be produced - 70,000 to $100,000 \mathrm{bbl} / \mathrm{d}$ - can be converted to isobutane and isobutylene for alkylation or MTBE production but will still fall short of the $800,000 \mathrm{bbl} / \mathrm{d}$ of isobutylene potentially needed to meet MTBE demands (Yepsen and Witoskhin 1991).

Butane supplies in the international marketplace will permit production of only $1.3 \mathrm{million} \mathrm{bbl} / \mathrm{d}$ of MTBE, enough to oxygenate the market economy gasoline pool to $8.3 \mathrm{vol} \%$ but not as much as is required in the United States alone (O\&GJ 1992c).

As progressively more MTBE production facilities are brought into production, a long-term shortage of isobutylene may occur. To counter this shortfall, there are plans to produce methyl ethers from other olefins such as isoamylenes (isopentenes) to produce TAME. The advantage of using isoamylene over isobutylene (and ethanol over methanol) to produce ethers is that higher-boiling ethers lower the volatility of the blended gasoline. Furthermore, ethers similar to MTBE will probably be used without needing to be extensively tested first (Diebold et al. 1992).

Indeed, light olefins can be used to produce excellent blending components for reformulated gasoline including alkylate, MTBE, tert-butyl alcohol (TBA), ETBE, TAME, and TAEE, subject to the following considerations (Yepsen and Witoshkin 1991):

- Isobutylenes and isoamylenes are the primary olefins in greatest demand because they are used to produce MTBE and TAME, the preferred oxygenate blending components for reformulated gasoline (Yepsen and Witoshkin 1991).

- Isobutylene is the most versatile of the butylenes; it yields excellent blendstocks for reformulated gasoline when it is converted to ethers (Yepsen and Witoshkin 1991).

- Isoamylenes can be converted to excellent blendstock ethers, such as TAME and TAEE, with a low RVP and high octane values (greater than 103, RON + MON/2) (Yepsen and Witoshkin 1991). 
- Unreacted straight chain alkenes can be alkylated (Parkinson 1992).

Aside from the oxygenate contribution, refiners will probably come as close to the olefins specification as possible so as to achieve needed octane (Parkinson 1992).

\subsection{OXYGENATE BLENDSTOCK (ETHERS) FOR REFORMULATED GASOLINE}

Oxygenates, commercially produced as the ethers of methanol or ethanol, are seriously being considered as substitutes for the light aromatics being removed from gasoline. They have a similar octane content, an attractive RVP, and enough oxygen to allow for complete combustion of $\mathrm{CO}$ to carbon dioxide $\left(\mathrm{CO}_{2}\right)$. Corresponding oxygenate levels for $2.7 \mathrm{wt} \%$ oxygen in gasoline are: 15 vol\% MTBE, 17 vol\% ETBE, and 17 vol\% TAME (Gilman 1990).

\subsubsection{MTBE}

MTBE is the only ether currently produced in the United States; it constituted about $1.4 \%$ of the U.S. gasoline pool in 1988 (Gilman 1990). In 1992, about 1.8 billion gal went into gasoline, almost 50\% more than in 1991 (Anderson 1993). MTBE is produced by reacting methanol with isobutylene. MTBE ranked nineteenth in U.S. chemical production (1992) at 5.43 million tons, methanol ranked twenty-second at 4.365 million tons, and isobutylene ranked fiftieth at 0.645 million tons. (Neither ETBE nor ethanol ranked in the top 50 U.S. chemicals produced [Reisch 1993].)

Large additional amounts of these two reacting materials will be required (Johnson and Peterson 1991). Current production capacity of MTBE in North America is approximately $126,500 \mathrm{bbl} / \mathrm{d}$. In November 1991, it was reported that another $76,000 \mathrm{bbl} / \mathrm{d}$ was scheduled to be on stream by January 1992, and construction plans accounted for an additional 96,000 bbl/d (Hollrah and Burns 1991). ARCO is the world's largest MTBE producer (Morris 1993).

Most MTBE is now produced at petrochemical plants, but many refineries have announced plans to construct small MTBE units at their facilities (Hollran and Burns 1991). Isobutylene generated from a typical refinery FCC unit can produce 1,000 to 3,000 bbl/d of MTBE (Gilman 1990).

One problem is that sulfuric acid consumption may rise considerably after an MTBE unit is installed because of the carry-over of methanol and various ethers. Mild hydrogenation of the 
alkylation feed may be required to reduce acid consumption and acid-soluble oils, a hazardous waste (Gilman 1990). Potential problems for etherification units include:

- Alcohol and ether carry-over to the alkylation unit,

- Poisons to the alkylation acid catalyst, and

- Future uncertain feedstock supply (Gilman 1990).

Worldwide methanol capacity will need to expand by more than $60 \%$ to meet MTBE needs. Many of the areas for expansion have already been identified, discussed, and, to some extent, financed. This gas will probably be relatively easy to obtain. Such an expansion will require only $0.1 \%$ of the world's gas reserves (Johnson and Peterson 1991).

However, as the quantity of reformulated gasoline increases, all of the isobutylene may be quickly used up. U.S. MTBE requirements will also cut into the world's supply of isobutane and nbutane, from which more isobutylene can be made. If other countries start using more oxygenates in their gasoline, the problem will be exacerbated. A worldwide shortage of $\mathrm{C}_{4} \mathrm{~s}$, including isobutylene, isobutane, and even $n$-butane, could result (Johnson and Peterson 1991). On the other hand, butanes have the potential to change from being a surplus product today to becoming an important product in the near future (Williams 1991).

Interest continues in the technical details concerning major components of worldwide MTBE production. Commercial technology and cost considerations lead to a focus on butane isomerization, isobutane dehydrogenation, and isobutylene etherification (Sarathy and Suffridge 1993). Worldwide capacity of MTBE is expected to grow from $377,000 \mathrm{bbl} / \mathrm{d}$ in 1992 to nearly double that figure in 1995 (Shearman 1991).

Recent statistics on MTBE production, stockpiling, and MOGAS blending are given in Table 4. One estimate suggests a tenfold growth in MTBE, from a 35,000 bbl/d average in 1991 to $450,000 \mathrm{bbl} / \mathrm{d}$ in 1995 . In 1993, MTBE requirements are estimated to be $3.3 \%$ of total gasoline demand. The MTBE share is expected to reach $6 \%$ of gasoline demand by 1995 , when reformulated gasoline is expected to reach its full effect. Hence, demand for MTBE is forecast to increase at an average rate of $24 \% / \mathrm{yr}$ for the period, and capacity is expected to increase from more than 10 million tons/yr in 1991 to 22.6 million tons/yr in 1996 (Rhoades 1992).

Current production capacity is approximately $1.9 \mathrm{billion} \mathrm{gal} / \mathrm{yr}$ at a rate of approximately $125,000 \mathrm{bbl} / \mathrm{d}$. The demand for MTBE as an octane enhancer and as an oxygenate is expected to double to 3.8 billion gal in 1995 (Haigwood 1991). 
TABLE 4 U.S. Status of MTBE

\begin{tabular}{|c|c|c|c|}
\hline Source & $\begin{array}{l}\text { Dec. } \\
1992\end{array}$ & $\begin{array}{c}\text { Calendar Year } \\
1992\end{array}$ & $\begin{array}{c}\text { Jan.-June } \\
1993\end{array}$ \\
\hline Production $\left(10^{3} \mathrm{bbl} / \mathrm{d}\right)$ & 125 & 101 & 123 \\
\hline Stocks $\left(10^{6} \mathrm{bbl} / \mathrm{d}\right)$ & 13.8 & Not applicable & 14.5 \\
\hline MOGAS blendstock $\left(10^{3} \mathrm{bbl} / \mathrm{d}\right)$ & 206 & 94 & Not available \\
\hline
\end{tabular}

Sources: DOE (1993a,b).

The EIA estimated that winter demand for gasoline blending oxygenates (i.e., MTBE or ethanol) will exceed U.S. oxygenate production by 140,000 to $220,000 \mathrm{bbl} / \mathrm{d}$, with the shortfall being made up by imports. This shortfall has not yet been felt. The EIA also projected that total U.S. demand for oxygenates during the 1992-1993 winter would be 450,000 to $500,000 \mathrm{bbl} / \mathrm{d}$ of MTBE equivalent. Oxygenate production was estimated at 280,000 to $310,000 \mathrm{bbl} / \mathrm{d}$ of MTBE equivalent. According to Shearman (1991), operable U.S. MTBE capacity grew to more than $135,000 \mathrm{bbl} / \mathrm{d}$ from about $50,000 \mathrm{bbl} / \mathrm{d}$ in 1986 and was expected to reach $168,000 \mathrm{bbl} / \mathrm{d}$ by the winter of 1992/1993 (Shearman 1991) and 202,000 bbl/d in early 1993. To make up for the oxygenate shortfall in succeeding winters, the EIA estimated that an MTBE working inventory of 21-33 million bbl of MTBE equivalent will be needed. Because of the proposed shortfall, the EIA predicted a premium price over traditional gasoline (O\&GJ 1992d).

The EIA cited industry studies that projected U.S. net MTBE imports would be 10,000 to $30,000 \mathrm{bbl} / \mathrm{d}$ during the $1992-1993$ winter. The EIA projected that production capacity would increase from $112,000 \mathrm{bbl} / \mathrm{d}$ at the end of 1991 to $165,000 \mathrm{bbl} / \mathrm{d}$ at the end of 1992 and $219,000 \mathrm{bbl} / \mathrm{d}$ by the end of 1993, and that world demand would increase from $76,000 \mathrm{bbl} / \mathrm{d}$ in 1990 to $105,000 \mathrm{bbl} / \mathrm{d}$ in 1993 (O\&GJ 1992d).

Industry observers have suggested that a U.S. stockpiling of 20 million bbl for use during winter would minimize the shortfall impact. Others have suggested that imports from Latin America, Canada, and the Middle East, where low-cost feedstocks are available, may help. U.S. refiners will be competing with Europeans for MTBE imports, which are considered an octane enhancer in Europe. The U.S. shortfall must be addressed by building new capacity and modifying refinery processes. Nevertheless, many observers believe supply and demand could be brought into balance by means of refining modifications, specifically an increase in butane dehydrogenation (olefin formation) and FCC butylenes functions. However, raw materials, not MTBE plant capacity, may be the larger concern (Shearman 1991). 
MTBE produced from refinery FCC isobutylene is forecasted to increase from 1.9 to 5.1 million metric tons/yr from 1991 to 1996 , for an average annual growth rate of $22 \%$. Production of MTBE via the dehydrogenation of isobutane to isobutylene is expected to increase at $42 \% / \mathrm{yr}$. World trade in MTBE is expected to increase from 970,000 to 4.4 million metric tons/yr from 1991 to 1996 , for an average annual growth rate of $35 \%$ (Rhoades 1992).

However, depending on the impact of the ethanol waiver situation, ethanol could displace MTBE demand by $50,000 \mathrm{bbl} / \mathrm{d}$. Demand for MTBE could also be affected if the EPA conducts additional assessments of the negative effects of oxygenates (Rhoades 1992).

\subsubsection{ETBE/TAME}

According to the API, neither ETBE nor TAME is available commercially in the United States (Shearman 1991). Because ETBE has a lower RVP than MTBE, it is expected to contribute less to pollution. Refiners without access to methanol may build units to produce ETBE that use ethanol and isobutylene as feedstocks. The most rapid growth of ETBE would probably be in the Midwest, where a majority of the ethanol is produced. If they are given a tax credit, manufacturers of MTBE might convert their production to ETBE (Hollrah and Burns 1991). The federal tax credit would make it economically feasible to use ethanol as a feedstock in place of methanol to produce ETBE rather than MTBE. Ultimately the market price of ethanol will determine whether existing MTBE producers will use methanol, ethanol, or both for oxygenate ether production (Haigwood 1991).

One indication that ETBE may begin to play an important role in gasoline blending is that Chevron has announced it will test ETBE gasoline in southern California and might consider adapting its MTBE plants for ETBE production. Conversion of ethanol to ETBE may become the best way for refiners to optimize their MTBE plants. And ARCO Chemical Co. has decided to produce ETBE at its Coastal Refining \& Marketing Inc.'s 12,000-bbl/d MTBE plant (Rhoades 1992).

Refiners who do not have sufficient isobutylene to run their MTBE units may decide to produce TAME instead (Shearman 1991). TAME is produced by reacting methanol with isoamylenes provided by the FCC unit and distilling the product. TAME raises octane by 10 and reduces RVP from 16 psi (isoamylene) to 1 psi (TAME). TAME processing also removes photochemically reactive $C_{5}$ olefins from gasoline (Gilman 1990). TAME is more widely accepted by European refiners than ETBE, since it provides an easier route to higher octanes than alkylation (Rhoades 1992). A German study has evaluated high-octane ethers as components in unleaded gasoline and assessed their commercial production from LPG by a combination of isomerization, dehydrogenation, hydration, and etherification (Gottlieb 1986). 


\subsection{INDUSTRY RESPONSES}

According to Bob Davenport of Coastal Refining and Marketing in Houston, to prepare for implementing the reformulated gasoline program, a number of U.S. firms have taken appropriate actions. In addition, new export-oriented plants are expected to be built in South America, the Middle East, and Canada because of the availability of low-cost feedstocks (Shearman 1991). (See Appendix C.) 


\section{COST PROJECTIONS}

One might ask a question considered central to the topic: At what point will an increase in the cost of MTBE make ethanol more competitive? Although that question is not answered here, this section summarizes cost estimates in the recent literature on the impact of the CAAAs on the use of reformulated gasoline and feedstocks/blendstocks and on capital investments.

\subsection{FEEDSTOCK/COMPONENT BLENDSTOCKS}

A study by Probe Economics of Millwood, New York (O\&GJ 1992c) suggests that the combination of the CAAAs requirements and the limited supply of raw materials has already begun to alter oxygenate (MTBE, methanol, ethanol, etc.) markets and could entirely transform them during the 1990s. The price of ethanol is projected to increase from $\$ 1.27 / \mathrm{gal}$ in 1991 to $\$ 1.52-1.82 / \mathrm{gal}$ in 2001 (Table 5). The price of ethylene is projected to increase from $\$ 0.22 / \mathrm{lb}$ in 1991 to $\$ 0.23-0.27 / \mathrm{lb}$ in 2001 . And the price of propylene could decrease over the near-term, from $\$ 0.17 / 1 \mathrm{~b}$ in 1991 to $\$ 0.12-0.16 / \mathrm{lb}$ in 1997 , then rise to $\$ 0.19-0.20 / \mathrm{b}$ in 2001 over the medium-term. Prices will certainly drop for commodities such as propylene, benzene, and toluene but soar for ethylene and ethanol (O\&GJ 1992c).

The requirements of the CAAAs for U.S. gasoline could affect the price and availability of a number of hydrocarbon materials on a worldwide basis and will surely do so if gasoline reformulation proposals are implemented in other countries (Johnson and Peterson 1991). The additional need for hydrogen could cost the U.S. refining industry between $\$ 1$ billion and $\$ 4$ billion (Simonsen et al. 1993). In October 1991, the list price for MTBE was about \$0.93/gal; it was expected to rise by 15 cents/gal in early 1992 (Shearman 1991).

TABLE 5 MTBE Raw Material Cost Projections

\begin{tabular}{lccc}
\hline Raw Material & 1991 & 1997 & 2001 \\
\hline Ethanol $(\$ / g a l)$ & 1.27 & $1.51-1.82$ & $1.52-1.82$ \\
Ethylene $(\$ / \mathrm{lb})$ & 0.22 & $0.21-0.31$ & $0.23-0.27$ \\
Propylene $(\$ / \mathrm{b})$ & 0.17 & $0.12-0.16$ & $0.19-0.20$ \\
\hline
\end{tabular}




\subsection{REFORMULATED GASOLINE}

Table 6 represents a consolidated comparison of the incremental cost of reformulated gasoline, even though the bases are not equivalent. The results are discussed in this section.

A 1991 study conducted by DOE suggested that refiners would be able to meet reformulated gasoline requirements in the winter of 1992/1993 at an increased cost of 4-7 cents/gal, including capital recovery and operating costs (O\&GJ 1992a). The EIA projected an increase of 3-5 cents/gal in CO nonattainment areas in the winter of 1992/1993, resulting from an increase of 20 cents/gal for MTBE-equivalent gasoline over a traditional gasoline blend. If the oxygenated gasoline used to meet winter requirements in $\mathrm{CO}$ nonattainment areas contains at least $15 \mathrm{vol} \% \mathrm{MTBE}$ and accounts for as much as $38 \%$ of the U.S. gasoline market, EIA estimates the oxygenated gasoline price premium will amount to 1-2 cents/gal nationwide (O\&GJ 1992d).

During the winter of 1992/1993, before Alaska suspended its oxygenated gasoline program, Alaskan consumers reportedly experienced a gasoline price increase of approximately 15 cents/gal (Anderson 1993).

Another study estimates that refiners' costs for reformulated gasoline will be 5.7 cents/gal higher than those for conventional gasoline. The added expense is due to refinery capital costs and purchases of oxygenates that cannot be produced at the refinery (O\&GJ 1992a).

TABLE 6 Results of Research Studies on the Incremental Cost of Using Reformulated Gasoline

\begin{tabular}{|c|c|c|c|c|c|}
\hline \multirow[b]{2}{*}{$\begin{array}{c}\text { Study Name } \\
\text { (Source) }\end{array}$} & \multicolumn{4}{|c|}{$\begin{array}{c}\text { Incremental Cost of Using Reformulated } \\
\text { Gasoline (cents/gal) }\end{array}$} & \multirow{2}{*}{$\begin{array}{c}\text { Cost of } \\
\text { MTBE } \\
\text { (cents/gal }\end{array}$} \\
\hline & $\begin{array}{l}\text { Winter } \\
1992 / 1993\end{array}$ & 1995 & 2000 & 2005 & \\
\hline 1991 DOE (O\&GJ 1992a) & $4-7$ & & & & \\
\hline ELA (DOE 1993b) & $3-5$ & & & & 20 \\
\hline Alaska (Anderson 1993) & 15 & & & & \\
\hline Study (O\&GJ 1992a) & & 5.7 & & & \\
\hline Other studies (Hadder 1992) & & $2.5-15$ & $5.2-7.6$ & & 28 \\
\hline Oil industry poll (Hadder 1992) & & $6-10$ & & & \\
\hline Amoco Oil (Levine 1992) & & $8-10$ & & & \\
\hline CARB (Parkinson 1992) & & $12-17$ & & & \\
\hline Turner, Mason \& Co. (Parkinson 1992) & & $15-22$ & & & \\
\hline Auto/Oil AQIRP (1993) & & & & $4-17$ & \\
\hline
\end{tabular}


On the basis of different assumptions about reformulated gasoline specifications, other studies have projected reformulation costs at 2.5-15 cents/gal. A poll of oil industry executives by Arthur D. Little projects the increased cost of refining will be 6-10 cents/gal (Hadder 1992).

Amoco Oil Co. estimates that reformulated gasoline will be $8-10$ cents/gal more than traditional gasoline (Levine 1992). CARB estimates that consumers will pay 12-17 cents/gal more for reformulated gasoline. Turner, Mason \& Co. (Dallas) suggests that the cost will be more like $15-$ 22 cents/gal. Turner, Mason \& Co.'s figures include 3-4 cents/gal over the estimated pump price to account for the fuel's lower Btu content because of the oxygenate (Parkinson 1992).

One study has projected reformulation costs for the year 2000 at 3.5-5.6 cents/gal, if MTBE is 28 cents/gal more than conventional gasoline. (The MTBE contribution is estimated at 3.2 cents/gal, and increased refining costs are estimated at 0.3-2.4 cents/gal.) After fuel economy effects are adjusted for, the cost of reformulation has been estimated to be 5.2-7.6 cents/gal (Hadder 1992).

One additional set of incremental costs comes from the Auto/Oil Air Quality Improvement Research Program (AQIRP), a cooperative program initiated by three domestic auto companies and 14 petroleum companies. Its objective is to conduct research and testing to develop data on the improvements in vehicle emissions and air quality (primarily ozone reduction) that could result from modifications to 30 gasoline compositions, use of various alternative fuels, and developments in technology for 53 automobile engines. A comparison indicated an incremental cost of 2-12 cents/gal would result from manufacturing "research fuels" instead of average conventional gasoline in 2005. These estimated costs are applicable to the larger refining regions, specifically an average Gulf Coast regional refinery and an average California refinery. An additional consumer cost of 2-5 cents/gal from a lower energy fuel content could also result (AQIRP 1993).

These research fuels are not intended to represent expressly the expected value of reformulated gasoline but are designed to assess a number of combinations of high and low values for several properties: aromatic content $(45 \%, 20 \%)$, MTBE content $(15 \%, 0 \%)$, olefin content $(20 \%$, $5 \%)$, and $\mathrm{T}_{90}$ distillation point $\left(360^{\circ} \mathrm{F}, 280^{\circ} \mathrm{F}\right)$.

\subsection{CAPITAL ESTIMATES}

Table 7 compares the results of various estimates of the capital cost for using reformulated gasoline. A discussion follows in this section.

The required changes in gasoline and diesel specifications could lead to a sharp increase in the demand for dedicated hydrogen production and could result in costing the U.S. refining industry more than $\$ 3$ billion in capital investments (Simonsen et al. 1993). Refiners will need to 
TABLE 7 Results of Research Studies on the Capital Cost of Using Reformulated Gasoline

\begin{tabular}{lc}
\hline \multicolumn{1}{c}{$\begin{array}{c}\text { Study Name } \\
\text { (Source) }\end{array}$} & $\begin{array}{c}\text { Capital Investment for } \\
\text { Using Reformulated } \\
\text { Gasoline } \\
\left(10^{9} \$\right)\end{array}$ \\
\hline Study (Simonsen et al. 1993) & $>3$ \\
Some industry experts (Gilman 1990) & 20 \\
API (Parkinson 1990) & $15-23$ \\
Kellogg (Parkinson 1992) & $\simeq 30$ \\
Amoco Oil (Levine 1992) & $20-30$ \\
CARB (Parkinson 1992) & $3-6$ \\
Study (Yepsen and Witoshkin 1991) & 20 \\
\hline
\end{tabular}

invest in facilities for hydrotreating (with associated hydrogen plants), hydrocracking, fractionation, alkylation, oxygenating (typically of MTBE), and isomerization (for MTBE feedstock), a costly undertaking (Parkinson 1992).

Some industry experts predict that capital expenditure requirements for gasoline reformulation will exceed $\$ 20$ billion. This number translates into a capital investment of just under $\$ 58$ million for refinery reconfigurations to meet a reformulated gasoline slate for $100,000 \mathrm{bbl} / \mathrm{d}$ by 1994 (Gilman 1990).

The API estimates that the industry will spend between $\$ 15$ and $\$ 23$ billion by the end of the decade to meet the requirements of the CAAAs of 1990 and other legislation. Estimates indicate that capital spending will run between $\$ 70$ and $\$ 100$ billion for this decade, including $\$ 24$ billion to produce reformulated fuels and $\$ 10-12$ billion to reduce refinery emissions, a total amount that equates to 10-15\% of capital expenditures (Parkinson 1992).

M.W. Kellogg Co. (Houston) estimates that refiners may have to spend up to $\$ 30$ billion this decade to meet the demand for reformulated gasoline (Parkinson 1992).

Amoco Oil Co. estimates a capital investment at \$20-30 billion, with consumers paying \$68 billion a year (Levine 1992). Finally, CARB estimates that the capital cost to California refiners will be $\$ 3-6$ billion (Parkinson 1992).

One process unit type - FCC - may not require significant capital investment because catalysts that could foster the production of light olefins and iso-olefins to raise gasoline selectivity 
are under development. Nevertheless, one estimate of $\$ 20$ billion has been proposed (Yepsen and Witoshkin 1991). It includes:

- Upgrading FCC units and downstream fractionation;

- Adding prefractionation and isomerization of $\mathrm{C}_{5} \mathrm{~s}$ and $\mathrm{C}_{6} \mathrm{~s}$ from reformer feed to reduce benzene production;

- Adding dehydrogenation and isomerization to butane for MTBE or TBA production;

- Increasing resid upgrading capability (coking, hydrocracking, etc.) (i.e., reducing the residual left in the barrel);

- Adding capacity to hydrocrack excess light aromatics $(300,000 \mathrm{bbl} / \mathrm{d})$ produced by undercutting FCC gasoline; and

- Increasing refinery hydrogen supply to compensate for reduced reformer severity.

Differences in incremental capital investments have been estimated for two test fuel formulations in each of six Petroleum Administration for Defense Districts (PADDs) that represent six regions of the United States. These PADDs allow aggregate refining industry comparisons on a regional basis (see Table 8). Under a severe reformulation scenario, a Gulf Coast or California facility with a 12,500-bbl/d MTBE plant might require an incremental capital investment of about \$45-75 million. Under a less severe reformulation scenario, it might require an investment on the order of \$30-50 million (in 1989 dollars), approximately two-thirds of the investment required under the severe scenario (AQIRP 1993).

\subsection{OTHER COSTS}

Refiners representing $44 \%$ of the U.S. distillation capacity estimate that meeting the requirements of the CAAAs will cost them about $\$ 4.8$ billion for producing reformulated gasoline, $\$ 2$ billion for producing low-sulfur diesel fuel, and $\$ 300$ million for changing the quality of crude oil (O\&GJ 1992a). The average outlay for refiners to meet the low-sulfur diesel fuel requirements and change the crude quality is about $\$ 900 / \mathrm{bbl}$ of crude distillation capacity (O\&GJ 1992a). 
TABLE 8 Regional Differences in Incremental Capital Investments for Gasoline $\left(10^{6} \$ / 10^{3} \mathrm{bbl} / \mathrm{d}\right)$

\begin{tabular}{|c|c|c|c|c|c|c|}
\hline $\begin{array}{l}\text { Type of } \\
\text { Facility }\end{array}$ & $\begin{array}{l}\text { PADD I }{ }^{\mathrm{a}} \\
\text { East Coast }\end{array}$ & $\begin{array}{l}\text { PADD II } \\
\text { Midwest }\end{array}$ & $\begin{array}{l}\text { PADD III } \\
\text { Gulf Coast }\end{array}$ & $\begin{array}{c}\text { PADD IV } \\
\text { Western } \\
\text { Rockies }\end{array}$ & $\begin{array}{l}\text { PADD V } \\
\text { West Coast } \\
\text { (excluding } \\
\text { California) }\end{array}$ & California \\
\hline \multicolumn{7}{|c|}{ Under severe reformulation scenario ${ }^{\mathrm{f}}$} \\
\hline Refinery & $2.8-4.7$ & 2.3-3.9 & $1.3-2.1$ & $2.6-4.3$ & $0.4-0.6$ & $1.2-2.0$ \\
\hline MTBE plant & $2.3-3.8$ & $2.3-3.8$ & 2.3-3.9 & $2.3-3.8$ & $2.3-3.8$ & $2.4-4.0$ \\
\hline Total & $5.1-8.5$ & $4.6-7.7$ & $3.6-6.0$ & $4.9-8.1$ & $2.7-4.4$ & $3.6-6.0$ \\
\hline \multicolumn{7}{|c|}{ Under less severe reformulation scenario ${ }^{\mathrm{g}}$} \\
\hline Refinery & $0.4-0.7$ & $0.4-0.6$ & $0.1-0.1$ & $0.5-0.8$ & $(0.7)-(1.2)$ & $(0.2)-(0.3)$ \\
\hline MTBE plant & $2.5-4.1$ & $2.4-4.1$ & $2.4-4.0$ & $2.4-4.0$ & 2.3-3.9 & $2.5-4.1$ \\
\hline Total & $2.9-4.8$ & $2.8-4.7$ & $2.5-4.1$ & $29 .-4.8$ & $1.6-2.7$ & $2.3-3.8$ \\
\hline
\end{tabular}

a PADD I = Florida, New York, Pennsylvania, Virginia, and West Virginia.

b PADD II = Illinois, Indiana, Kansas, Kentucky, Michigan, Missouri, Nebraska, North Dakota, Ohio, Oklahoma, South Dakota, and Tennessee.

c PADD III = Alabama, Arkansas, Louisiana, Mississippi, New Mexico, Texas, and offshore Gulf.

d PADD IV = Colorado, Montana, Utah, and Wyoming.

e PADD V = Alaska, Arizona, California, Nevada, and offshore Pacific.

f Severely reformulated fuel contains $20 \%$ aromatics, $15 \%$ MTBE, and $5 \%$ olefins, with a $\mathrm{T}_{90}$ of $280^{\circ} \mathrm{F}$.

$g$ Less severely reformulated fuel contains $20 \%$ aromatics, $15 \% \mathrm{MTBE}$, and about $94 \%$ unconstrained olefins, with a $\mathrm{T}_{90}$ of $310^{\circ} \mathrm{F}$ (an intermediate level). 


\section{EMISSIONS AND ATMOSPHERIC IMPACT}

Currently 41 areas in the United States are classified as $\mathrm{CO}$ nonattainment areas, whereas 96 are classified as ozone nonattainment areas. Even although there has been a significant downward trend in ambient-air $\mathrm{CO}$ concentrations, several tough $\mathrm{CO}$ nonattainment problems remain. For example, it has been projected that areas with extreme conditions, such as Alaska and Colorado, will not attain the $\mathrm{CO}$ standard without applying additional controls. About $80 \%$ of the nationwide $\mathrm{CO}$ inventory is from mobile sources. Most $(91 \%)$ of the mobile source CO emissions are from lightduty gasoline-powered vehicles (Klausmeier and Draves 1991).

One of the most persistent air quality problems in the United States has been the nonattainment of the NAAQS for ozone. Currently, approximately 90 million people live in areas that have the ambient ozone standard. A downward trend in ozone levels is not yet evident. In 1988, there were more ozone violations than in many previous years (Klausmeier and Draves 1991). Ozone is formed in the lower atmosphere (troposphere) by photochemical reactions between nonmethane organic gases and $\mathrm{NO}_{\mathrm{x}}$ and, to a lesser extent, between nonmethane organic gases and $\mathrm{CO}$. Mobile sources account for about half of these emissions (Klausmeier and Draves 1991).

\subsection{AUTOMOTIVE EMISSIONS}

Nonmethane organic gases include alcohols (e.g., ethanol and methanol), aldehydes (e.g., formaldehyde and acetaldehyde), and nonmethane hydrocarbons (e.g., olefins, paraffins, and benzenes). Mobile sources emit nonmethane organic gases in two ways. Tailpipe emissions (i.e., exhaust emissions after combustion) occur as a result of incomplete combustion and/or chemical reactions during combustion. (For example, $\mathrm{NO}_{\mathrm{x}}$ is emitted largely as a result of reactions between nitrogen and oxygen at high temperatures). Evaporative emissions (emissions before combustion) occur when the tank is being fueled or the engine is resting (Klausmeier and Draves 1991).

Air toxic (HAP) emissions occur because pollutant compounds are either present in the fuel prior to combustion (evaporative) or formed during its combustion (tailpipe). For example, because benzene is present in gasoline, it can be emitted as a result of evaporation or incomplete combustion. However, estimates indicate that over half the benzene in the exhaust is formed during combustion by chemical reaction. Formaldehyde is an example of a pollutant that is formed during fuel combustion but was not present in the input fuel. The air toxics emitted by motor vehicles include the following (Klausmeier and Draves 1991):

- Aromatic hydrocarbons such as benzene $\left(\mathrm{C}_{6} \mathrm{H}_{6}\right)$, toluene $\left(\mathrm{C}_{6} \mathrm{H}_{5} \mathrm{CH}_{3}\right)$, o-, m-, and p-xylenes $\left(\mathrm{C}_{6} \mathrm{H}_{4}\left[\mathrm{CH}_{3}\right]_{2}\right)$, and styrene $\left(\mathrm{C}_{6} \mathrm{H}_{5} \mathrm{CH}=\mathrm{CH}_{2}\right)$; 
- 1,3-butadiene $\left(\mathrm{CH}_{2}=\mathrm{CHCH}=\mathrm{CH}_{2}\right)$; and

- Aldehydes such as formaldehyde ( $\mathrm{HCHO})$, acetaldehyde $\left(\mathrm{CH}_{3} \mathrm{CHO}\right)$, and acrolein $\left(\mathrm{CH}_{2}=\mathrm{CHCHO}\right)$.

Olefin concentration does not appear to have much of an impact on vehicle exhaust emissions. Heavy olefins are present in the back end of FCC gasoline and are estimated at $10-20 \mathrm{vol} \%$ in the boiling fraction from $380-430^{\circ} \mathrm{F}$. Because FCC gasoline makes up about $35 \mathrm{vol} \%$ of the U.S. gasoline pool, finished marketed gasoline would contain 3.5-7 vol\% of olefins in that boiling range (Unzelman 1991).

Contributing to evaporative emissions are four light hydrocarbons: $n$-butane, 2-methyl-1-butene, 3-methyl-1-butene, and 2-methyl-2-butene. $n$-Butane is low in atmospheric reactivity but high in RVP. Concern centers on butene $\left(\mathrm{C}_{4}\right.$ olefins) and benzene emissions, which are high in photochemical reactivity. However, in reformulated gasoline, the concentration of light olefins will probably fall off slightly as more of these light compounds are processed to branchedchain paraffins and ethers to minimize evaporative emissions (Unzelman 1991).

Alkylation of $\mathrm{C}_{5}$ olefins appears to be environmentally acceptable. However, blending $\mathrm{C}_{5}$ olefins directly into the gasoline pool may contribute to ozone formation (Gonzalez 1992).

Recent studies have shown that the catalyst MMT can help reduce automotive tailpipe emissions in the United States by $7.8 \%$ or about 0.8 million metric tons/yr on the basis of projections for 1999. However, as already stated, the EPA has raised questions about the health, environmental, and performance characteristics of MMT. It is classified as a Class B poison, which is toxic to humans if inhaled, ingested, or absorbed through the skin. It is also thermally stable, has a freezing point of $30^{\circ} \mathrm{F}$, has a very low RVP, and decomposes quickly in sunlight to oxides and carbonates of Mn (Hollrah and Burns 1991).

\subsection{ATMOSPHERIC IMPACT OF REFORMULATED GASOLINE}

There is no doubt that U.S. refinery operations will be driven by environmental regulations and not by the consumer (Hadder 1992). But what evidence has been come to light to date? What actual measurements of the use of oxygenated fuels have been made? Have these fuels achieved the desired effect of mitigating emissions and decreasing atmospheric concentrations of $\mathrm{CO}$ and ozone?

Experimental modeling results from the Auto/Oil AQIRP indicate that changes in gasoline composition can help reduce both vehicle emissions and atmospheric ozone. The model considers the effects of content changes in aromatics, olefins, and oxygenates (MTBE) on auto emissions of 
hydrocarbons, $\mathrm{CO}$, and $\mathrm{NO}_{\mathrm{x}}$, and on the air toxics benzene, 1,3-butadiene, formaldehyde, and acetaldehyde (Colucci 1991).

However, actual atmospheric monitoring suggests not only that reformulated gasoline may not significantly reduce $\mathrm{CO}$ levels but also that it may actually raise ambient concentrations of compounds such as formaldehyde and $\mathrm{NO}_{\mathrm{x}}$. These results were presented at a recent American Chemical Society (ACS) meeting in Denver less than a month after public concern about the health effects of MTBE heightened. Researchers claimed that much of the effectiveness attributed to oxygenated fuels is based on emissions testing of cars as well as calculated extrapolations, not atmospheric monitoring (Rotman 1993).

Apparently, oxygenate use has little impact on CO as measured in Denver (since 1988), Albuquerque, and Brazil (since the late 1970s) - areas where oxygenated fuels have been used for several years. Moreover, in these areas, relatively high levels of acetaldehyde, formaldehyde, and related compounds - including the mutagen peroxyacetyl nitrate (PAN) - have been found in the atmosphere. Measured levels of acetaldehyde in three Brazilian cities appear to be among the highest in the world. These findings could cast serious doubts on the ambitious U.S. oxygenates program, which has increasingly required U.S. cities to use reformulated fuels (Rotman 1993).

In 1988, Denver became the first U.S. city to mandate an oxygenated fuel program. Oxygenates - mainly MTBE - were used in Denver for four months each year. Although a 15-20\% drop in ambient CO was predicted by 1993, there was no measurable statistical effect on CO in the air. Moreover, the University of Colorado has gathered considerable evidence that the level of formaldehyde has actually increased (Rotman 1993). Although the analysis reportedly demonstrates a strong downward trend in ambient CO concentration in the area, the trend began well before the use of oxygenated fuels was initiated (Illman 1993).

One group observed a $55 \%$ reduction in $\mathrm{CO}$ - a much larger reduction than expected, even from the emissions model. But it did not observe any statistically significant contribution to the overall trend due to the use of oxygenated fuel. According to the emissions model, a 15-20\% reduction in the $\mathrm{CO}$ level should have been observed as a result of the introduction of reformulated gasoline. But oxygenated fuel use has contributed little to the downward trend in the ambient $\mathrm{CO}$ concentration. Instead, the decrease has been attributed to the replacement of old cars by new ones with cleaner-burning engines (Illman 1993).

This position was echoed by an independent audit mandated by the Colorado legislature in 1989 and issued in December 1992. That report found that "the limited benefits from oxygenated fuels are decreasing as the average emissions from new cars decrease, and will continue to decrease as new cars replace older cars." Thus, proper vehicle maintenance, for new and old cars alike, and not the use of oxygenated fuel may be the key to clean-burning, low-emissions automobiles (Illman 1993). 
In addition to the big expense of reformulated gasoline, ${ }^{10}$ other costs may be associated with the use of oxygenated fuels. First, atmospheric aldehyde concentrations may be on the rise. Tests suggest that when oxygenated gasoline is used, formaldehyde emissions increase by $15-75 \%$, depending on the vehicle's emissions control technology. Specifically, motor vehicles emit at least two tons of formaldehyde each day in the Denver area (Illman 1993).

Second, elevated levels of organic carbonyl compounds, especially formic acid, could occur. They have been found in the atmosphere in Albuquerque, presumably due to the use of ethanol as a gasoline additive. Also, the ratio of the pollutant PAN to peroxypropionyl nitrate - a ratio thought to be indicative of anthropogenic sources of atmospheric organics - has risen in Albuquerque to a level comparable to that found in Rio de Janeiro, where alcohol fuel is used exclusively. And Brazil has the highest atmospheric aldehyde concentration in the world for two reasons. Acetaldehyde ${ }^{11}$ is emitted directly from vehicle tailpipes because of the incomplete combustion of ethanol, and it is formed in the atmosphere during the photochemical oxidation of emitted ethanol (Illman 1993).

Third, there is a possibility of health problems from direct exposure to MTBE in oxygenated fuels. The EPA has issued a waiver for Fairbanks, Alaska, because residents reported symptoms including headaches, nausea, throat and eye irritation, dizziness, and disorientation. The presence of MTBE in blood samples was confirmed (Illman 1993).

In studies of single-component fuels that generate automotive exhaust, oxygenated organic compounds were shown to vary widely in catalytic reactivity, depending on the specific compounds involved. However, in oxygenated fuels, catalytic conversion of the air toxic 1,3-butadiene was essentially complete to within detection limits (McCabe et al. 1992).

Testing by one research group showed that a reduction in fuel sulfur from 450 to 50 parts per million (ppm) cut hydrocarbon emissions by $16 \%$, CO by $13 \%$, and $\mathrm{NO}_{\mathrm{x}}$ by $9 \%$ (Parkinson 1992).

One research study suggested that different blends of reformulated gasoline may be required for vehicles of different ages. Tests of 16 fuel compositions in a current fleet of vehicles (model year 1990) showed that nonmethane hydrocarbon emissions (the precursors to ozone) decrease if:

- Aromatic content is lowered,

${ }^{10}$ It is interesting to note that motorists in Colorado's Front Range area, which is east of the Rocky Mountains and includes Denver, Colorado Springs, and Fort Collins, spent an estimated $\$ 14$ million/yr more for reformulated gasoline, consisting mostly of MTBE, than other motorists paid for conventional gasoline. (Illman 1993).

11 Acetaldehyde is a precursor to PAN, a phytotoxic and mutagenic compound as well as a severe eye irritant, which is observed at parts-per-billion (ppb) levels in Rio de Janeiro. 
- MTBE content is raised, or

- $\mathrm{T}_{90}$ temperature is reduced.

These emissions increase, however, when the olefin content is decreased. The largest average percentage reduction in nonmethane hydrocarbon emissions, $22 \%$, resulted from a decrease in the $\mathrm{T}_{90}$ from 360 to $280^{\circ} \mathrm{F}$ (i.e., a decrease in the heavy boiling fraction components). For an older fleet of vehicles (model years 1985 to 1989), these emissions were reduced only by the addition of MTBE, approximately 7\% (Klausmeier and Draves 1991).

In the same study, $\mathrm{CO}$ emissions decreased if the aromatic content was lowered or the MTBE content was increased for the current fleet. Reducing $\mathrm{T}_{90}$ or the olefin content had no effect on the $\mathrm{CO}$ emissions. The largest average percentage reduction in $\mathrm{CO}$ emissions, $14 \%$, resulted from decreasing the aromatic content from $45 \%$ to $20 \%$. For an older fleet, $\mathrm{CO}$ emissions were reduced only by the addition of MTBE (Klausmeier and Draves 1991).

\subsection{MTBE STATIONARY SOURCE EMISSIONS AND ASSESSMENT}

Returning to the important specific issues raised at the outset of this document brings up the core issue of this study: What is the likely impact of Title III (HAPs from stationary sources) on Title II (mobile sources introducing reformulated gasoline) with respect to impediments to the appropriate implementation of Title II? A number of specific questions arise:

1. Will Title III dictate that MACT be applied to the stationary sources that produce the two oxygenate blendstocks, MTBE and methanol?

2. Will other oxygenate blendstocks become subject to MACT under Title III?

3. If MTBE is subject to Title III, will the markets for oxygenated fuels and oxygenate blendstocks be skewed because of the severity of the MACT standards developed for refineries and specifically for MTBE units?

4. Finally, will regulators allow the other oxygenate blendstocks - ethanol, TBA, ETBE, TAME, and TAEE - to escape the intent of Title III?

\subsubsection{Determining the Level of HAP Emissions Expected}

The organic compounds MTBE and methanol appear on the HAPs list in Title III of the 1990 CAAAs. Therefore, if a stationary source producing MTBE (or methanol) is likely to emit 
10 tons per year of MTBE (or methanol) to the atmosphere, it becomes a "major source" subject to Title III, and its operator must proceed to implement MACT to mitigate its emissions of the HAP to the fullest extent.

What level of HAP emissions is expected from a unit during its production of MTBE (or methanol) or its subsequent transfer to a blending operation for reformulated gasoline? A rigorous search revealed no data or literature on this topic. Perhaps proprietary information or analyses would provide some leads. However, at this time, the question, although a good one and of valid concern, will remain unanswered until such time as actual measurements are taken. Nevertheless, that is the very question that this study seeks to address.

Table 9 lists all the announced plant expansions and new construction for North America to date. These facilities may ultimately provide direct feedstock for U.S. refineries and reformulated gasoline blenders producing motor gasoline. They range in capacity from 1,000 to $15,000 \mathrm{bbl} / \mathrm{d}$, equivalent to 40,000 to 635,000 tons/yr. Since no estimates of MTBE emissions were available, estimates were calculated on a hypothetical basis, by assuming a plant availability of $70 \%$ and an emissions factor of $0.005 \%$ (equivalent to 50 parts of chemical emissions to every $1,000,000$ parts of chemical produced, i.e., $\simeq 50 \mathrm{ppm}$ ).

Under these assumptions, a MTBE unit exceeding $6,000 \mathrm{bbl} / \mathrm{d}$ would be subject to the 1990 CAAAs Title III constraint for a stationary source emitting 10 tons per year of a HAP, specifically MTBE. Of the 18 units listed on the table, 12 would be subject to Title III MACT. If the hypothetical assumption regarding emissions is too high, the units might not become subject to Title III and its MACT stipulation.

Thus, Title III appears to mandate that MACT be applied to a majority of the stationary sources that are slated to produce MTBE (and methanol), since the larger units (greater than $6,000 \mathrm{bbl} / \mathrm{d}$ ) may exceed the 10 -tons-per-year level.

\subsubsection{Assessing Regulatory Treatment for Non-MTBE Oxygenates}

Simply because these organic compounds are omitted from the HAPs list in the 1990 CAAAs, the facilities producing alternative oxygenates - ethanol, TBA, ETBE, TAME, and TAEE and other such alcohols and ethers - will not become subject to MACT. As the law is written currently, the interpretation must be that MACT does not apply to alternative oxygenates. However, it does apply clearly to MTBE (or methanol) units that are large enough to generate more than 10 tons per year of evaporative or fugitive emissions. They must comply. 
TABLE 9 North American MTBE Projected Expansions and New Plants

\begin{tabular}{llccc}
\hline & & \multicolumn{2}{c}{ Capacity } & \\
\cline { 3 - 4 } \multicolumn{1}{c}{ Company } & \multicolumn{1}{c}{ Location } & $\begin{array}{c}10^{3} \\
\text { bbl/d }\end{array}$ & $\begin{array}{c}10^{3} \\
\text { tons/yr }\end{array}$ & $\begin{array}{c}\text { Hypothetical } \\
\text { Emissions } \\
\text { (tons/yr }^{\mathrm{b}}\end{array}$ \\
\hline Texaco Chemical & Port Neches, Texas & 15.0 & 635 & $24.8^{\mathrm{c}}$ \\
M.W. Kellogg/EGP Fuels & Morgan's Point, Texas & 15.0 & 635 & $24.8^{\mathrm{c}}$ \\
Proesa/Pemex & Campeche Bay, Mexico & 13.0 & 550 & $21.5^{\mathrm{c}}$ \\
Neste Oy/Petro Canada & Edmonton, Alberta, Canada & 12.5 & 530 & $20.6^{\mathrm{c}}$ \\
Mitsui & Houston, Texas & 12.5 & 530 & $20.6^{\mathrm{c}}$ \\
Tenneco & Houston, Texas & 12.5 & 530 & $20.6^{\mathrm{c}}$ \\
Marathon Petroleum & Garyville, Lousianna & 12.5 & 530 & $20.6^{\mathrm{c}}$ \\
Valero Refining & Corpus Christi, Texas & 12.5 & 530 & $20.6^{\mathrm{c}}$ \\
M.W. Kellogg/Global Octanes & Deer Park, Texas & 12.5 & 530 & $20.6^{\mathrm{c}}$ \\
Exxon U.S.A. & Baton Rouge, Louisiana & 7.0 & 295 & $11.5^{\mathrm{c}}$ \\
Exxon U.S.A. & Baytown, Texas & 7.0 & 295 & $11.5^{\mathrm{c}}$ \\
Exxon U.S.A. & Benicia, California & 7.0 & 295 & $11.5^{\mathrm{c}}$ \\
Coastal Chemical & Cheyenne, Wyoming & 4.6 & 195 & 7.60 \\
Occidental Chemical & Chocolate Bayou, Texas & 1.9 & 80 & 3.14 \\
Kerr-McGee & Corpus Christi, Texas & 1.8 & 75 & 2.97 \\
Pemex & Morelos, Mexico & 1.4 & 60 & 2.31 \\
Pemex & Hidalgo, Mexico & 1.0 & 40 & 1.65 \\
Pemex & Salamanca, Mexico & 1.0 & 40 & 1.65 \\
Total & & 150.7 & 6375 & \\
\hline & & & & \\
\hline
\end{tabular}

a Assuming $90 \%$ nameplate capacity.

b Emissions are estimated at $\cong 0.005 \%$ of production, and a plant availability of $70 \%$ is assumed.

c The volume of estimated emissions presented subjects the individual plant to the stationary source, 10/25-tons-per-year rule of Title III of the CAAAs.

\subsubsection{Skewing the Oxygenate Market Because of MACT Applicability}

Of the six potential oxygenates for reformulated gasoline discussed here, MTBE and methanol are on the HAPs list, while ethanol, ETBE, TAME, and TAEE are not. More importantly, of the six possible feedstocks for the six potential oxygenates, only one (methanol) is on the HAPs list. The other five - two alcohols (ethanol and TBA) and three olefins (isobutylene, ethylene, and isoamylene) - are not. (See Figure 2.)

Capital investment is being expended presently; plans and construction are underway for a number of MTBE plants around the world, especially in North America. Although many of these 


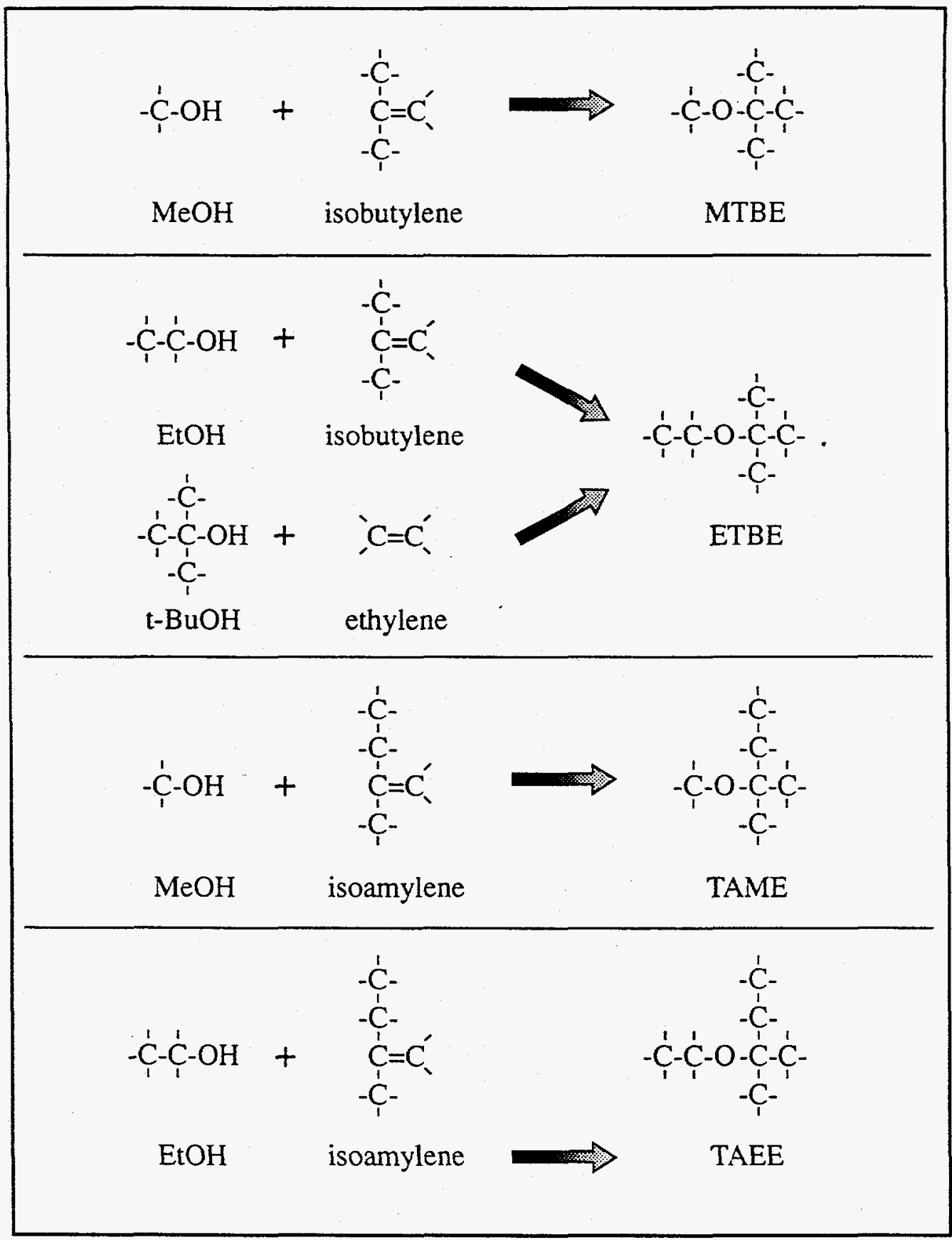

FIGURE 2 Reactions to Produce Oxygenates for Reformulated Gasoline 
units could be converted to use alternative ethers or feedstocks, health research data may not support such a conversion. Hence, MACT severity may not even become an issue. Nevertheless, the corporate world will continue to hedge to some extent regarding feedstocks and blendstocks.

Ethanol may be the distant second choice as a viable oxygenate feedstock for the blendstock ETBE in projected volume (given appropriate lead time) regarding blending and the imparting of finished-product characteristics (see Section 5.2.1). However, according to many analysts, increased ethanol production without significant federal subsidy is just not economically viable.

Market skewness away from MTBE is likely to simply be a result a of not being able to keep up with reformulated gasoline demand, until such time as MTBE capacity expansions catch up. But MTBE imports may be able to fill the gap until that time. In addition, whenever a nonattainment area achieves $\mathrm{CO}$ attainment (compliance), that metropolis will be able to get off the list for oxygenated fuel in the following winter season, thereby decreasing demand for MTBE. Hence, it is unlikely that the oxygenate market will be skewed away from MTBE unless significant quantities of another oxygenate additive that imparts superior finished-product characteristics can be found. And although MTBE is presently on the list of HAPs, toxicological data and research results to date on its risk to public health and even occupational health do not support its continued presence on that list.

\subsubsection{Adjusting the HAPs List}

The answers to two questions need to be clarified:

1. Are MTBE and methanol of such significant risk to the U.S. public health to merit their continued inclusion on the HAPs list?

2. Are ethanol, ETBE, TBA, isobutylene, isoamylene, and other similar alcohols, ethers, and their precursors of such low risk to the U.S. public health to merit their continued exclusion from the HAPs list?

In the winter of 1992/1993, the oxygenated fuels program's first year, about 40 metropolitan areas were required to use oxygenated fuels. However, because of health complaints - principally headaches and nausea - Alaska's governor unilaterally suspended the program in Fairbanks, and an Alaskan Congressman initiated legislation to allow the EPA to issue a waiver for Alaska's compliance. Because refiners were concerned about the potential health threat and significant investment dollars were in jeopardy, the EPA, API, Oxygenated Fuels Association, and other trade groups began a extensive test program to investigate the validity of the health claims (Anderson 1993). 
In July 1993, the scientific data presented at a conference assembled by the EPA at Falls Church, Virginia, dispelled the notion that MTBE is harmful; in fact, the data indicated "a large margin of safety" (Anderson 1993). In one set of tests under the Toxic Substances Control Act to determine MTBE's potential chronic health effects (actually initiated in 1988), animals were exposed to very high levels of MTBE to assess the oxygenate's toxicological potential. Researchers found these results:

- At worst, drowsiness and lack of motor coordination were experienced for a short period.

- Conversion of MTBE to TBA was very rapid and complete. TBA is safely eliminated from the body in urine (Anderson 1993).

In another study, one medical researcher interpreted that the inhalation reference concentration ${ }^{12}$ data indicate that MTBE poses only "minimal" health risks.

Apparently the only thing wrong with MTBE is that it makes the small of gasoline different. The distinctive odor of ether is not familiar to the typical motorist. This odor may trigger a psychological reaction of unfamiliarity more than anything else. Not surprisingly, MTBE-gasoline blends have lower odor threshold levels than conventional gasoline. In other words, motorists tend to notice the odor of gasoline quicker when MTBE is in it. "MTBE isn't bad, it just smells differently" (Anderson 1993).

Two other studies - one at Yale University and the other at the EPA in Research Triangle Park, North Carolina - found conclusively that MTBE caused no increase in symptoms such as headaches, nasal or eye irritation, or coughing and that exposure to MTBE did not change the psychological performance or mood of healthy individuals. In tests of individuals with sensitivities to chemicals and chronic fatigue subjects, the Environmental \& Occupational Health Sciences Institute was able to dismiss MTBE as the cause of many health effects (Anderson 1993).

What are the facts about the events in Alaska that led up to the program suspension? Alaskan exposure studies are not available, and the Centers for Disease Control and Prevention (CDC) have not been able to correlate the Alaskan experience with direct exposure data at the service station. Furthermore, extremely cold temperatures $\left(-40\right.$ to $\left.-50^{\circ} \mathrm{F}\right)$ may have played some role. Also, other compounds (e.g., carcinogenic benzene) were detected but not eliminated as possible culprits, thereby preventing any fair comparisons (Anderson 1993).

12 The inhalation reference concentration is the airborne concentration that can be inhaled over a lifetime by people, including chemically sensitive people, without posing any appreciable health hazard. 
The results of all the test programs launched since the Alaskan incident and those initiated before it have produced an overwhelming consensus: "MTBE has been given a clear bill of health" (Anderson 1993). At this time, the EPA believes that MTBE gasoline remains, on balance, a safe, effective, and relatively inexpensive solution for supporting the Congressional mandate to use oxygenated fuels to reduce $\mathrm{CO}$ emissions. Perhaps MTBE should be removed from the CAAAs HAPs list, if research continues to bear out the results that MTBE poses minimal health risks for the public (Anderson 1993).

Additional research is required to determine the risks of methanol and assess whether it belongs on the HAPs list.

There appears to be no reason to add ethanol, TBA, ETBE, TAME, or TAEE to the HAPs list at this time. Not many of the alcohols and ethers (except MTBE) to be used in gasoline blends or to satisfy the demand for oxygenated fuels or reformulated gasoline are being produced. Moreover, there has not been enough toxicological testing to determine public health risk (Anderson 1993). 


\section{CHALLENGES AND FUTURE DIRECTIONS}

Producers and distributors of petroleum products will continue to face a number of longterm challenges. Under Title III of the CAAAs, many petroleum refineries may be required to install MACT to prevent releases of HAPs at their production and blending facilities. Once the EPA promulgates the MACT standards in 1995, refineries will have 3-5 years in which to comply.

In and of itself, the anticipated gradual decline in the quality of crude oil inputs, coupled with relatively flat demand for residual fuel oil, will present another challenge. U.S. refineries will need to alter refinery configurations and invest in conversion units to be able to handle crude oils with higher sulfur contents and lower specific gravities (DOE 1995). ${ }^{13}$

Another challenge will result from continued pressure to produce more environmentally friendly products based on Title II. The requirements of the CAAAs for cleaner-burning fuels are being phased in over several years, and reformulated gasoline is expected to come into use by 1995. Certification of reformulated gasoline is currently based on a uniform set of EPA standards described as the "simple model," which includes specifications for the content of aromatics, benzene, oxygen, sulfur, and RVP. But beginning in 1998, reformulated gasoline will have to be certified by using a results-oriented "complex formula," based on achieving EPA emissions parameters. Moreover, initial requirements for a $15 \%$ reduction of volatile organic compounds and air toxics relative to baseline 1990 gasoline will be stepped up after 2000 (DOE 1995).

Combined with federal clean fuel requirements, state gasoline requirements ${ }^{14}$ will multiply the logistical problems already complicating the distribution of motor fuels. Refiners and distributors will be forced to produce and handle multiple octane grades of conventional, oxygenated, and reformulated gasoline. In addition, during the summer months, all gasoline blends will have to meet regional requirements for RVP. And reformulated blendstock for oxygenate blending may be delivered to terminals for possible blending with ethanol and other oxygenates before delivery at the pump. The greatly increased number of gasoline products and blendstocks can be expected to restrict the flexibility of the marketing system and increase the potential for distribution problems. Design, testing, and recordkeeping will play increasingly vital roles (DOE 1995).

With these challenges looming ahead in the very near term, a number of specific questions and concerns could be addressed in the future. They are discussed briefly in the following sections.

13 In preparing this report for publication in 1995, additional information became available. Some of it is cited in this section.

14 As already mentioned, California will require its own version of reformulated gasoline statewide, beginning in 1996. As an alternative to federal reformulated gasoline, a number of states have proposed further restrictions on RVP as a means of reducing pollution in ozone nonattainment areas (DOE 1995). 


\subsection{AUTOMOTIVE EMISSIONS FROM TITLE II REFORMULATED GASOLINE}

Two questions require actual measurements and continued study. What types and levels of automotive pollutants (fugitive and evaporative) are emitted during the manufacture and use of reformulated gasolines? What are the probable atmospheric impacts of implementing oxygenated fuels in this country, or any other country, over time?

These questions can and must continue to be addressed by regulators entrusted to protect the public welfare and their analysts. The appropriateness of the Title II mandate to implement reformulated gasoline is of concern. Are the means legislated to date to achieve the desired outcome, (i.e., the mitigating $\mathrm{CO}$ emissions and preventing ozone precursor formation) the best?

Of lesser significance are the evaluation of lead and its phase-out and the substitution of other metal-based catalysts in boosting octane. A study in this area may prove worthwhile, from both an emissions and an atmospheric impacts perspective.

\subsection{OXYGENATES AND THE TITLE III HAPS LIST}

Further study is required to determine whether MTBE and methanol should be removed from the CAAAs HAPs list on the basis of their health risks. If the health risks are not found to be significant, MTBE should be taken off the list. MTBE could then be evaluated as an option appropriate for reformulating gasoline.

Additional sources (substrates) of oxygenates (or their equivalents) should also be examined from an economics perspective; examinations should include cost/benefit analyses. Various alcohol and alkene (olefin) substrates should be studied in context, in addition to the touted ethers.

Since aromatics curtailment and octane enhancement are critical to manufacturing acceptable motor fuels, shifts in anticipated refinery processes should undergo detailed study, especially regarding FCC, reforming, and alkylation/isomerization.

\subsection{STATE IMPLEMENTATION PLANS}

Various states have designed and are beginning to execute their own air toxics programs; they cover toxics from mobile sources. These SIPs should be reviewed and compared to evaluate the best elements of each. In this way, all the states may be able to take full advantage of lessons learned. Individual states' positions could be assessed, and special attention could be given to estimates of their demand for gasoline, reformulated gasoline, and oxygenates relative to national market demand. 
Experiences in California, Colorado, and Alaska may prove to serve as particularly useful and pointed examples.

\subsection{EPA MOBILE SOURCE AIR TOXICS STUDY}

In December 1993, a new study by the EPA is expected to provide additional guidance. The study is expected to integrate additional language and elaborate on policies and regulations for reformulated gasoline and oxygenated fuels. Effectively, the two separate and distinct programs are expected to be merged. Review and analysis of the facts in line with that guidance may prove helpful to regulators and program stewards alike. In addition, recent National Petroleum Council reports may prove to be particularly helpful in gathering the facts. 


\section{REFERENCES}

Anderson, E.V., 1993, "Health Studies Indicate MTBE Is Safe Gasoline Additive," Chemical and Engineering News 71:38:9-18, Sept. 20.

AQIRP, 1993, Estimated Costs of Modifying Gasoline Properties, Economic Bulletin No. 2, Auto/Oil Air Quality Improvement Research Program, Washington, D.C.

Brockwell, H.L., et al., 1991, "Synthesize Ethers," Hydrocarbon Processing, pp. 133-134, Sept.

Colucci, J.M., 1991, "Results from Phase I of the Auto/Oil Program," presented at the 1991 Windsor Workshop on Alternative Fuels, sponsored by the Canada Centre for Mineral and Energy Technology (Ottawa, Ontario, Canada), U.S. Department of Energy (Washington, D.C.), and Ontario Ministry of Energy (Toronto, Ontario, Canada), Toronto, Ontario, Canada, June 24-26, pp. 121-147.

C\&EN News, 1995, "EPA Grants Ethyl Corp. a Fuel Additive Waiver," July 24, p. 21.

Considine, D.M. (editor), 1989, "Petroleum Refining," Van Nostrand's Scientific Encyclopedia, 7th ed., Vol. II, Van Nostrand Reinhold, New York, N.Y., pp. 2178-2184.

Diebold, J.P., et al., 1992, "Reformulated Gasoline Components Production from Renewable Feeds," in Proceedings of the American Society of Agricultural Engineers Alternative Energy Conference, Nashville, Tenn., pp. 154-161.

DOE, 1993a, Weekly Petroleum Status Report, DOE/EIA-0208(93-08), U.S. Department of Energy, Washington, D.C., Feb. 19.

DOE, 1993b, Petroleum Supply Monthly, DOE/EIA-0109(93/07), U.S. Department of Energy, Washington, D.C., July.

DOE, 1995, Annual Energy Outlook 1995, DOE/EIA-0383(95), U.S. Department of Energy, Washington, D.C., Jan.

EPA, 1988, Derivation of Technology Specific Effects of the Use of Oxygenated Fuel Blends on Motor Vehicle Exhaust Emissions, EPA-AA-TSS-PA-88-1, U.S. Environmental Protection Agency.

Gajda, G.J., 1991, Development of a Catalyst for Conversion of Syngas-Derived Materials to Isobutylene, DOE/PC/90042-T2, U.S. Department of Energy, Washington, D.C., Oct. 3. 
Gilliland, E.R., "Distillation," McGraw-Hill Encyclopedia of Science and Technology, Vol. 5, McGraw-Hill Book Company, New York, N.Y., pp. 364-368.

Gilman, R.H., 1990, "Capital Outlays for Gasoline Reformulation Can Be Minimized," Oil and Gas Journal 88(36):44-49, Sept. 3.

Gonzalez, R., 1992, "Refineries Need More Alkylation," Hydrocarbon Processing 71(7): 19, July.

Gottlieb, K., et al., 1986, Oxygenated Components for Unleaded High-Octane Gasoline: Production and Application, NTIS Accession Number TIB/A93-00555/XAB, Oct.

Gron, L.U., et al., 1992, "Quantitative In-Situ Infrared Spectroscopy for the Kinetic Study of the Resin-Catalyzed Dehydration of tert-Butyl Alcohol," in Symposium on Octane and Cetane Enhancement Processes for Reduced-Emissions Motor Fuels, Proceedings of the National Meeting of the American Chemical Society (Washington, D.C.), San Francisco, Calif., April 5-10, p. 93.

Hadder, G.R., 1992, "Future Refining Impacts of the Clean Air Act Amendments of 1990," Energy 17(9):857-868.

Haigwood, B., 1991, "North American Markets for Alcohol and Alcohol-Derived Motor Fuels and Need for Tax Incentives," in Energy from Biomass and Wastes XV, Proceedings of the 15th Annual Conference on Energy from Biomass and Wastes sponsored by the Institute of Gas Technology (Chicago, Ill.), Washington, D.C, pp. 767-781.

Harris, D.H., et al., 1992, "Novel FCC Catalysts to Meet the Gasoline Reformulation Challenge," in Symposium on Octane and Cetane Enhancement Processes for Reduced-Emissions Motor Fuels, Proceedings of the National Meeting of the American Chemical Society (Washington, D.C.), San Francisco, Calif., April 5-10, p. 698.

Herring, P. 1992, "Producing MTBE on the Canadian Prairie," Neste Kide (Finland) 32(4):28-29.

Hollrah, D.P., and A.M. Burns, 1991, "MMT Increases Octane While Reducing Emissions," Oil and Gas Journal 89(10):86-90, March 11.

Hunter, D., 1993, "How Alan Hirsig Plans to Play ARCO Chemical's Strong Hand," Chemical Week 152(6):44-45, Feb. 17.

Illman, D., 1993, "Oxygenated Fuel Cost May Outweigh Effectiveness," Chemical and Engineering News 71(15):28, 30, April 12. 
Johnson, J.E., and F.M. Peterson, 1991, "Watch Out: Here Comes Reformulated Gasoline," Chemtech 21(5):296-298, May.

Klausmeier, R.F., and J. Draves, 1991, "Assessment of Environmental Issues Related to the Use of Alternative Transportation Fuels - Analysis of Recent Data," No. 91-106.3, presented at the 84th Annual Meeting and Exhibition of the Air and Waste Management Association, Vancouver, British Columbia, Canada, June 16-21.

Levine, J.L., 1992, "Gasoline Blends," in Alternative Transportation Fuels and Vehicles, edited transcript of roundtable sponsored by the American Solar Energy Society (Boulder, Colo.), April 28, pp. 32-34.

Luckenbach, E., 1992, "Cracking," McGraw-Hill Encyclopedia of Science and Technology, Vol. 4, McGraw-Hill Book Company, New York, N.Y., pp. 500-504.

McCabe, R.W., et al., 1992, "Speciated Hydrocarbon Emissions from the Combustion of Single Component Fuels," Journal of the Air and Waste Management Association 42(8):1070-1077, Aug.

Morris, G.D.L., 1993, “'POSM IU' Finds Markets Playing Dead,” Chemical Week 152(7):12, Feb. 24.

Morrison, R.T., and R.N. Boyd, 1966, Organic Chemistry, Allyn and Bacon, Inc., Boston, Mass.

O\&GJ, 1992a, "CERA: Refiners Can Cope with CAA Requirements," Oil and Gas Journal 90(7):27, Feb. 17.

O\&GJ, 1992b, " $\mathrm{H}_{2} \mathrm{SO}_{4}$ Alkylation Shows Promise for Upgrading Gasoline Pentenes," Oil and Gas Journal 90(7):72-74, Feb. 17.

O\&GJ, 1992c, "Gasoline Reformulation to Roil Petrochem Markets," Oil and Gas Journal 90(23):32-33, June 8.

O\&GJ, 1992d, "Oxygenates to Hike Gasoline Price," Oil and Gas Journal 90(31):28, Aug. 3.

O\&GJ, 1992e, "Petrochem Industry Expands North American MTBE Capacity," Oil and Gas Journal 90(40):34, Oct. 5.

Parkinson, G., 1992, "Refining's Clean New Jingle," Chemical Engineering 99(4):35-39, April.

Reisch, M.S., 1993, “Top 50 Chemicals Production Recovered Last Year," Chemical and Engineering News 71(15):11, April 12. 
Rhoades, A.K., 1992, "Huge Supply/Demand Increases Seen in Oxygenate Forecasts," Oil and Gas Journal $90: 48-50$, Nov. 30.

Rotman, D., 1993, "Effects of Oxygenated Fuels Are Questioned at ACS Meeting," Chemical Week 152(13):9, April 7.

Sarathy, P.R., and G.S. Suffridge, 1993, "Etherify Field Butanes: Part 2," Hydrocarbon Processing 72(2):43-51, Feb.

Schmidt, R.J., et al., 1992, "Maximum Flexibility in Producing Reformulated Gasoline," in Symposium on Octane and Cetane Enhancement Processes for Reduced-Emissions Motor Fuels, Proceedings of the National Meeting of the American Chemical Society (Washington, D.C.), San Francisco, Calif., April 5-10, p. 699.

Shannon, H.F., 1992, "Gasoline," McGraw-Hill Encyclopedia of Science and Technology, Vol. 7, McGraw-Hill Book Company, New York, N.Y., pp. 617-620.

Shearman, J., 1991, "Fuel Oxygenates: Demand Outpaces Supply," Chemical Engineering, pp. 57, 59, Oct.

Simonsen, K.A., et al., 1993, "Changing Fuel Formulations Will Boost Hydrogen Demand," Oil and Gas Journal 91:45-58, March 22.

Smylie, M., et al., 1991, "Assessing the Effects of Reformulated Gasoline on Air Quality," presented at the 84th Annual Meeting and Exhibition of the Air and Waste Management Association, Vancouver, British Columbia, Canada, June 16-21.

Speight, J.G., 1992a, "Alkylation (Petroleum)," McGraw-Hill Encyclopedia of Science and Technology, Vol. 1, McGraw-Hill Book Company, New York, N.Y., pp. 385-386.

Speight, J.G., 1992b, "Reforming Processes," McGraw-Hill Encyclopedia of Science and Technology, Vol. 15, McGraw-Hill Book Company, New York, N.Y., pp. 249-251.

Speight, J.G., 1992c, "Petroleum Processing," McGraw-Hill Encyclopedia of Science and Technology, Vol. 13, McGraw-Hill Book Company, New York, N.Y., pp. 293-299.

Sperling, D., 1990, “An Incentive-Based Transition to Alternative Transportation Fuels," in J.W. Tester, Energy and the Environment in the 21st Century, Proceedings of Conference Sponsored by and Held at the Massachusetts Institute of Technology (Cambridge, Mass.), March 26-68, MTT Press, Cambridge, Mass., pp. 251-264. 
U.S. Bureau of National Affairs, 1993, "Mexican National Petroleum Company to Produce ReducedSulfur Diesel Fuel," News 177:A-5, Sept. 15.

U.S. Congress, 1990, “Clean Air Act as Amended,” Public Law 101-549.

Unzelman, G.H., 1991, "Oxygenate/Hydrocarbon Shift Will Rewrite Gasoline Recipes," Oil and Gas Journal 89(17):62-65, Apr. 29.

Williams, F., 1991, "Challenges of MTBE Development from Field Butanes," in Gas Processing - Support a Clean Environment, Proceedings of the 70th Annual Convention of the Gas Processors Association (Tulsa, Okla.), San Antonio, Texas, March 11-12.

Wise, J.J., 1992, “Auto/Oil Program Data and Knowledge Growing Rapidly," Fuel Reformulation 2(3):64-69.

Yepsen, G., and T. Witoshkin, 1991, "Refiners Have Options to Deal with Reformulated Gasoline," Oil and Gas Journal 89(14):68-71, April 8.

Yung, K.Y, et al., 1992, "The FCC Process as a Producer of Light Olefins: Building Blocks for Gasoline Reformulation," in Symposium on Octane and Cetane Enhancement Processes for Reduced-Emissions Motor Fuels, Proceedings of the National Meeting of the American Chemical Society (Washington, D.C.), San Francisco, Calif., April 5-10, p. 688. 
APPENDIX A:

REFINERY PROCESSES AND TERMS 


\section{APPENDIX A:}

\section{REFINERY PROCESSES AND TERMS}

The need for refineries is great. "August 1990 . . saw (gasoline) demand reach a record 7.86 million barrels per day, driving crude distillation utilization rates to $93 \%$ and conversion unit utilization to 100\%" (Yepsen and Witoshkin 1991). Seventy-five percent of the total U.S. crude oil distillation capacity is located in coastal and near-coastal regions: Bureau of Mines Districts 1, 2, 7-11, and 13, which include Delaware, New Jersey, New York, Pennsylvania, Virginia, West Virginia, Georgia, North Carolina, Mississippi, Alabama, Louisiana, Arkansas, Texas, New Mexico, Arizona, California, Hawaii, Nevada, Oregon, Washington, and Alaska (Hadder 1992).

Refineries need to be flexible. One reason is that the inherent characteristics of the various crude oils are different and require different refining processes. More important is the need to address demands that vary according to geographic region and season of the year. Refineries must be flexible enough to produce customized products, including gasoline, for specific market demands (Considine 1989). (See Figure A.1.)

\section{A.1 DISTILLING CRUDE OIL}

Crude oil is separated by fractional distillation into several components (according to their boiling ranges) for subsequent processing. Crude oil distills into these components or fractions (Considine 1989):

- A light straight-run (SR) fraction consisting primarily of $\mathrm{C}_{5}$ and $\mathrm{C}_{6}$ hydrocarbons, with some $\mathrm{C}_{4}$ and lighter gases dissolved in the crude by atmospheric distillation;

- A naphtha fraction with a nominal boiling range of $200-400^{\circ} \mathrm{F}\left(93-204^{\circ} \mathrm{C}\right)$ by atmospheric distillation;

- A light distillate with a boiling range of $400-650^{\circ} \mathrm{F}\left(204-343^{\circ} \mathrm{C}\right)$ by atmospheric distillation, which includes No. 1 and No. 2 fuels, diesel, and kerosene; 


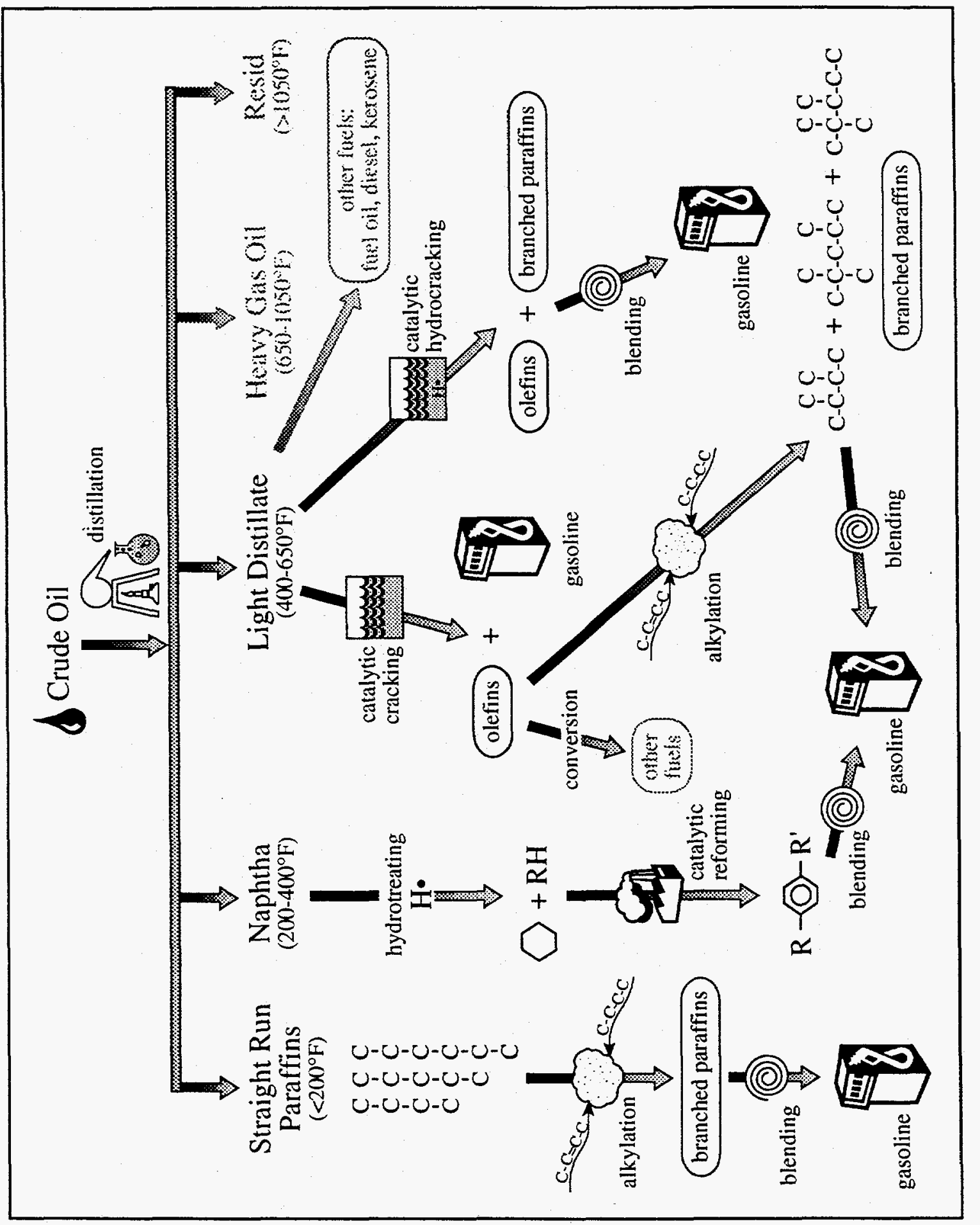

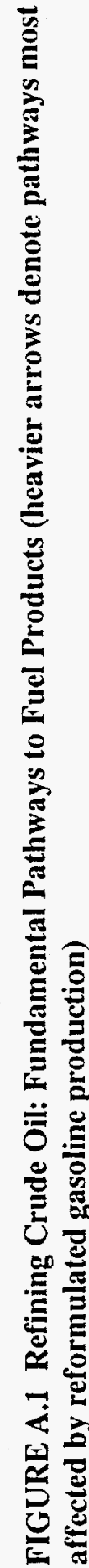


- A heavy gas oil with a boiling range of $650-1,050^{\circ} \mathrm{F}\left(343-566^{\circ} \mathrm{C}\right)$ from vacuum flashing; and

- A nondistillable residual pitch from vacuum flashing.

Gasoline is blended from components that fall into those boiling ranges that are $650^{\circ} \mathrm{F}$ and lower $\left(343^{\circ} \mathrm{C}\right.$ and lower) - the light SR, naphtha, and light distillate fractions.

\section{A.2 REFINING CRUDE OIL COMPONENTS AFTER DISTILLATION}

The major processes for refining crude oil for the manufacture of gasoline are listed below, in order of decreasing volume output in the U.S. refining industry (Considine 1989; Shannon 1992). Hence, this order should also indicate which processes will be most affected by reformulated gasoline requirements (those with more output being more affected) (Figure A.2).

1. Fluid catalytic cracking $(F C C):{ }^{1}$ converts fractions with boiling ranges higher than that of gasoline $\left(650^{\circ} \mathrm{F}\right)$, specifically the gas oil-plus portions of the light distillates, into gasoline. Typically, these heavy fractions are cracked to naphtha-yielding olefins and aromatics, which can contribute to a higher octane rating. FCC also produces olefin feed for alkylation, distillate, fuel oil, and fuel gas (Considine 1989; Shannon 1992).

2. Catalytic reforming: In this process, the naphtha fraction is processed after it has been hydrotreated. Catalytic reforming increases the octane number by converting naphthenes (such as cyclohexane) and paraffins (alkanes) into higher-octane aromatics (such as benzene, toluene, and xylenes). The paraffins are cyclized and dehydrogenated (i.e., hydrogen is removed), yielding aromatics that can contribute to an even higher octane rating (Considine 1989; Shannon 1992).

3. SR fraction: Direct distillation from crude oil yields paraffins, which do not contribute much to the octane rating (Shannon 1992). This distillation component is also subjected to catalytic reforming to form aromatics.

4. Alkylation: In this process, olefins are combined with other hydrocarbons to produce a product with a higher molecular weight and higher carbon number (alkylate). These features improve the octane rating and, hence, the quality of gasoline-range fuels (Speight 1992a). For example, isobutane may be added

1 Cracking may be carried out by thermal, catalytic, or hydrocracking methods (Luckenbach 1992). 
to a light olefin to yield an isoparaffin, which contributes to a higher octane rating (Shannon 1992).

5. Catalytic hydrocracking: ${ }^{1}$ This process converts uncracked distillates (cycle oils) into gasoline in the presence of a catalyst and hydrogen (Considine 1989). Heavy fractions are cracked with hydrogen to yield isoparaffins, which contribute to a higher octane rating (Shannon 1992).

6. Catalytic isomerization: In this process, straight chains are branched to yield isoparaffins, which contribute to a higher octane rating (Shannon 1992).

Other processes include thermal cracking ${ }^{1}$ and hydrotreating. In thermal cracking, carboncarbon and hydrogen-carbon bonds are severred through a free-radical process, thereby reducing the molecular size of the intermediate product and allowing the formation of olefins, paraffins, and some aromatics (Luckenbach 1992). In hydrotreating, feedstocks are treated with hydrogen, a process that removes sulfur and nitrogen by replacing them.

The refiner must adjust the conditions of, and thereby the volumes from, the various refinery processes to formulate a finished product that will meet the quality requirements of the particular market being supplied and the American Society for Testing Materials specifications for gasoline, especially with respect to volatility, octane, and additive-derived properties. Hence, gasoline is formulated by blending a number of the many refinery-produced streams - distillation cuts and process cuts - (Figure A.2) and additives external to the refinery.

\section{A.3 SOME TERMS IMPORTANT IN GASOLINE REFINING}

Distillation is heating a liquid to produce a gas or vapor. The purpose is to separate volatile components from nonvolatile materials or to separate a mixture of volatile components. The separation of volatile components from nonvolatile materials is carried out by simple distillation, in which the material is placed in a still and heated, and the vapor is removed and condensed (Gilliland 1992).

In fractional distillation, the vapor produced in the still is brought into contact with a portion of the condensate in a countercurrent or stepwise countercurrent system, either in batches or continuously. The more volatile components from the liquid condensate pass to the vapor, and the less volatile components pass in the reverse direction, to the condensate. The separation is much wider and more complicated to achieve than that accomplished through simple distillation, depending on the relative volatility of the components, the effectiveness of the transfer between the liquid and vapor phases, and the ratio of the liquid to vapor in the column (the fraction of reflux) (Gilliland 1992). 


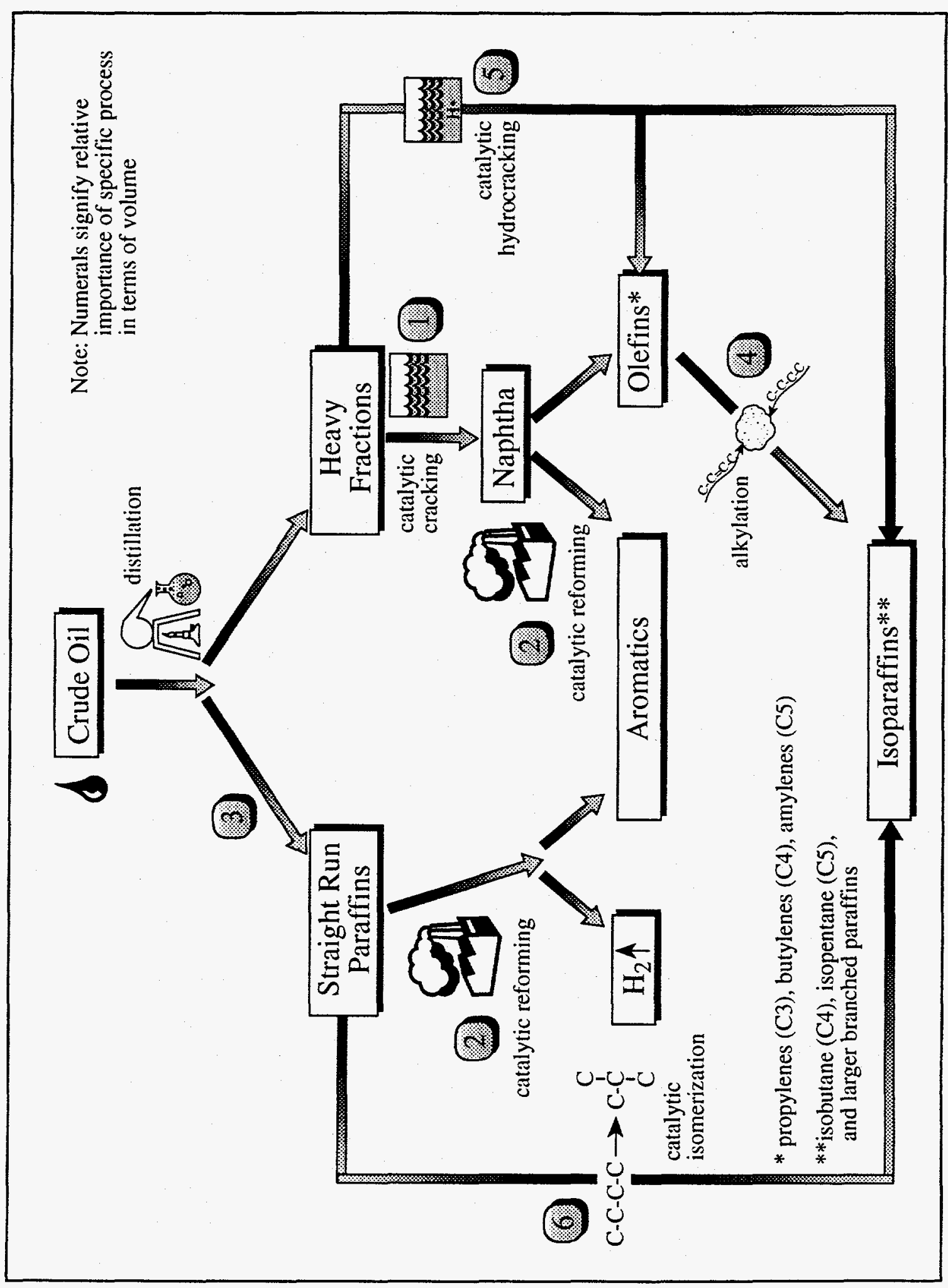

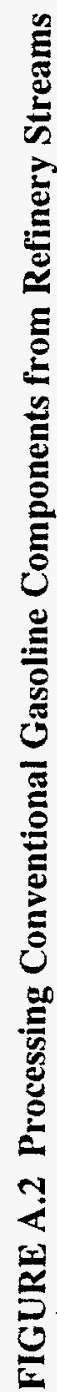


Catalytic cracking is the major process used to produce high-octane, quality gasoline. It converts intermediate- and high-boiling petroleum distillates to products with lower molecular weights, such as lower-boiling olefins, isoparaffins, isoolefins, and aromatics. It usually involves a proprietary technology (catalysis) that fosters the formation of carbonium ion (positively charged carbon ion) intermediates on a catalyst surface. Rapid intramolecular rearrangements typically occur before cracking, leading to more highly branched hydrocarbon structures than those that result from thermal cracking (Luckenbach 1992).

Until the reformulated gasoline mandate, the production of aromatics in the gasoline boiling range was typically favored. The production of branched aliphatic hydrocarbons, especially in the lower-boiling portion, allowed a catalytically cracked gasoline to achieve a high-octane rating (Luckenbach 1992).

The catalytic cracking of fractions from a wide variety of crude oils rather uniformly produces gasoline of 90-95 research octane number (RON) without tetraethyl lead. Thermal cracking produces gasoline of only 65-80 RON; these figures vary with the crude oil source (Luckenbach 1992).

Although the primary objective of catalytic cracking is the production of gasoline, large amounts of propylene and butylenes are also produced, depending on the demand from chemical manufacturers. Isobutane and isopentane are also produced in large quantities. They are valuable for alkylating olefins as well for being directly blended into gasoline as high-octane components (Luckenbach 1992).

Thus, the catalytic cracking process is used in refineries to shift production to match swings in market demand. Either light gases, gasoline, or diesel oil can be emphasized by varying the process conditions, feedstocks, and boiling ranges (Table A.1) (Luckenbach 1992).

Catalytic reforming - a method for producing higher-octane gasolines - is conducted in the presence of hydrogen over hydrogenation-dehydrogenation catalysts supported on alumina or silica-alumina. (An early process known as thermal reforming is essentially an extension of thermal cracking [Speight 1992b].)

Upgrading by catalytic reforming is essentially a treatment to improve a gasoline's octane number. It may be accomplished, in part, by increasing the volatility (reducing the molecular size) of the gasoline. Or it may be accomplished by converting $n$-paraffins to isoparaffins, olefins to aromatics, and naphthenes to aromatics. Organic nitrogen compounds are converted into ammonia under reforming conditions (Speight 1992b). 
TABLE A.1 Representative Product Yields from Catalytic Cracking as Demanded by Market Swings ${ }^{\text {a }}$

\begin{tabular}{lccc}
\hline & \multicolumn{3}{c}{ Product Output } \\
\cline { 2 - 4 } \multicolumn{1}{c}{ Process Variable } & Light Gases & Gasoline & Light Cycle Oil \\
\cline { 2 - 4 } Type of feed (input) & Light gas oil & Gas oil & Gas oil \\
Reactor temperature $\left({ }^{\circ} \mathrm{F}\right)$ & 990 & $950-990$ & $890-900$ \\
Reactor temperature $\left({ }^{\circ} \mathrm{C}\right)$ & 532 & $510-532$ & $477-482$ \\
Light gases (wt\%) & 4.5 & 2.8 & 1.6 \\
Propane/propylene $($ vol\%) & 15 & 10.0 & 7.5 \\
Butane/butylene (vol\%) & 22 & 16.4 & 11.2 \\
Gasoline (vol\%) & 46 & 69.5 & 32.6 \\
Catalytic diesel oil (vol\%) & 18 & 10 & 43.6 \\
Bottoms (vol\%) & 5 & 5 & 5 \\
\hline
\end{tabular}

Source: Luckenbach (1992).

Dehydrogenation is the main chemical reaction that occurs in catalytic reforming, and hydrogen gas is produced in large quantities. Catalytic reforming processes are unique in that they are the only petroleum refinery processes to produce hydrogen as a by-product (Speight 1992b).

Alkylation is a chemical process in which an olefin (ethylene, propylene, etc:) and a hydrocarbon, usually 2-methylpropane (isobutane), are combined to produce a product with a higher molecular weight and higher carbon number (alkane). This product also has a higher octane rating and is used to improve the quality of gasoline-range fuels. One feedstock for the alkylation process is isobutane or an isobutane-enriched stream recovered from refinery gases or produced by means of isobutane isomerization. The olefin feedstock is derived from the gas produced by an FCC unit. Alkylation of 1-butene with isobutane gives an alkylate with a RON of about 93, whereas using 2-butene as the olefin yields an alkylate with a RON of about 98 (Speight 1992a).

Hydrocracking, a relative newcomer to the refining industry, is based on the catalytic formation of hydrogen radicals that saturate olefinic bonds. This process allows intermediate- and high-boiling distillates to be converted to middle distillates that are high in paraffin and low in cyclic and olefin content. It also allows for the production of benzene and naphthalene (Luckenbach 1992). 
APPENDIX B:

CASE STUDY THAT ILLUSTRATES REFINERS' CHOICES 


\section{APPENDIX B:}

\section{CASE STUDY THAT ILLUSTRATES REFINERS' CHOICES}

Akzo (Houston) performed a case study of a fictional but typical 100,000-barrel-per-day (bbl/d) refinery with no downstream petrochemical facility. It was designed to illustrate how refiners might make choices with regard to feedstocks, product distribution and quality, and capital expenditures to meet reformulated gasoline specifications (Gilman 1990). Pertinent facts, factors, and data are listed below:

- Input: $100,000 \mathrm{bbl} / \mathrm{d}$ of light Arabian crude oil. This oil, which represents $10 \%$ of all U.S. crude imports, is similar to West Texas Intermediate and Louisiana Sweet crude oils.

- Refinery configuration and throughput, in $\mathrm{bbl} / \mathrm{d}$ :

- Vacuum distillation unit

52,000

- Catalytic reformer pretreater

30,000

- Catalytic reformer

30,000

- Fluid catalytic cracking (FCC) unit

42,000

- Alkylation unit

8,000

- Coker

12,000

- Distillate hydrotreaters

30,000

- Product distribution from crude $\left(34.2^{\circ} \mathrm{API}, 1.65 \%\right.$ sulfur $)$ distillation, in $\mathrm{bbl} / \mathrm{d}$ :

- Light ends

- Light straight-run (SR) naphtha $\left(\mathrm{C}_{5}-212^{\circ} \mathrm{F}\right) \quad 9,620$

- Heavy SR naphtha $\left(212-325^{\circ} \mathrm{F}\right) \quad 11,000$

- Kerosene $\left(325-430^{\circ} \mathrm{F}\right) \quad 11,600$

- Diesel $\left(430-650^{\circ} \mathrm{F}\right) \quad 21,600$

- Gas oil $\left(650-1,050^{\circ} \mathrm{F}\right) \quad 32,100$

- Residue $\left(1,050^{\circ} \mathrm{F}+\right) \quad 12,500$

- In addition, the refinery must purchase $11,000 \mathrm{bbl} / \mathrm{d}$ of heavy SR naphtha to load out the reformer, since heavy SR naphtha cut from the crude distillation is narrowed to $212-325^{\circ} \mathrm{F}$. This narrowing reduces the amount available for reforming. It removes reformer benzene precursors from the front end and increases kerosene for in-demand jet fuel from the back end. 
- The FCC unit overcracks the vacuum and coker gas oils by using a selectivematrix catalyst that contains $\operatorname{Re}_{2} \mathrm{O}_{3}$. The catalyst is made of zeolite with a high silica-to-alumina-ratio.

- A liquefied petroleum gas (LPG) depentanizer that acts as an FCC unit handles the $22 \%$ increase in throughput resulting from an increase in debutanizer overhead. The increase results from overcracking and removal of $\mathrm{C}_{5} \mathrm{~s}$ from the gasoline front end for further processing in the MTBE, TAME, and alkylation units. Processing yields, in bbl/d, are:

- MTBE

- TAME

- $\mathrm{C}_{3}-\mathrm{C}_{5}$ alkylate

13,665

- Additional isobutane required for alkylation and MTBE

- The resulting reformulated gasoline pool essentially meets proposed specifications of the Clean Air Act Amendments as of September 1990, with an $89.9(\mathrm{RON}+\mathrm{MON}) / 2$ octane (Table B.1). In January 1992, the minimum oxygen requirement was increased to $2.0 \%$.

TABLE B.1 Reformulated Gasoline Pool Projected from a Typical 100,000-bbl/d Refinery

\begin{tabular}{|c|c|c|c|c|c|c|c|c|}
\hline Source & $\begin{array}{c}\text { Amount } \\
\left(10^{3} \mathrm{bbl} / \mathrm{d}\right)\end{array}$ & $\begin{array}{l}\text { Amount } \\
(\text { vol\%) }\end{array}$ & $\begin{array}{l}\text { Aromatics } \\
(\text { vol\%) }\end{array}$ & $\begin{array}{l}\text { Olefins } \\
\text { (vol\%) }\end{array}$ & RON/MON & $\begin{array}{l}\text { RVP } \\
\text { (psi) }\end{array}$ & $\begin{array}{l}\text { Oxygen } \\
(\text { vol \%) }\end{array}$ & $\begin{array}{l}\text { Benzene } \\
\text { (vol \%) }\end{array}$ \\
\hline Reformate & 18.000 & 27.6 & 60.0 & 1.0 & $96.0 / 85.7$ & 5.3 & 0.00 & 0.39 \\
\hline $\begin{array}{c}\mathrm{C}_{5}-\mathrm{C}_{6} \text { isomerate } \\
\text { (single pass) }\end{array}$ & 9.620 & 14.8 & 0.0 & 0.0 & $84.0 / 84.0$ & 13.0 & 0.00 & 0.15 \\
\hline FCC gasoline & 12.634 & 19.4 & 35.0 & 15.0 & $92.0 / 82.0$ & 5.0 & 0.00 & 0.16 \\
\hline Coker naphtha & 3.009 & 4.6 & 34.0 & 11.0 & $66.0 / 57.0$ & 13.0 & 0.00 & 0.09 \\
\hline Alkylate & 15.979 & 24.5 & 0.0 & 0.0 & $93.2 / 91.1$ & 7.9 & 0.00 & 0.00 \\
\hline MTBE & 5.100 & 7.8 & 0.0 & 0.0 & $113.0 / 100.0$ & 8.0 & 1.46 & 0.00 \\
\hline TAME & 0.840 & 1.3 & 0.0 & 0.0 & $111.0 / 98.0$ & 7.0 & 0.20 & 0.00 \\
\hline Total & 65.182 & 100.0 & 24.9 & 3.7 & $93.1 / 86.6$ & 8.0 & 1.67 & 0.79 \\
\hline
\end{tabular}

Source: Gilman (1990). 
- The refinery hydrogen balance is positive, although a higher end-point feed $\left(7,325^{\circ} \mathrm{F}\right)$ would probably require more production or imports of hydrogen. All these figures are in millions of standard cubic feet per day.

- Generator: reformer

- Consumers:

Naphtha hydrotreater

Kerosene hydrotreater

Diesel hydrotreater

$\mathrm{C}_{5}-\mathrm{C}_{6}$ isomerization hydrotreater

Alkylation mild hydrogenation

Subtotal
0.75

0.40

13.31

0.27

0.01

14.74
14.74

0.43

- Excess hydrogen:

- Capital expenditures for the construction needed to meet reformulated gasoline specifications are estimated to be $\$ 57.7$ million in 1990 dollars. The primary expenditures will probably be for alkylation expansion, a new $\mathrm{C}_{5}{ }^{-} \mathrm{C}_{6}$ isomerization unit, and a MTBE/TAME unit. Capital requirements for tanks with pollution abatement equipment and additional utilities and wastewater treatment facilities are not included in the estimate.

- Alkylation expansion from 8,000 to $15,000 \mathrm{bbl} / \mathrm{d} \quad \$ 25.0$

- Catalytic depentanizer $(15,000 \mathrm{bbl} / \mathrm{d}) \quad 2.2$

- Alkylation mild hydrogenation reactor $(15,000 \mathrm{bbl} / \mathrm{d}) \quad 5.0$

- $\mathrm{C}_{5}-\mathrm{C}_{6}$ isomerization $(10,000 \mathrm{bbl} / \mathrm{d}) \quad 12.0$

- Isomerization pretreater $(10,000 \mathrm{bbl} / \mathrm{d}) \quad 6.0$

- MTBE/TAME (3,000 bbl/d) 7.5

- Total (in millions of 1990 dollars) $\$ 57.7$ 
APPENDIX C:

INDUSTRY RESPONSES TO REFORMULATED GASOLINE 


\section{APPENDIX C:}

\section{INDUSTRY RESPONSES TO REFORMULATED GASOLINE}

\section{C.1 ANNOUNCED REFINERY/CHEMICAL/MTBE UPGRADE PLANS}

Shell Oil Company (Houston) sold part of its 130,000-barrel-per-day (bbl/d) refinery in Wilmington, California, to Unocal Corp. (Los Angeles) and closed most of the rest of it. The refinery is considered to be too small to be retrofitted/refurbished/upgraded to meet the new environmental regulations (Parkinson 1992).

Unocal's purchase of Shell's Wilmington unit, added to its own nearby unit, allows Unocal to produce reformulated gasoline. The addition of a $125,000-\mathrm{bbl} / \mathrm{d}$ crude unit, coker, gas-oilhydrotreater, and sulfur plant allow Unocal to abandon a \$515-million hydrotreater project it had underway (Parkinson 1992).

Chevron Corp. (San Francisco) will reduce its Port Arthur, Texas, refinery to a single-train configuration, thereby cutting capacity from 315,000 to $200,000 \mathrm{bbl} / \mathrm{d}$ and eliminating less efficient, outmoded process equipment. Chevron has chosen to simplify its Port Arthur refinery rather than upgrade an out-of-date process configuration. Reportedly, Chevron cannot justify spending nearly $\$ 1$ billion to upgrade Port Arthur while its other, more competitive refineries require financial investments. Chevron estimates that it will spend about $\$ 2$ billion at its eight refineries over the next five years, an expenditure that includes modifying all of them to produce reformulated fuels (Parkinson 1992).

Conventional industry technology either coproduces propylene oxide with styrene or coproduces propylene oxide with MTBE. In early 1993, all three markets were oversupplied in North America; worldwide, they were considered balanced to soft. With the recent addition of ARCO Chemical's second world-scale propylene oxide/styrene plant at Channelview, Texas, and the pending completion of Texaco Chemical's mammoth MTBE/propylene oxide plant at Port Neches, Texas, these three markets are becoming firmly intertwined. No more additions to MTBE capacity appear to be imminent, but they are expected to pick up as the 1995 gasoline reformulation deadline nears (Morris 1993).

ARCO Chemical's growth strategies include employing its core proprietary technological competence in coproducing propylene oxide with either styrene monomer or TBA (tert-butyl alcohol) - a key MTBE feedstock. ARCO is the largest producer worldwide of propylene oxide and MTBE and claims a $28 \%$ share of global MTBE capacity, at 78,500 bbl/d. (Its nearest rival, Texas Petrochemicals, has $8 \%$.) ARCO is considering having its 10 th propylene oxide plant, scheduled for late 1990s start-up, make TBA/MTBE rather than styrene as the coproduct because of the worldwide 
(especially European) interest in reformulated gasoline. Jakarta, Bangkok, Mexico City, Milan, Turin, and Athens are some of the major cities interested in using MTBE in reformulated fuels. Given Europe's traditional 10-yr lag with respect to the United States in adopting environmentally friendly technologies and processes like catalytic mufflers and unleaded gasoline, ARCO sees significant prospects for the use of reformulated gasoline there (Hunter 1993).

M.W. Kellogg Company (Houston) finished building two MTBE plants in Texas on the Houston Ship Channel; their combined design capacity is $27,500 \mathrm{bbl} / \mathrm{d}$. Global Octanes is ready to start a 12,500-bbl/d plant at its petrochemical complex in Deer Park; it is the first grassroots MTBE plant on the Gulf Coast. EGP Fuels, a subsidiary of Enron Corp., is ready to start a 15,000-bbl/d plant at Morgans' Point, Louisiana (O\&GJ 1992e).

Exxon U.S.A. (Houston) plans to construct MTBE facilities at three of its refineries. Construction of a 7,000-bbl/d MTBE unit at the Baton Rouge, Louisiana, refinery was scheduled for October 1991, and start-up was scheduled for the end of 1992. Exxon was said to be evaluating a similar plant at its Baytown, Texas, refinery for start-up in 1993; and it is studying a third plant for its Benicia, California, refinery (Shearman 1991).

Finland's Neste commissioned a 530,000-metric-ton-per-year (1,500-metric-ton-per-day) joint-venture 12,300-bbl/d MTBE plant in Edmonton, Alberta, Canada. It is planned to be owned and operated by Neste in a 50-50 partnership with Chevron Corp. This $\$ 390$ million (in Canadian dollars) plant, the only field butane-based facility of this kind in North America, was slated to supply the bulk of its output to refiners in California that use MTBE in reformulated gasoline. (Neste produces MTBE at Porvoo, Finland; at Sines, Portugal; and at a joint-venture plant in Saudi Arabia. It is planning also a Malaysian joint-venture plant.) Neste chose Edmonton because it is the center of Alberta's oil and gas production, refining, and petrochemicals industries and is near the U.S. West Coast market. Construction started in April 1990; start-up was in March 1991 (O\&GJ 1992e; Herring 1992).

The joint-venture partners of Productos Ecologicos SA de CV (Proesa) agreed with Petroleos Mexicanos (Pemex) to build a 13,000-bbl/d MTBE plant in Mexico, estimated at $\$ 300-350$ million. Start-up is expected by the second half of 1995. (Proesa partners are Valero Energy Corp. and Promociones Industriales Banamex SA de CV [Pibsa], each with a 35\% interest; Grupo Infomin SA de CV, with a $20 \%$ interest; and Dragodos Construcciones SA, with a $10 \%$ interest.) This plant will upgrade butane feedstock bought from Pemex at market-based prices. In return, Pemex will buy all or a substantial part of plant production under a long-term contract that is based on a price formula designed to minimize risk to the Proesa partners and Pemex. A site on Campeche Bay will probably be chosen because feedstock will be available from Pemex's petrochemical operations in the area. For $\$ 290$ million, Valero expects to complete a virtually identical 13,000-bbl/d MTBE plant at Corpus Christi, where there are many off-site facilities (O\&GJ 1992e). 
Mobil (Fairfax, Virginia) and Chemvest, a Saudi Arabian petrochemical firm, have been reported to be completing engineering studies for a 20,000-bbl/d MTBE plant in Yanbu, Saudi Arabia (Shearman 1991).

Kashima Oil (Tokyo) is constructing a 60,000-metric-ton-per-year ( $\approx 1,400 \mathrm{bbl} / \mathrm{d}) \mathrm{MTBE}$ plant. Another Japanese refiner, Nippon Oil (Tokyo), is also expected to build a plant (Shearman 1991).

Table C.1 lists worldwide MTBE projected expansions and new plants that have been announced, in chronological order of anticipated start-up.

\section{C.2 POSSIBLE ETBE/TAME UNITS}

American Eagle Fuels (Lincoln, Nebraska) has produced ETBE at a pilot plant (Shearman 1991).

ARCO Chemical (Newton Square, Pennsylvania), the world's largest MTBE producer, can manufacture ETBE in its units but has no plans to do so (Shearman 1991).

Several companies plan to build TAME units. Star Enterprises (Houston, Texas) intends to build two TAME units at its Delaware City, Delaware, and Convent, Louisiana, refineries; total capacity will be 6,200 bbl/d. Start-up was announced for 1993 and 1992, respectively.

Diamond Shamrock (San Antonio, Texas) plans to build a 2,000-bbl/d TAME unit at its McKee, Texas, facility; completion is scheduled for mid-1993.

\section{C.3 CATALYST DEVELOPMENT}

Reportedly, a new fluid catalytic cracking (FCC) catalyst from Katalistiks International (Baltimore, Maryland), a UOP (DesPlaines, Ilinois) unit, can increase the yields of light olefins, including isobutylene (Parkinson 1992).

Akzo Chemicals Inc. (Houston, Texas) continues to design FCC catalysts for component-selective cracking. According to Donald Keyworth, one is slated to produce more isobutylene for MTBE, another to increase gasoline yield while lowering olefin production (Parkinson 1992).

Traditional commercial routes for producing isobutylene will not be able to meet the large growth in demand anticipated for fuel ethers. A process in which coal could be converted to blending 
TABLE C.1 Worldwide Projected Expansions of and New MTBE Plants

\begin{tabular}{|c|c|c|c|}
\hline Company & Location & $\begin{array}{c}\text { Capacity } \\
\text { (bbl/d) }\end{array}$ & Start-up ${ }^{a}$ \\
\hline Neste Oy/PetroCanada & Edmonton, Alberta, Canada & 12,500 & 1Q/92 \\
\hline Coastal Chemical & Cheyenne, Wyoming & 4,600 & $2 \mathrm{Q} / 92$ \\
\hline Mitsui & Houston, Texas & 12,500 & $2 \mathrm{Q} / 92$ \\
\hline Tenneco & Houston, Texas & 12,500 & $3 Q / 92$ \\
\hline Kerr-McGee & Corpus Christi, Texas & 1,800 & $3 \mathrm{Q} / 92$ \\
\hline $\begin{array}{l}\text { Petronas/NesteOy/Idemitsu } \\
\text { Petroleum }\end{array}$ & Kuantan, Malaysia & 7,000 & $3 Q / 92$ \\
\hline Occidental Chemical & Chocolate Bayou, Texas & 1,900 & $4 Q / 92$ \\
\hline M.W. Kellogg/Global Octanes & Deer Park, Texas & 12,500 & 1992 \\
\hline M.W. Kellogg/EGP Fuels & Morgan's Point, Texas & 15,000 & 1992 \\
\hline Exxon U.S.A. & Baton Rouge, Louisiana & 7,000 & 1992 \\
\hline Exxon U.S.A. & Baytown, Texas & 7,000 & 1993 \\
\hline Pequiven & Cardon, Venezuela & 2,100 & 1993 \\
\hline Pequiven & Palito, Venezuela & 2,800 & $2 \mathrm{Q} / 93$ \\
\hline Pequiven & Amuay, Venezuela & 3,700 & $3 Q / 93$ \\
\hline Pequiven & Jose, Venezuela & 11,600 & 1994 \\
\hline Marathon Petroleum & Garyville, Louisiana & 12,500 & $3 \mathrm{Q} / 93$ \\
\hline Valero Refining & Corpus Christi, Texas & 12,500 & $3 \mathrm{Q} / 93$ \\
\hline Pemex & Morelos, Mexico & 1,400 & 1993 \\
\hline Pemex & Hidalgo, Mexico & 1,000 & 1993 \\
\hline Pemex & Salamanca, Mexico & 1,000 & 1993 \\
\hline Texaco Chemical & Port Neches, Texas & 15,000 & $1 \mathrm{Q} / 94$ \\
\hline Kashima Oil & Tokyo, Japan & 1,400 & 1994 \\
\hline Proesa/Pemex & Campeche Bay, Mexico & 13,000 & $2 \mathrm{H} / 95$ \\
\hline SABIC & Saudia Arabia & 32,500 & 1995 \\
\hline Exxon U.S.A. & Benecia, California & 7,000 & Under study \\
\hline Mobil Oil/Chemvest & Yanbu, Saudia Arabia & 20,000 & Under study \\
\hline Nippon Oil & Tokyo, Japan & 1,400 & No date \\
\hline Total & & 233,200 & \\
\hline
\end{tabular}

a $1 \mathrm{Q}=$ first quarter, $2 \mathrm{Q}=$ second quarter, $3 \mathrm{Q}=$ third quarter, $4 \mathrm{Q}=$ fourth quarter, $2 \mathrm{H}=$ second half.

Sources: Shearman (1991); O\&GJ (1992e). 
components for oxygenated gasoline would take advantage of the vast coal reserves in the United States. The technology for making methanol from coal-derived syngas already exists. Numerous commercial processes to make MTBE from methanol and isobutylene are also available. A new technology that could be used to make isobutylene from syngas would complement the syngas-tomethanol process and help to ease the anticipated shortages of isobutylene. UOP (DesPlaines, Ilinois) is developing a catalyst and technology to produce isobutylene directly from coal-derived syngas. It will be capable of utilizing a lower hydrogen-to-carbon monoxide ratio (Gajda 1991).

The impact of oxygenates in motor gasoline and the effect of aromatics and end-point reduction will dramatically change gasoline composition and processing technology. Straight-run and FCC heavy-naphtha streams in the range of $350-450^{\circ} \mathrm{F}$ are particularly difficult to achieve if $90 \%$ end-point gasoline specifications are reduced. One solution is a technology being developed by UOP. It incorporates an active, solid, acid catalyst operating at mild conditions to achieve selective cracking of heavy naphtha and kerosene-range materials. High yields of isobutane and isopentane are obtained, and virtually no light ends are produced (Schmidt et al. 1992).

\section{C.4 PROCESS/BLENDSTOCK CHANGES}

A hydrotreating process said to reduce the sulfur content of diesel to less than $0.05 \%$ and cut aromatics by up to $90 \%$ is being offered by Criterion and ABB Lummus Crest Inc. (Bloomfield, New Jersey). The process uses an alumina-based metal catalyst. It operates at only 900 pounds per square inch (psi), compared with the typical hydrotreating range of 1,500-2,000 psi. Moreover, it operates at standard hydrotreating temperatures of $600-700^{\circ} \mathrm{F}$. Its cost is substantially lower than that of the normal hydrotreating process (Parkinson 1992).

In 1990 , the industry found that reducing the boiling range of the $T_{90}$ gasoline fraction from $360^{\circ} \mathrm{F}$ to $280^{\circ} \mathrm{F}$ lowers hydrocarbon emissions from vehicles by $22 \%$, apparently because the heavy aromatic fraction concentrated in the $280-360^{\circ} \mathrm{F}$ range is a significant contributor to hydrocarbon emissions. Thus, the U.S. Environmental Protection Agency may elect to specify that aromatics be removed by means of boiling-range shifts (Unzelman 1991).

Tenneco Natural Gas Liquids has embarked on a new project to produce MTBE from butanes (as have several other companies, with more expected in the future) (Williams 1991).

ARCO has noted the French interest in ETBE production. ARCO launched ETBE production in the United States in December 1992 (Hunter 1993).

ARCO is testing a proprietary tert-butyl-alcohol-based hydroperoxide in diesel fuels. It improves the cetane number and cleans up exhaust emissions, features that have recently caught the interest of Tokyo (Hunter 1993). 
Some producers may opt to modify existing routes. A process introduced by UOP (DesPlaines, Mlinois), Huls AG (Marl, Germany), and Koch Engineering (Wichita, Kansas) increases the yield of MTBE, TAME, and ETBE by combining fractionation and distillation steps in a single vessel (Shearman 1991).

Another process introduced by the Badger Company (Cambridge, Massachusetts) and Linde AG (Munich, Germany) integrates Mobil's olefins-to-gasoline technology and Linde's isobutane pyrolysis system to provide additional isobutylene for MTBE production (Shearman 1991).

Pemex announced 40,000-bbl/d production of a new, reduced-sulfur diesel fuel to be used primarily in Mexico City to reduce smog. The new diesel will contain $0.05 \mathrm{wt} \%$ sulfur, an amount 10 times less than that in the diesel currently used in Mexico. Its introduction is part of a 4-year-old, $\$ 1$ billion environmental program (U.S. Bureau of National Affairs 1993). 